\title{
Science and the Second Renaissance of Europe
}

\author{
A. Danzin
}

Chairman, European Committee for

Research and Development

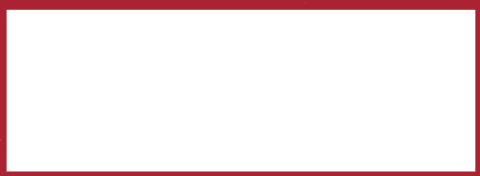

Published for the

Commission of the European Communities

by

Pergamon Press 
Available in paperback only from

Pergamon Press

Maxwell House,

Fairview Park

Elmsford, New York 10523

(914) 592-7700

$\$ 16.00$ 
SCIENCE AND THE

SECOND RENAISSANCE

OF EUROPE 
Published for the Commission of the European Communities, European Committee for Research and Development

\section{LEGAL NOTICE}

Neither the Commission of the European Communities nor any person acting on behalf of the Commission is responsible for the use which might be made of the following information. 


\section{SCIENCE AND THE SECOND RENAISSANCE OF EUROPE}

by

\section{A. DANZIN}

Chairman of the European Committee for Research and Development (CERD)

Published for the

COMMISSION OF THE EUROPEAN COMMUNITIES

by

\section{PERGAMON PRESS}

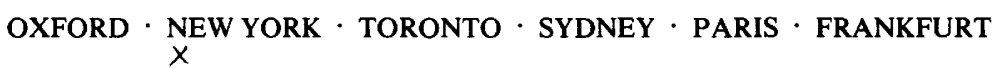


U.K.

U.S.A.

CANADA

AUSTRALIA

FRANCE

FEDERAL REPUBLIC OF GERMANY

Pergamon Press Ltd., Headington Hill Hall, Oxford OX3 OBW, England

Pergamon Press Inc., Maxwell House, Fairview Park, Elmsford, New York 10523, U.S.A.

Pergamon of Canada, Suite 104, 150 Consumers Road, Willowdale, Ontario M2 J1P9, Canada

Pergamon Press (Aust.) Pty. Ltd., P.O. Box 544,

Potts Point, N.S.W. 2011, Australia

Pergamon Press SARL, 24 rue des Ecoles,

75240 Paris, Cedex 05, France

Pergamon Press GmbH, 6242 Kronberg-Taunus, Pferdstrasse 1, Federal Republic of Germany

Copyright (C) 1979 ECSC, EEC, EAEC, Luxembourg

All Rights Reserved. No part of this publication may be reproduced, stored in a retrieval system or transmitted in any form or by any means: electronic, electrostatic, magnetic tape, mechanical, photocopying, recording or otherwise, without permission in writing from the copyright holders.

First edition 1979

British Library Cataloguing in Publication Data

Danzin, A

Science and the second renaissance of Europe.

1. Technological innovations - European

Economic Community Countries

I. Title

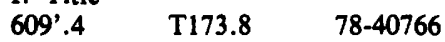

ISBN 0-08-022442-3

EUR 5982 ef 


\section{CONTENTS}

Foreword by Prof. I. Prigogine

PART I. The Search for the European Identity

Chapter 1. The Balance-sheet

The political evolution

Population trends

Geographical data

Economic equilibria

Capacity for innovation

The challenging of moral values

What are the conclusions of the "balance-sheet"?

Chapter 2. The Cultural Forces

The idea-forces of Western Europe's culture

Chapter 3. Aspirations to a New Development

Free time; the hope for a new development

Information activities: free scope for new growth 59

The call for a new development

Euro-South solidarity

Competitiveness and size

Work and quality of life

Mastery of complexity

Complexity and policy 
PART II. Proposals for Mild Treatment:

A Community Scientific and Technical Policy

Introduction

Is European research competitive? Is is correctly oriented?

Science challenged

An attempt to devise a strategy of priorities

89

Catalysis of research and innovation

National strategies and Community strategy 


\title{
FOREWORD
}

\author{
by Prof. I. Prigogine
}

It is a particular pleasure for me to be writing this brief foreword to the important essay by Andre Danzin. Not surprisingly, I was moved both as a scientist and as a European by the problems raised. The roles and the very existence of science and of Europe will henceforward be joined together, each acting as a powerful influence on the other.

The reader will appreciate, as I did, Andre Danzin's clarity of perception as he paints his picture, setting Europe in perspective. To read about this landscape with him is to grasp the principal points of strength for evaluation of the semistrategic course which must be taken.

The picture is undoubtedly realistic. Although the author stresses the particular importance of science within the cultural, economic, and social fabric of Europe, he does so to bring to the fore serious problems which lie on the periphery of what must be referred to as a certain urgency. These problems are to some extent paradoxical. On the one hand, I am firmly convinced that we are capable of achieving the best. I see no noticeable difference here between young research workers encountered in Europe and in the United States; it can only be said that they have the same quality of training and enthusiasm, and I feel the same pleasure in discussing their projects with them. However, whilst this may portend well for the future, it must be admitted that the present shows signs of being a double failure.

Applied European research is at present drastically dependent. We are already paying the price, and shall pay more and more dearly in the future, for not granting the investments required to set up industrial infrastructures geared to the growth industries. Not only are we failing to reap the benefits of technological achievements which reward, accompany, and stimulate investment, we are furthermore obliged to subsidize the dynamism of those countries from whom we purchase and hire products and services typical of these sectors, whether satellite vehicles or data processing. 
With regard to pure research, whatever the criterion adopted (mention in reviews, scientific esteem, etc.), European research looks as though it will find itself reduced to being an adjunct to a movement in which it is no longer a driving force.

I should not like these thoughts to be misconstrued. I have the greatest admiration for the innovating dynamism of large countries like the United States. I am merely concerned for the future of research which must surely affect the development of Europe.

As a citizen of a small country, I understand very clearly the handicaps described by Danzin in his analysis. Political partitioning of states and the burden of the past have so far prevented many of our scientific institutions from embarking upon specialized studies and achieving the breadth necessary to carry out meaningful projects. At the same time the lack of mobility amongst research workers is depriving them of the specialism essential for any innovating research.

The solution to the problem (magnitude, diversification, mobility) implies reorganization on a European scale in view of the low level of centralization of the EEC's financial resources at the present time.

The value of Danzin's analyses lies in the fact that they lead on to solutions which take account of the resources and data inherent in the problems. This is tantamount to saying that action can be taken right away by finding a few sensitive fields where there is a European social demand and where it is possible to engage small teams likely to mobilize advanced scientific resources in which Europe can cut a dash. Such action might have - to use André Danzin's felicitous phrase - a catalytic effect on scientific advance and social progress in Europe.

Since I have spent a part of my scientific career studying fluctuations in science, I am sufficiently familiar with the extraordinary effect which a minor fluctuation, occurring where there is a certain instability, can have on the organization of the whole field of science.

"A second renaissance or acceptance of decline?" asks Danzin with striking insight. By improving our understanding of these problems he will contribute to the decision-making process which over the years to come will shape the future of Europe. 


\title{
FOREWORD
}

\author{
By Dr. G. Brunner
}

Since in the next few decades, Europe will be confronted by many major complicated problems, we must increase our efforts to find new solutions now. The development of a new world economic growth in the Community and the structural change which our high-technology civilization is undergoing, all involve a vast number of problems.

Energy and raw material requirements, environmental protection, and the population explosion in many developing countries are all critical factors which we cannot ignore. Science and technology will often have a leading role to play in meeting these undeniable and unavoidable challenges. The European public is aware of this fact, and in a recent study carried out by the Commission of the European Communities it clearly expresses the hopes it pins on, and the confidence it has in, science as the instrument which will make tomorrow's world a better place in which to live. However, confidence in scientific progress as the vehicle for economic growth and consequently for the welfare of the Community's citizens is no longer undisputed; there are even those in the Member States who recommend a slowing down of scientific and technological activity, fearing that its disadvantages will outweigh its advantages.

Given this situation, the European Research and Development Committee discussions have revealed the need for in-depth consideration of both the concept of the European Communities and the function of science and technology in Europe. The Advisory Committee, comprising twenty-one members of known independence, assists and advises the Commission in defining common policy on research and development. We are greatly indebted to its Chairman, Mr. A. Danzin, for having provided a number of ideas for consideration in response to this need and for helping us to make a clear analysis of our situation.

Science and the Second Renaissance of Europe is an important work for several reasons.

First, it provides a survey which is an analysis of the present situation in Europe (as regards demography, economics, technology, etc.) and demonstrates the vulnerability of a Europe where space is limited and the balance of the environment easily upset, which lacks the primary resources essential for its development and which will soon be facing serious demographic problems.

In spite of the handicaps from which it suffers, the European Community must continue its growth if it is to offer a response to the requirements and satisfy the 
aspirations of the peoples of Europe. This need and these aspirations are the subject of the second part of the book, which is really an attempt to define a new type of growth which takes account of both the "European situation" and the ideesforces of European culture. The second section is therefore a plea for a new type of European development based on the strength of European culture and the abilities of the Europeans. In this framework, emphasis would be placed on intellectual activities, on activities in the field of information (dissemination, processing), and on co-operation with the developing countries - all activities sparing in consumption of raw materials and energy and which have immense development potential.

If such a development model is to be contemplated, the facilities for creative R\&D activities will have to be provided on a large scale. Individual countries' programmes are inadequate, being too limited in terms of resources and experience. In a third section, therefore, the author outlines a plan for science and technology in the European Community. It is worth pointing out in this connection that there is a definite dovetailing of the aims of this project with those of the common scientific and technical policy which is already being pursued by the European Community. The views propounded are of interest both as regards methods and procedures (budgetary control, "executive body", catalytic action) and as regards the proposed areas of activity.

They can be seen as an encouragement to proceed along the path we have already mapped out and a source of stimulating ideas for the constant improvement of Community strategy and methods of operation in the field of R\&D.

The proposed plan for science and technology in the European Community sometimes appears too limited in view of the extent and complexity of the problems to be solved in order to meet the requirements and aspirations of the citizens of the Community. But whether or not one accepts the proposed "scientific and technical programme" in its entirety, it represents a possible route to a new, a second Renaissance of Europe marked by progress along lines which would be in keeping with our Continent's specific genius.

I am therefore pleased that one of Europe's leading scientists, who also has considerable experience of industry, has provided us with this overall survey of our situation, our capacities, and our requirements, which will help us to examine the problem and lay the foundations for what I hope will be the broadest possible discussion of the question among the peoples of Europe. 


\section{PREFACE}

This book is the offspring of anguish and hope.

Europe may well slip towards underdevelopment. This study shows that the risk is a real one and that very little seems to be being done to counteract it. Europe, eroded by scepticism, lacking ambition, wanting in projects relating to man and society, is not even aware that its divisions make it ill-suited to the dimensions of the modern world. This vision fosters anguish.

Hope comes from the European heritage and the forces of change that the future requires. Moral and cultural values are still alive and form the background for challenge; even if they are discussed, their questioning may be viewed as the sign of an effort to adapt, a move towards the renewal of progress, towards a new Renaissance. The world has never had such a great need of a social laboratory to overcome the difficulties caused by the very excesses of human success. Europe is under pressure and appears predestined to become the melting-pot from which will come a resurgence.

This meditation on Europe leads one to ask why, when so many other economic and political factors could be regarded as more important and relevant, scientific and technical innovation should be singled out for special consideration? The answer lies in a deeper line of thought; it arises from a new concept of evolution that is acceptable today.

Even when they differ in their metaphysical views, scientists agree that evolution in the living world is always in the same direction: the drive towards complexity, the constant increase in mental processes.1 Throughout geological time the apparent form of this progress has been, through the random action of genetic mutations, a long series of trials and new solutions which only the best-adapted forms have survived. Although there has been no systematic destruction of ancient species, in particular as a result of the conservation of lateral forms, the success of each new species has generally caused that from which it was directly derived to disappear. In evolution it is fair to say, from several points of view, that "life flourishes on death".

Since Man appeared, the transformation of the living world has been overtaken by the speed of evolution of the artificial universe, generated by the human hand and brain; evolution has moved to the field of culture and social life. Genetically, man is stabilized. However, evolution continues with the accumulation of tools forming the

1 Cf. Jacques Ruffie, De la Biologie a la Culture, Flammarion, 1977. 
"machine kingdom", I which is on the way to supplanting the plant and animal kingdoms to which nature was adapted. This coexistence with our increasingly powerful tools is bringing about a profound evolution in our society. The drive towards complexity and psychism continues, but it has become the work and responsibility of the human race, and suddenly the process has speeded up.

And yet, confusing as it may seem, this evolution retains all the outward signs of a gamble between chance and necessity. The field in which chance comes into play is that of scientific research; selection by necessity is carried out by economic competition, by the development of innovation. ${ }^{2}$ The acknowledged role of chance reopens from the philosophic viewpoint, the full range of problems arising from relations between responsibility and freedom and all our ideas on planning structures.

Although it is justifiable to link the changes in the present-day world with evolution, the association must nevertheless be examined with the closest attention. History teaches us that the backward are liable to be eliminated at any moment, and to the selection process man has added a ruthless cruelty. Today the conflict between the societies frozen at the pre-industrial stage and the mutated post-industrial societies shows a dual imbalance. The overwhelming population pressure amongst the poor peoples is accompanied by the crushing weight of the arms and economic power of the rich, rich essentially by reason of their technological superiority. There is every indication that over the next quarter of a century the main mode of selection will continue to be the power of technological innovation.

Man refuses, however, to submit to a purely biological law of evolution; he is aware of his responsibility. A great step forward in recent years has been the realization that there are certain limits to man's power over his destiny, despite the powerfulness of the new tools; science knows that it will not be able to explain everything nor to govern everything. This return to a healthy modesty does not rule out responsibility; man can choose the fields in which to apply his knowledge and influence the speed and direction of his development.

Europe is involved in this immense debate. It is gambling its very existence as the cradle of independent civilization. I hope that this book will bring home the importance of the stakes, that it will bring the realization that the game is already lost if the peoples neglect their community of interest as they play.

1 The term was coined by Mr. Denielou, Chairman of UTC of Compiègne, member of CERD.

2 Scientific research tends to increase knowledge; it knows what it is asking, but not the reply. It does not know what it will find, still less what man will decide to do with its findings. Hiroshima was contained in particle physics, but no one could have imagined it at the outset. Solid state physics has led to microprocessors, a very complex type of artificial nerve cell, endowed with logic and memory, and fundamental biology is developing an unbelievable capacity for genetic manipulation. Only thirty years ago it would have been impossible to believe that man would discover the keys to such an enormous power to influence nature and himself. 


\section{ACKNOWLEDGEMENTS}

I cannot express my gratitude here to the many who have helped me in preparing this work. Some of them will recognize the echo of their advice, and many more will smile, I hope, when they see how little their opinions have changed my viewpoint. Be this as it may, their views have given me much food for thought.

My special thanks are due to those who have assisted me within the organization of the Commission of the European Communities, in particular to Dr. G. Schuster, Director General for Research, Science, and Education, and his staff.

Acknowledgement must, of course, be made to the invaluable contribution of my colleagues of the European Committee for Research and Development, without whom the task would not have been undertaken.

Thanks also to the little team meeting at the Fondation Internationale des Sciences Humaines in Paris, and to the Director General, Henri Cavanna.

Dr. Guido Brunner, Member of the Commission, and Professor Ilya Prigogine have kindly written forewords to this book. May I say how much I was moved by their gestures. 



\section{INTRODUCTION}

Science and the Second Renaissance of Europe reproduces almost in full a report which, as Chairman of CERD (European Committee for Research and Development), I submitted to the Commission of the European Communities. This was under my own responsibility but with the encouragement of my colleagues, the members of this advisory body. The report was not intended to tackle the European problem as a whole; its aim was merely to propose a suitable policy for scientific and technical research within the Community. However, research paves the way for meeting the future. Reflection on its aims and its ways and means calls for a good understanding of the past and the present, combined with a dynamic view of the evolution of internal forces and a vision of the future of Europe.

Although my colleagues in CERD are not personally committed to any specific opinions which I express in this work and which will, I am sure, provoke many objections (a constructive outcome), I believe it fair to say that there was almost complete unanimity in affirming certain subjects of concern and in asking certain questions.

(a) A profound movement is sweeping through the world of research, an acknowledgement of the social and moral responsibility of scientists. Scientists cannot be disinterested in the use made of their results. They know that they must answer to public opinion for the usefulness of their work and that they must co-operate in the study of the socio-economic consequences of the technological evolution which they originate. This movement is universal. It ignores the frontiers of states and communities. It has not yet found the mechanisms through which it can act. Its credibility vis-ă-vis the decision-makers is debatable since "scientists" and "professors" are not deemed to be good judges of economic, social, or political situations. Contact with the public at large is difficult since their language, which bears the stamp of intellectualism, is ill-suited. The message transmitted by the mass media is distorted by a taste for the sensational or the tragic. This situation must be corrected, and it is necessary to justify the confidence in science and technology expressed by public opinion ${ }^{1}$ but apparently not shared by governments, since only technical

\footnotetext{
${ }^{1}$ An opinion poll conducted by the Commission of the European Communities indicates that an average $70 \%$ of the populations of the nine countries has confidence in the ability of scientific research to improve living conditions.
} 
progress, which takes account of man in his full dimensions, will enable the eight to twelve billion, which is the estimated levelling-of $f$ point for the world population during the next century, to live decently.

(b) A second conclusion has emerged from the Committee's debates. Europe must prepare itself, starting from today, for a new economic order which will not be based mainly on increased growth in the consumption of material goods. Europe must steer, very positively, in the direction of a quest for economies, especially in the field of energy. It must manufacture goods which last and which can be repaired, rather than products which rapidly deteriorate. It must recycle scarce raw materials and protect a particularly fragile ecology. The members of CERD recognize the dramatic nature of the energy problem and would like to see a "low-energy-consumption society" established. However, they cannot suggest how this could be done. Under these circumstances, the spread of nuclear production appears to be inevitable; however, it does not seem that sufficient technical efforts are being made to bring the hazards under control.

(c) A third conclusion of major importance can be drawn from the discussions of CERD. This is the conviction that although the future is largely unpredictable, the present, to a far greater extent than in past history, shapes the future, and that it is possible to predict the speed of certain economic events fifteen years ahead, barring major catastrophes such as nuclear war. This conviction has nothing to do with inconsistent futurology. It is the result of two observations:

(1) In certain fields, such as that of fossil energy, the near future can be predicted fairly exactly as regards the probability of scarcity and variation in the cost of extraction. As regards the birth rate, the inertia of trends makes it possible to calculate up to the end of this century, to better than $10 \%$, the size of the population and its age structure, even assuming that, over the next ten years, the populations' intentions regarding fecundity were to change radically.

(2) As regards conversion of production, it commonly takes from fifteen to twenty-five years to pass through all the stages from the prototype to industrial mass production. This is the length of time that has to be reckoned with for the exploitation on a significant scale of solar energy or breeder reactors; for automobile traffic employing electric traction to become general; or for recourse to be had to poor ores instead of rich ores. It takes more than thirty years for a forest to grow and at least fifteen to build a dam on a river in a desert area; to irrigate a large area; to train and settle farmers; start agricultural undertakings and obtain crops. And what is to be said of town and country planning, the organization of a new diversified industrial complex, an inter-river network of heavy-flow canals? A lot more additional time will be needed to acquire relevant fundamental knowledge and apply it to social and economic problems.

These factors of inertia in the variation of parameters, this need to take, today, decisions which condition the future, induced CERD to associate itself with recommendations for setting up a European forecasting institute which, according to Professor Dahrendorf's proposal, will throw light on the course to be followed over the next thirty years. ${ }^{1}$

${ }^{1}$ A possible programme for this institute has been studied by Lord Kennet (member of CERD) and a working party known as Europe +30 . 
Overcoming the loss of confidence affecting society throughout the world while proposing new objectives for consumption, working out a "desirable" model for the near future, and determining research aims for our laboratories are, perhaps, as the objectives of a study, an impossible challenge. However, it did seem to me that, as far as Europe was concerned, we could make progress in the right direction by seeking answers to the following two questions:

(1) Is Europe's cultural identity, inherited from history and forged by geography, felt with sufficient strength and originality for it to be translated into economic and social objectives capable of inspiring scientific policy?

(2) Do European scientific research workers wish to re-define their objectives and are they aware of their responsibilities vis-à-vis the post-industrial society which is in the process of being formed?

The first part of the study, conducted at FISH $^{1}$ headquarters by Mr. Henry Cavanna, took the form of a series of inquiries and interviews.

For most of the personalities consulted - historians, philosophers, jurists, and sociologists-'the question of Europe's cultural identity was not clear despite, and perhaps because of, the considerable weight of published literature on the subject. Those to whom I talked proclaimed considerable solidarity as Europeans, but immediately dwelt upon the disparities between the Mediterranean and the north, the Catholic countries and those of the Reformation, the regions of Roman-Germanic law and those of common law. A look at history and culture a1so shows the arbitrary nature of the Europe of the Nine, too large to be really homogeneous, too small to include a11 the countries with an eminently European tradition such as those on the Iberian and Scandinavian peninsulas, Switzerland, and Austria, not to mention the countries in central Europe under Soviet influence. Certain members of the EEC feel more intensely their bonds with the United States or Australia, to whom they consider they gave birth, than their bonds with some of their partners in the Community. Generally speaking, many agree that Europe's diversity, variety of languages, and peculiarities of regional culture are an asset. However, they never explain how this diversity can become the source of a desire to act with a common purpose.

Nor does the reaction of scientists to their moral responsibilities regarding the impact of their work upon the evolution of Society lend itself to simple analysis, illuminated by the concept of the European Community. Their feeling of solidarity extends to the entire world, or at all events to a much larger part of the world than Western Europe alone.

As for the fundamentalists, their first concern is the need to increase knowledge. This goal is good in itself and needs no further justification. However, this desire is accompanied by the need for free communication with other specialists, wherever they may be in the world, providing they are suitably competent. In this respect, the Community of the Nine does not contribute much. It is too narrow and, if it wished to intervene, there would be a danger of it acting like a restricting filter. For the rest, the European Science Foundation, with its sixteen member countries, should settle the problem of a communications infrastructure and meeting place.

As for the leaders of industry, research workers, and engineers engaged in applied research or in the effort to achieve industrialization, their attention is fixed on their objectives. Very few of them have the time, the inclination, or the com-

1 FISH, International Foundation of Human Sciences, Paris. 
petence to ask themselves about the cultural value, and the social consequences of what they do. The proposed study is very interesting to them but, save for a few remarkable exceptions, they do not wish to participate.

And so, instead of easily arriving at a consensus on Europe's cultural personality, its geographical, historical, and political identity, and its common aspirations towards certain social objectives which might have been at the root of a common scientific policy, we found only a sympathetic but sceptical reaction regarding the project's ambition, more conscious of the opposition and diversity than of the common good.

At the same time, however, it was confirmed that there is a shared feeling of anxiety about the future, an inability on the part of the nations, individually, to acquire the stature necessary to achieve effectiveness. Indeed Europeans do not know what Europe is, nor where it is going. They know the future may give rise to great difficulties, but they prefer not to think about it. The breadth of the dangers disturbs them but the summons to make an effort in order to take charge of their destiny frightens them.

$$
* \quad * \quad *
$$

In order to proceed further it was necessary to draw up a balance-sheet which, under such circumstances, was inevitably on the advice of Jean Monnet. The balance-sheet is based upon the work of a number of experts and a symposium organized by FISH in Luxembourg from 3 to 5 october 1976. The present report is a very personal attempt to summarize this work. The summary is not, by any means, by way of being a group consensus. In order to provoke reflection and call forth opposition, I have taken the risk of setting out an argument based on the following viewpoints adopted a priori:

1. A cultural viewpoint. At the point we have reached in economic development there is a lag between culture and technological progress. The power of the tools of production and its secondary effects triumph over the political will and cultural aspirations. This situation must be reversed, and in the cultural subsystem must be found the reasons for re-orienting the economic subsystem. In other words, the human sciences must step in when the knowledge acquired by the exact sciences is exploited in order to decide the objectives and monitor progress.

2. A viewpoint regarding future prospects. Questions must be asked of the future by all available means. More particularly, despite their obvious flaws and while keeping an eye on their shortcomings and without ever regarding them as an oracle which means that the myth surrounding them must be demolished - recourse should be had to the principles of systems analysis and applied models ${ }^{1}$ for overall social and economic forecasting. For the political decision-makers or leaders of industry, rejection of these means of investigation would be tantamount to committing an error comparable to that of a doctor, biologist, or economist who refused, in judging society, to take account of the cultural forces emanating from history, law, or philosophic thought.

In this study I have been able to use certain results obtained in Cleveland with the Mesarovic-Pestel mode1, which was kindly placed at our disposal.

3. A non-Malthusian viewpoint. Europe cannot satisfy itself with zero growth but it can no longer, as can the United States or the Soviet Union, count on wealth in the form of space and primary resources. If it does not wish to accentuate its

1 See Annex I. 
economic dependence to the point at which imbalances on financial accounts would be unacceptable to its trading partners, it must develop a new type of growth, based upon the consumption of goods that are economic and not on the waste of raw materials and energy. It must increase its capacity for making specific development products for the countries in the process of industrialization, by organizing with them reciprocal technical and commercial relations.

4. A neutra1 viewpoint with regard to different political profiles. The study leads inevitably to reflections of a political nature. The reader will perhaps be surprised not to find herein any choice in favour of one doctrine or one ideology. This is not a refusal to be committed but a resolution to stick to the facts without associating myself with any of the major options of the nineteenth century. These I consider, for the most part, to be empty of meaning, faded, word-worn, and distorted by the image of the déja $v u$. In addition, these options are profoundly il1-suited to the realities of the modern world. Instead of being based on ideologies, the study systematically endeavours to observe reality, the interaction of cause and effect, by using the new ways of thought offered by systems analysis. The reader is then free to introduce his own political options to embellish the solutions he favours to the problems posed.

We have now embarked on a search to discover what the European identity can be, accompanied by meditation on its long-term consequences. In a preliminary analysis I have tried to draw up a balance-sheet that is as objective and as uncontroversial as possible. My thinking becomes more deliberately personal when I come to the aspirations and projects that Europe appears to have in its womb. However, this projection to the future is by no means, to my mind, an idealistic view of what the European society of tomorrow ought to be. Rather, it is a view of what tomorrow's European society is, to some extent, predestined to become on account of the endogenous and exogenous forces arising from its environment. As will be seen, the forces of the environment are assumed to be an emanation from the past, of historical and cultural origin; an emanation from geography, the birth rate, economic and political competition, and the economic needs of the rest of the world. There is no question of pronouncing a moral judgement on tomorrow's society. Even less is it a question of assuming that political action could prefabricate the future. The future, in essence, remains unknown to us. No man has the right to predetermine it for his fellows. The future must remain free but have light thrown on it, in so far as it is predictable, in order to eliminate or mitigate the major threats.

What can be said now about Europe is that if it is decided to do nothing or to do little, a crucial decision regarding its future will have been taken and a rendezvous with tragedy will have been made as regards economic dependence, unemployment and social tension.

$* \quad * \quad *$

Fundamentally, this study has a utilitarian aim: to promote the formulation of a Community scientific and technical research policy. The main aim of this policy would be to enlarge the freedom of choice open to the generation of decisionmakers thirty years ahead. If results of certain studies are available, governments will be able to make their choices in full knowledge of the facts. If the effort to acquire these results is not made, either the solutions will be imposed or decisions will be taken blindly

The reader will probably regret that the conclusions stop short at the consideration of research policy. As far as European economic forces are concerned, the weak 
point is chiefly the lack of an industrial and economic policy. In the rooms of the House of Europe set aside for innovation, the fires do not always draw we11; instead of helping to warm the partners, they sometimes tend to smoke them out. If this situation is prolonged it will have disastrous consequences in other fields that will adversely affect commercial competitiveness, the balance of payments, and the level of employment.

Europe must be taken as it is today, incapable of political unification in the conventional meaning of the term. But the true problem in the Community is perhaps not to install a hierarchical power superior to the national powers. Europeans are too attached to their diversity to allow this, and perhaps, all things considered, it is better thus. It is necessary to invent new systems of intervention that will interconnect decisions at national and Community levels, so as to generate movements of solidarity or to allow all to benefit from scale effects of European dimension. This will not make the Community a super-government but an instrument for the promotion of complementary or supplementary activities that would not have been originated, and would not have prospered, in its absence. It will be multilateral. It will allow emulation between the partners, which has up to now been one of the sources of European progress. And the problem will be solely to foster the synergy of the specifically Community activities with national activities. The implementation of a research and development policy by the Commission of the European Communities could provide an opportunity for trying out these new intervention arrangements; it would be a kind of trial on a reduced scale of what new types of Community policies could become in more sensitive and more ambitious fields. This is the background against which the proposed solutions have been devised. The advocates of a highly unified Europe may consider them merely as one stage towards more formal structures; those who are mainly concerned to preserve national identities will be reassured and able to give their support to the experiment without misgivings.

Nothing will be done for Europe, however, until progress is made towards the "addition from the soul" to the European effort in response to the invitation in the Tindemans Report. I hope that the reader will find in my work incentive towards a turning point to be negotiated by our society. The interest of the text lies not in the quality of the guidelines proposed, but in the encouragement to new thinking that it may provide.

of course, Europe cannot negotiate this turning point on its own; it must become complementary with the other major geographical areas. If it wished to isolate itself, the forces of interdependence which dominate today's world would soon recall it to harsh reality. But Europe should claim a vocation: to become one of the "social development laboratories" which humanity needs so greatly today. It has yet to realize, by proposing a project, that it could play the role; after that, it is probable that Europe will decide how it is to be done. 
Part I

THE SEARCH FOR THE EUROPEAN IDENTITY 



\section{Chapter 1 \\ THE BALANCE-SHEET}

As opposed to the remainder of this study, which may in some respects be regarded as a plea on behalf of certain arguments, the balance-sheet given below endeavours only to relate facts and comment upon certain estimates resulting from the extrapolation of trends noted over recent years.

The figures and the curves quoted are subject to errors. The statistical apparatus at our disposal for assessing the present, and even more so the past, is unsatisfactory. Projections into the future are the result of debatable hypotheses. If, however, like doctors, we devote our attention to orders of magnitude in phenomena while neglecting detail, the conclusions are firm and make meaningful diagnosis possible.

This balance-sheet shows Europe as it appears today in the light of the political situation, demography, and geographical and economic data.

\section{THE POLITICAL EVOLUTION}

Without going back into very ancient times, which continue to exercise an influence although almost exclusively in the cultural field, the history of the last few centuries is rich with lessons which help us to understand the importance of the change which has been imposed upon Europe as regards political and military power. ${ }^{1}$

For four centuries Europe engaged in conquering and then occupying space on this planet, creating an immense empire which was at its apparent peak on the eve of the Second World War. With the exception of China, Japan, and a number of states in Asia, which were never deeply penetrated, all the continents have been subject to this expansion, some to settlement and others to exploitation by European colonialism.

The first phase of expansion was essentially Latin. It was in the direction of the West Indies and was undertaken by the Iberian powers with the support of maritime techniques which had come from Italy. It extended from the end of the fifteenth

1 This chapter is based on a bibliographic survey carried out by Mrs. A. Devred on behalf of FISH (February 1977). 
to the beginning of the nineteenth century, when Spain and Portugal lost control of their American possessions. However, they left behind them their languages, their religion, a marked cultural imprint, and a large proportion of their ethnic elements. Latin America is the daughter of Iberia.

The second phase of expansion, slowly prepared in the fifteenth and sixteenth centuries, was by France, Great Britain, and Holland during the seventeenth and the beginning of the eighteenth century. Maritime superiority was lost by the Spanish and Portuguese to the hands of the north-west Europeans who were more enterprising and concerned with discovering new territories to populate. The Caribbean islands changed hands. France and Britain competed for the North American continent. Trading centres, which constituted the bridgeheads for colonization, were founded in India and Indonesia. Australia was discovered and became New Holland. France claimed rights to Madagascar. Africa had as yet but little to say except as a supplier of slaves.

On the North American continent the adventure started with the independence of the United States. In that country the aboriginals living there before conquest have practically disappeared, so that the ethnic elements are almost exclusively European with the exception of black forced immigrants. The languages of Western Europe, its culture, its different forms of Christianity and especially Puritanism, its enterprising spirit, its capacity for invention and for giving expression to democratic forms of political power, helped in the explosive rise to power of a new nation to which was open the conquest of virgin space rich in possibilities for agricultural, mining, and finally industrial development. Right through its period of growth the United States continued to swell its population by immigrants from northern and Central Europe and the Mediterranean. The North American melting pot gave them homogeneity. The United States is a branch of Europe transplanted into a basically different environment in terms of available space, the scale of natural phenomena such as rivers, deserts, and climate, and the resources in the soil and the subsoil. When US supremacy over Europe has affirmed itself, the US people may be regarded by the Europeans themselves and by other peoples as "the Europeans who succeeded".

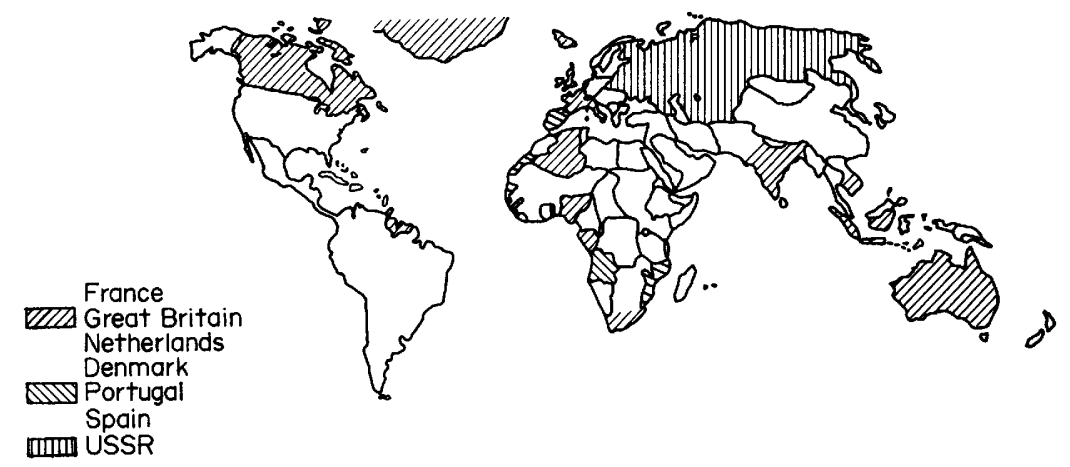

Fig 1. European colonial empire in 1870. 


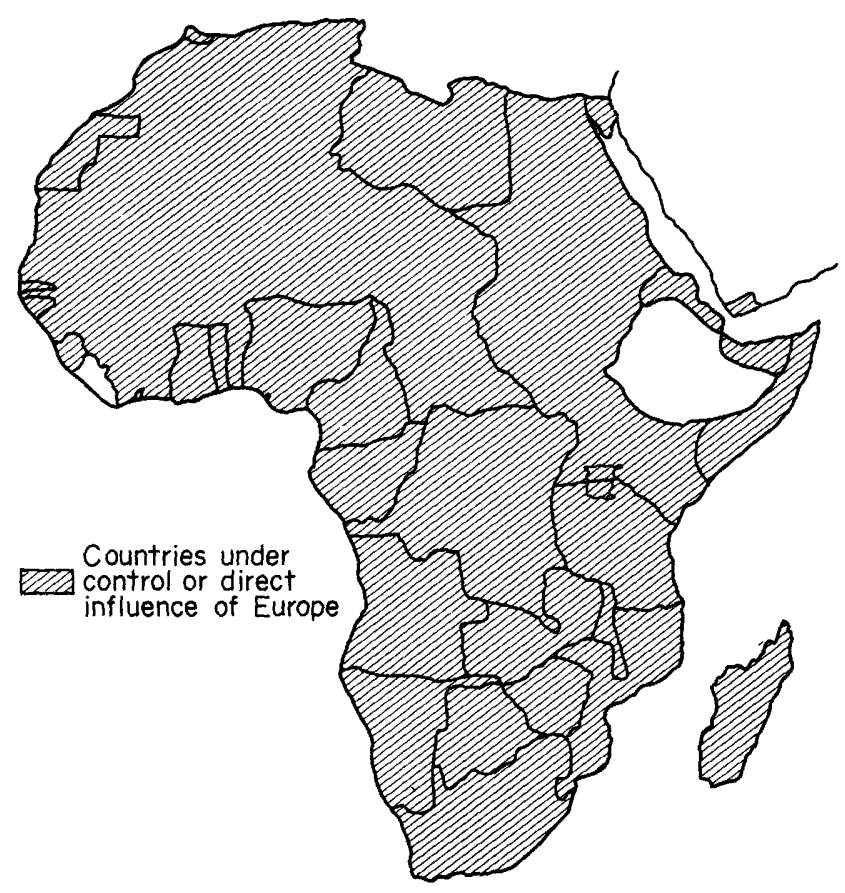

Fig. 2. Africa in 1914.

After the Napoleonic wars, Europe bound its wounds and devoted its strength to promoting the Industrial Revolution, the main scene of which was the regions in the north and the north-west. The expansionary phases calmed down over almost three-quarters of a century, and then flared up again even more vigorously after 1870 (Fig. 1). By then Africa had been almost entirely conquered and shared out (Fig. 2). With the exception of Thailand, southern and South-east Asia was subjected in the form of colonies or protectorates. The collapse of Turkey in 1918 opened up to the allied powers the road to the Middle East and the whole of North Africa (Fig. 3). On the eve of the Second World War, Italy conquered Ethiopia, Africa's last independent nation. Australia, Canada, and South Africa were alongside Great Britain in a Commonwealth covering five continents.

European domination was then apparently at its peak. Without counting Russia who, during this period, confirmed its hold over Siberia while ceding Alaska to the United States, the European colonial powers, whose metropolitan base was not more than 1.8 million square kilometres, associated within their political system and placed under their military control more than 50 million square kilometres of overseas possessions, i.e. more than one-third of the world's land surface.

One-quarter of the world population was under the direct domination of Europe's political power. Control of the seas was disputed only by the United States. The sources of enormous quantities of raw materials, both mineral and vegetable, were controlled by the states of Europe or by the power of the capital of Europe's entrepreneurs. Middle East oil was subject to the political influence of Great Britain, whose currency possessed international value. 


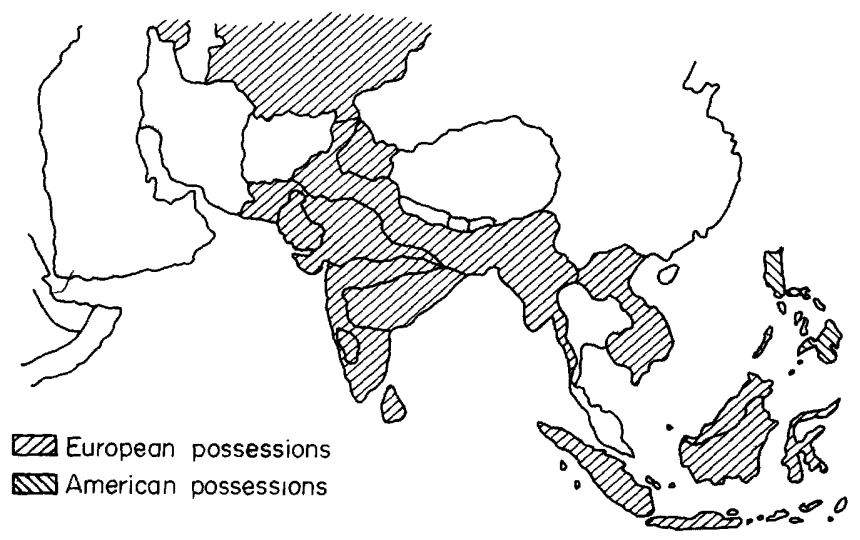

Fig. 3. Southern Asia in 1914.

However, Europe was profoundly divided, and the Second World War came to an end amid the Continent's ruins. The leading roles fell to the United States and the Soviet Union. The vicissitudes of the war had given the dominated peoples a taste of independence and the idea that it might be achieved. The moral force which argued that colonization was good because it brought civilization and technical progress to peoples who did not possess it was entirely reversed. World opinion, amplified by the United Nations, was in favour of independence for the former colonies. The Bandung Conference in 1955 proclaimed the will of the peoples of the Third World.

In 1956, Western Europe stood by without reacting in the face of the vicissitudes of the Hungarian insurrection. Great Britain and France yielded at Suez before the combined intimidation of the Americans and the Soviets. In doing this they announced to the rest of the world that they no longer possessed their own political power.

From then on, the retreat from what was left of positions acquired over four centuries was certain (Fig. 4). It was to be accomplished inexorably, and not without some shudders, over a period of less than twenty years, terminating in 1975 with the independence of the Portuguese territories in Africa. Meanwhile, Western Europe became fully aware again; the freedom of peoples to dispose of their own destiny is, indeed, a cultural product which came from Western Europe itself. It is consistent with the practical and moral ideas regarding democracy and responsibility which the occident considers to be essential values. In addition, the idea spread that economic wealth and standard of living are not a function of the availability of basic products but of the efficiency of systems of production and distribution. Freed from the burden of its colonies, Europe became free to devote its attention to domestic progress and an export effort. 


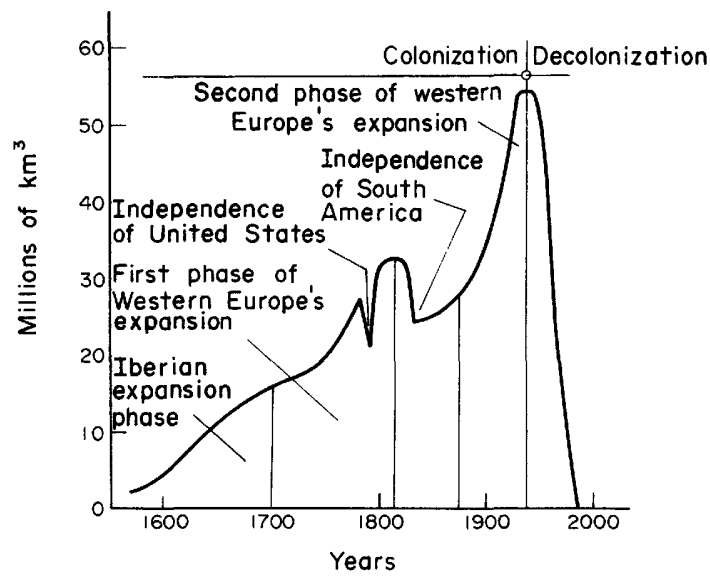

Fig. 4. Rate of variations in area of European colonies or protectorates from 1600 to the present day.

On 15 August 1971, without consulting its European partners, the United States took capital decisions in monetary matters and affirmed the absolute supremacy of the dollar; Europe's reaction was zero or to no avail. In the autumn of 1973 the oil producers agreed to quadruple the price of a fuel which accounts for $57 \%$ of the energy resources of the European Economic Community. Instead of the reaction being one of uniting to establish targets for economy and develop new sources which became dramatically necessary, national egoism enjoyed almost full play. The Middle East powder barrel is saturated with exports of arms employed as an instrument for balancing budgets. It is, doubtless, useless to dwell here on the weakness of Western Europe's military positions; its naval forces are no longer master even of the Mediterranean. As $f a r$ as the land and air forces are concerned, they are entirely dependent upon US goodwill (Table 1).

TABLE 1. Armaments table ${ }^{l}$

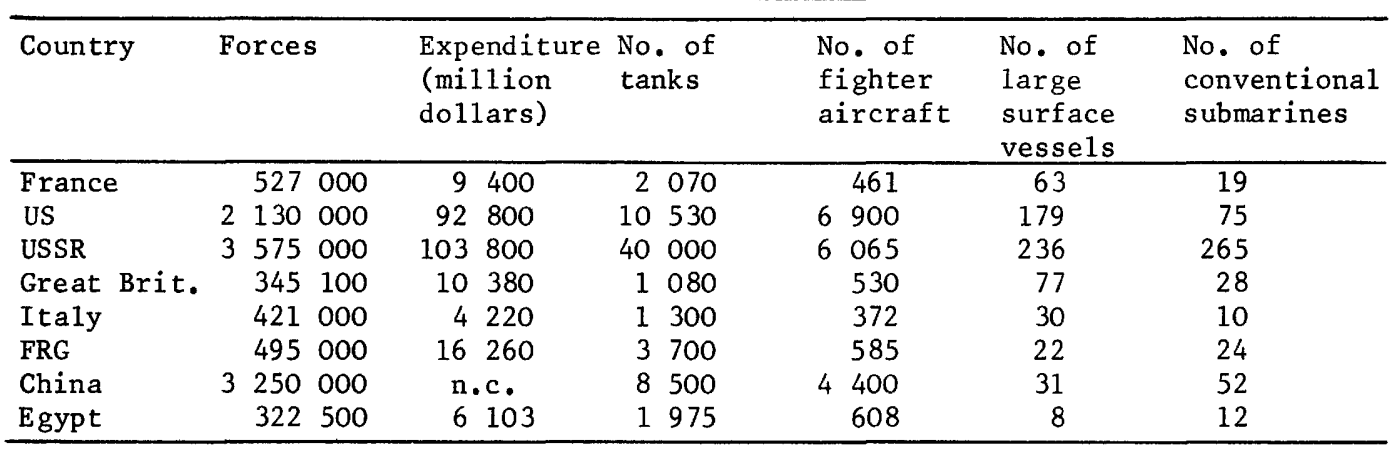

In the case of France, the numbers do not include the gendarmerie and paramilitary forces.

Source: Military Balance (1975-1976).

1 Taken from France-Fomum No. 149, July/August 1976, Dominique Kerga11

"Quel avenir pour 1'Occident?" 
The events of recent years have thus demonstrated that politically Europe is extremely weak. For the first time in their history, Europeans are obliged to observe the wisdom of ceasing to wage war in order to dissipate a surplus of aggressiveness. Europe, if it wishes to defend its identity, can take the offensive only on the basis of its cultural strength and its economy's potential for competition.

This situation is not yet generally accepted, however. Most Europeans have no idea of the danger to which this political weakness exposes them. And their partners in the developing world, newly independent, are only slowly developing their own identity, with the impression that they are still subject to an economic dependence that weighs heavily on them.

On the other hand, Europe's military and political weakness should make it easier for the peoples of the developing countries to regard Europeans as partners having absolutely no imperialist intentions (or at least power) who are naturally complementary on a basis of reciprocity (Table 2).

TABLE 2. The main stages of decolonization

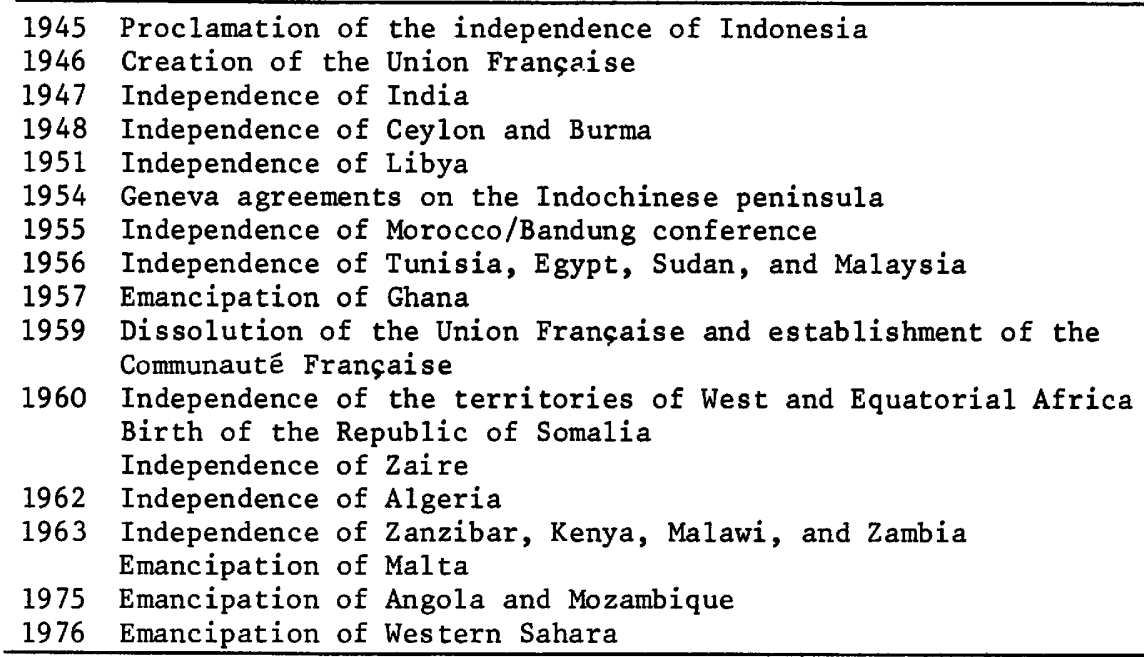

\section{POPULATION TRENDS}

The size of the population in absolute terms and in relation to the remainder of the world, its density in the space available for population, and its composition per age category are fundamental data if it is desired to comprehend certain economic and social phenomena. In this field, Western Europe's situation is, by comparison with the rest of the world, in a phase of complete change.

For a long time Western Europe was the world's major reservoir of men. Upon emerging from the Middle Ages it was, after China and India, the most populated region. Although its density of population per square kilometre never reached the levels observed today, it has always been Europe's endeavour to find territories to populate outside itself. This desire partly explains its efforts to achieve overseas conquests. 
Europe's fecundity has created considerable migration flows which have supplied the foundation for populating the Americas, South Africa, and Australia. However, despite having ceded part of its population to other continents, Europe maintained until the nineteenth century its position as a very densely populated territory by comparison with the rest of the world.

The trend of events was reversed in the nineteenth century. Western Europe's relative share in the world population fell progressively until the watershed of the fifties, when the population decrease speeded up dramatically. Reduced fecundity on the part of the Europeans contrasted with a sharp population growth in the developing countries, where the fight against perinatal mortality was making spectacular progress.

It is important to take recent events into account and even more those which can be forecast with a fairly safe margin of approximation for the next twenty-five years. Although modern contraceptive techniques and legalized abortion can today profoundly change the trends observed in the past as regards fecundity, there are in fact sufficient inertia factors for relatively short-term population forecasts to be valid.

For the past, United Nations statistics have been taken as a basis. For the period 1975-2050 the figures are from the Mesarovic-Pestel mode1.1 Questions were fed into the model on the basis of two extreme hypotheses, one according to which the fertility trends observed during the years 1950-1970 remain unchanged, and another whereby a very strict anti-birth policy is enforced immediately in the developing countries. The truth lies between these two hypotheses. As far as Europe's future place is concerned, the degree of uncertainty is of no importance. Whatever happens, its place must be quantitatively minute; it will count only qualitatively. This is the fundamental lesson to be learnt from these forecasts. As far as the nations which make up the Europe of the Nine are concerned, in the most populated among them Great Britain, Federal Germany, Italy, and France, which each accounted in 1950 for more than $2 \%$ of the world population - children born today will see this percentage fall rapidly to less than $0.6 \%$. This is unless the trends observed in most recent years in the direction of a further fall in the birth rate are confirmed. The level of the population is maintained at a rate of about 2.1 children per woman. In Europe, particularly northern Europe, rates of 1.8 or lower have recently been observed. If the phenomenon continues, a country such as Federal Germany would fall below $0.4 \%$ of the world population in 2050 - even if the developing countries were to reduce their birth rate considerably (Figs. 5 and 6 ).

And so the EEC, while ceasing to become a territory from which there is emigration, is tending, despite an immigration flow in the opposite direction, to occupy in less than twenty-five years a humble place in the world, in terms of numbers of human beings, more humble than the relative position occupied in the eighteenth century by any one of the great nations now a member of it (Table 3 ).

1 The results obtained with the help of the Mesarovic-Pestel model were reviewed by INED specialists for the period 1975-2000. They were sufficiently near the United Nations most recent forecasts for there to be no need to adjust them. The figures given in the tables for the Europe of the Nine come from INED (Institut National d'Etudes Démographiques, Paris). 


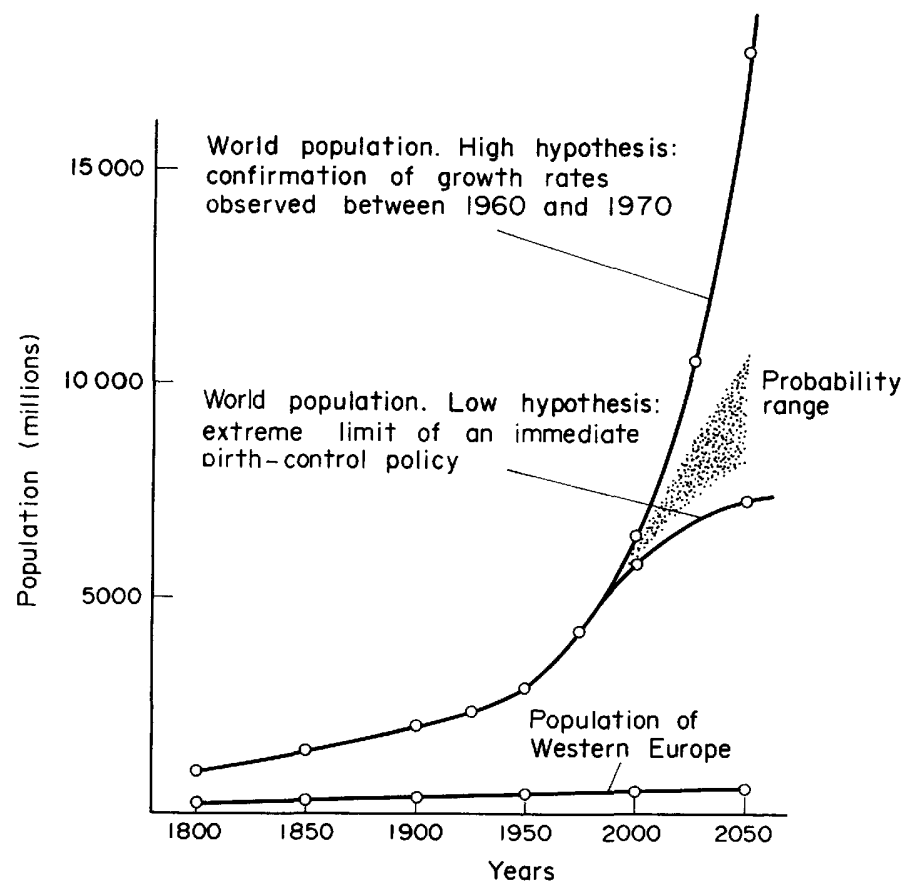

Fig. 5. Forecast of comparative trends in the world and Western European populations.

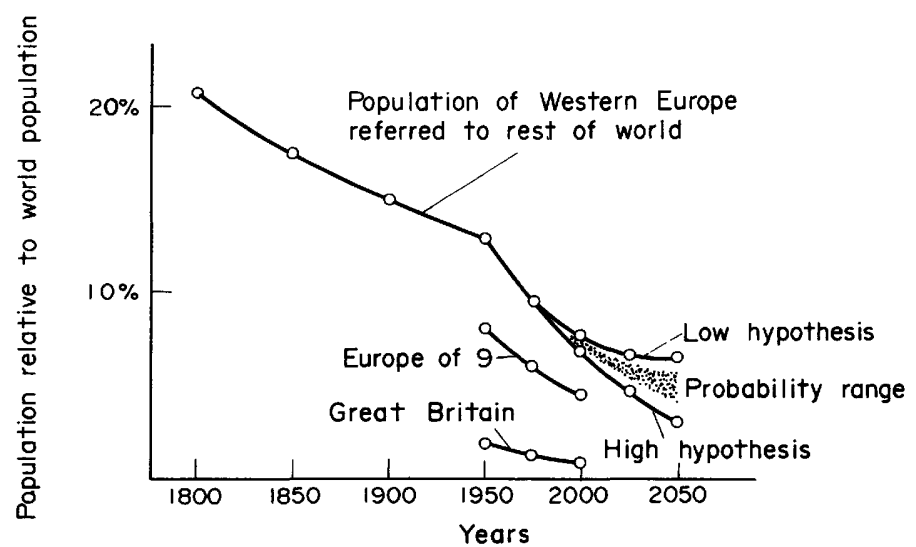

Fig. 6. Forecast trend in the ratio of European to world population. Western Europe: Mesarovic-Pestel model. Europe of the Nine: INED. 
TABLE 3. Forecasts of population trends (millions)

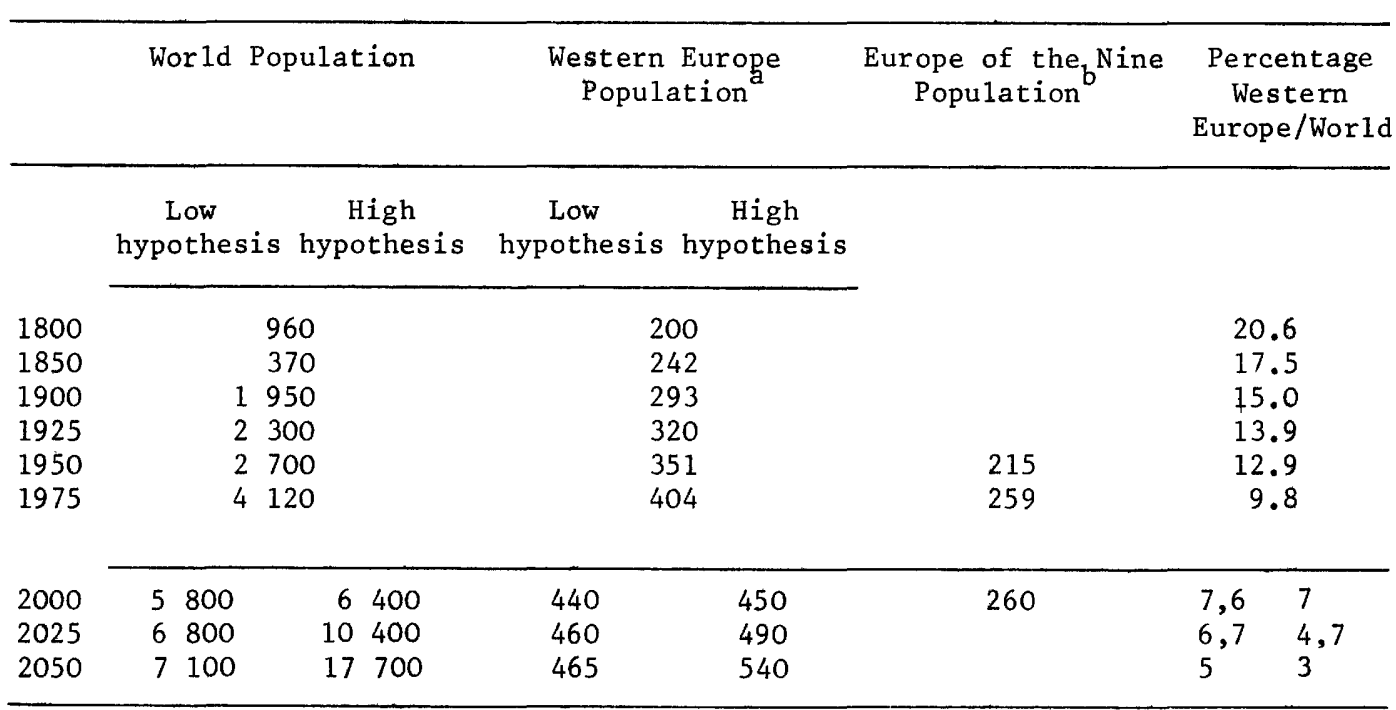

Note: Western Europe is here Region No. 2 in the Mesarovic-Pestel model. This includes not only the Nine but also all non Soviet-bloc

European countries.

a Mesarovic-Pestel model figures.

INED figures.

This situation must be considered highly probable in the absence of catastrophes. Contesting the figures - attributing an error of approximately $20 \%$, which is certainly excessive for the period separating us from the year 2000 - does not change the orders of magnitude at a11, any more than would be the case if an extremely determined policy for encouraging the birth rate were pursued in Europe alone.

Western Europe's comparative demographic shrinkage by comparison with the remainder of the world is not an isolated phenomenon. It is found in a11 the industrially developed regions in comparison with the developing countries. It affects both the countries with an economy based on free competition and those with a planned economy. If, in outline and omitting Japan, we regroup the industrialized countries into three main regions - the North American continent, the Soviet bloc, and Western Europe - it will be seen that in the years to come there will build up at the frontiers of these three areas considerable demographic pressures derived from Latin America, South-eastern Asia, and the Arab world respectively.

A comparison of the population trends of Western Europe and the Arab world is particularly significant on account of the shared responsibility for the Mediterranean, the economies' complementarity and the proximity of their cultural heritage. Figure 7, provided by the Mesarovic-Peste1 mode1, shows 
that with effect from the year 2000, i.e. almost tomorrow, young Arabs ${ }^{1}$ below the age of 15 will be more numerous that young Western Europeans, ' whereas in 1950 the percentage for young Arabs was scarcely $40 \%$.

The structure of the populations by age group will, of course, be radically different. The opposing partners in the situation will be an Arab world composed mainly of young persons and a European community peopled by persons of a ripe age, not to say old. This is the second inexorable forecast which can be made regarding the population (Figs. 8 and 9).

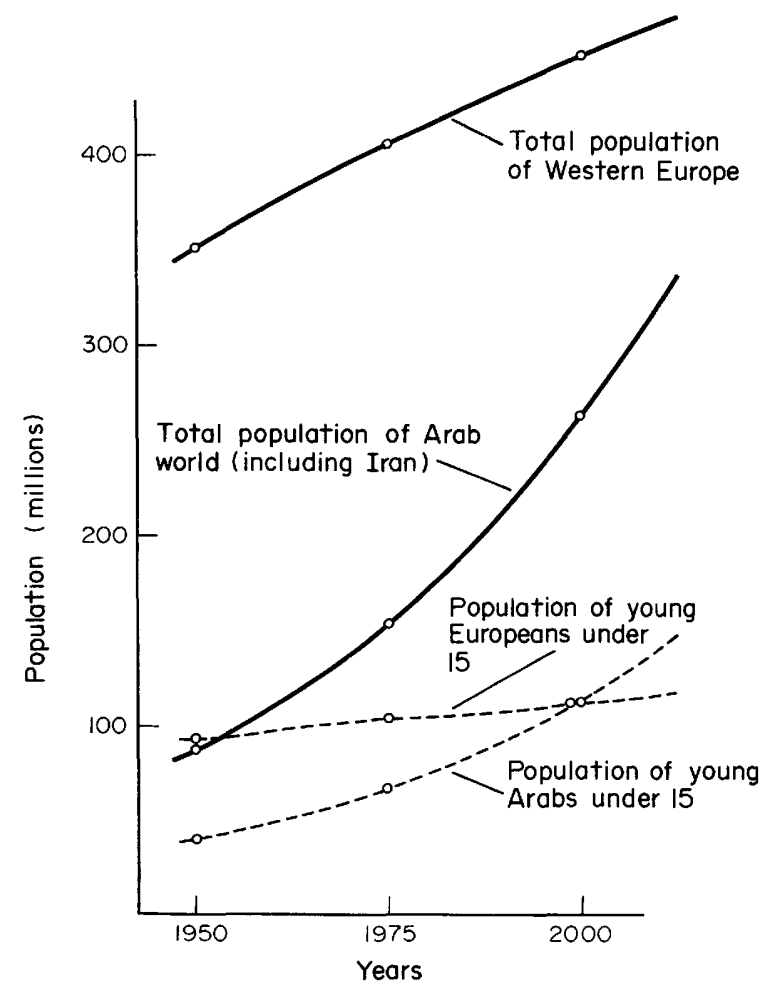

Fig. 7. Comparative trend for the populations of Western Europe and the Arab countries including Iran. Total populations and young persons under 15. Hypothesis: continuation of current trends.

1 It should be remembered that in the Mesarovic-Pestel model the Arab countries include all the countries in North, West, and East Africa, the Middle-East countries and Iran. Western Europe covers all the countries not integrated into the Soviet bloc, more particularly Yugoslavia, Greece, and Turkey. 


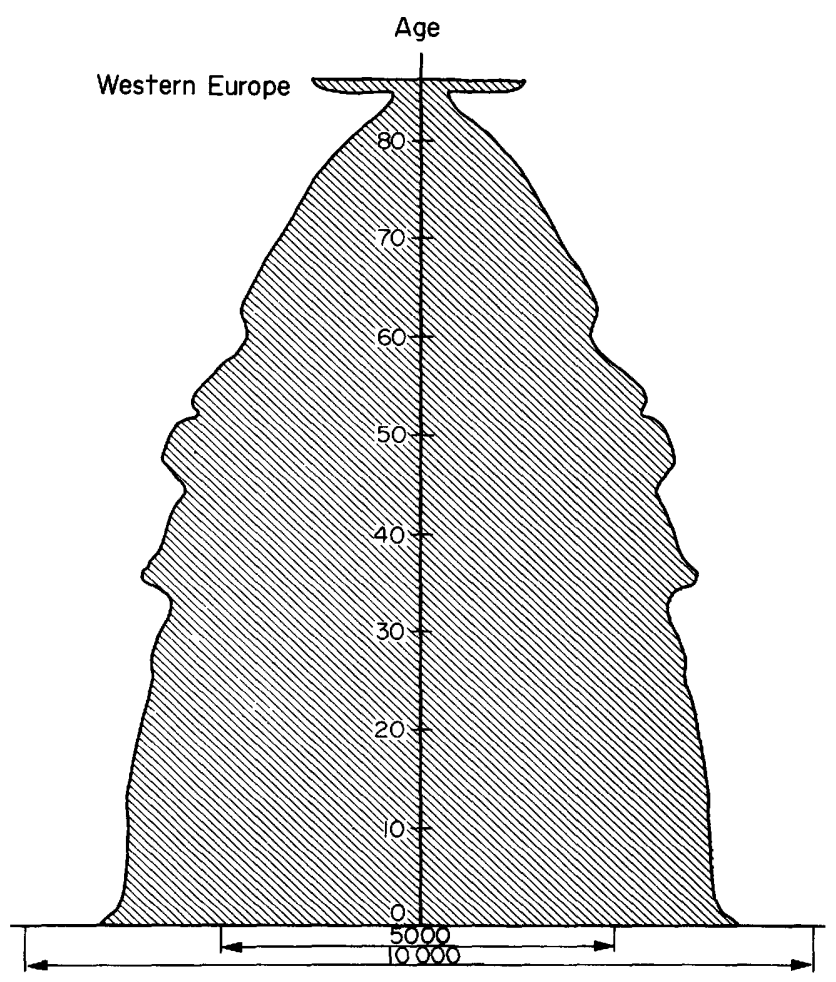

Fig. 8. Study of age structures: forecast for Western Europe for the year 2000.

\section{GEOGRAPHICAL DATA ${ }^{1}$}

Western Europe constitutes a geographical whole which is remarkably homogeneous by reason of its temperate climate, even in the most northern regions, which are under the influence of warm sea currents, its irregular coastline, its orography and hydrography where extremes are absent, and the ease with which its territory can be penetrated by man for the purpose of transport, town and country planning, agriculture, and industrial development.

A11 Europe's dimensions are on a scale appropriate to agricultural, artisanal, or intellectual man. No natural phenomenon is excessive. The lines of communication are short. The largest river, the Rhine, is a dwarf by comparison with the Amazon, the Mississippi, the Nile, the Yang-Tse or even the Volga. The Alps, dissected by morainic valleys, are far more open to human traffic than is the Andean Cordillera or the Himalayas. There is neither desert nor jungle. The 1 and has been cleared of all species of animals hostile to man. The permeation of nature by man, and a population density that has been high for centuries has meant that there now exist only flora and fauna which are tolerated and useful to human 1 ife.

1 This chapter draws strongly on the paper read by Mr. Kormoss at the symposium organised by FISH in Luxembourg in October 1976. See proceedings: "Some aspects of the geographical and demographic bases of European integration". 


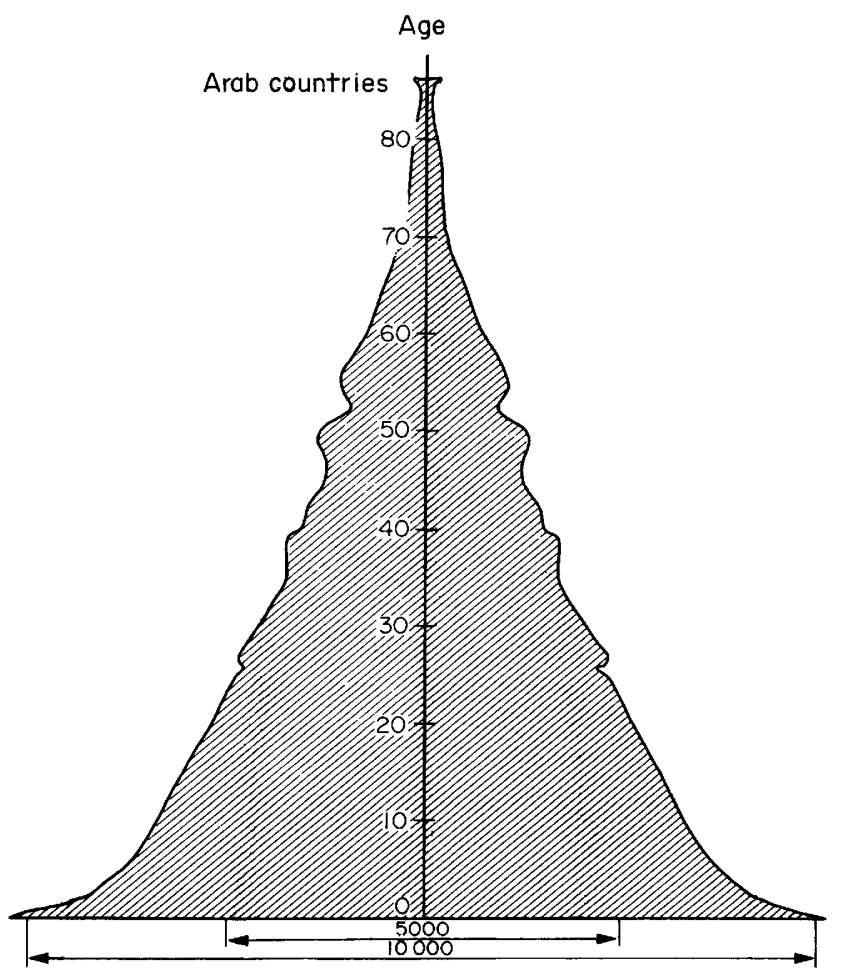

Fig. 9. Study of age structures: forecast for the Arab countries for the year 2000 .

Western Europe lacks room. On average it is the region in the world where the population is most dense (Figs. 11 and 12). In this respect, among the industrialized countries, only Japan experiences similar problems which there are rendered even more acute on account of the small area of land suitable for settlement (approximately $16 \%$ as opposed to $30 \%$ for Europe).

Western Europe is relatively poor in easily accessible rich ores. Intensive mining of the most readily available resources has gone on throughout history with the result that the most accessible deposits are exhausted. What is true of gold, diamonds, tin, lead, mercury, and coal is true also of the more recently exploited ores such as bauxite. In addition, sources of fossil energy are scarce or difficult to reach (ocean deposits). Europe's hydrology is not very conducive to the production of large quantities of energy. If Europe wants to obtain the raw materials it needs from its own soil, it will on average have to spend more than most of the other major industrialized countries, work less economically, and use more energy for the processing of low-grade ores.

The scenery is not conducive. The littoral opens on to shallow seas which are closed or almost closed. The rivers flow through highly urbanized areas. It is intolerable that they should be used as carriers of waste. The large forest areas are not much developed. 


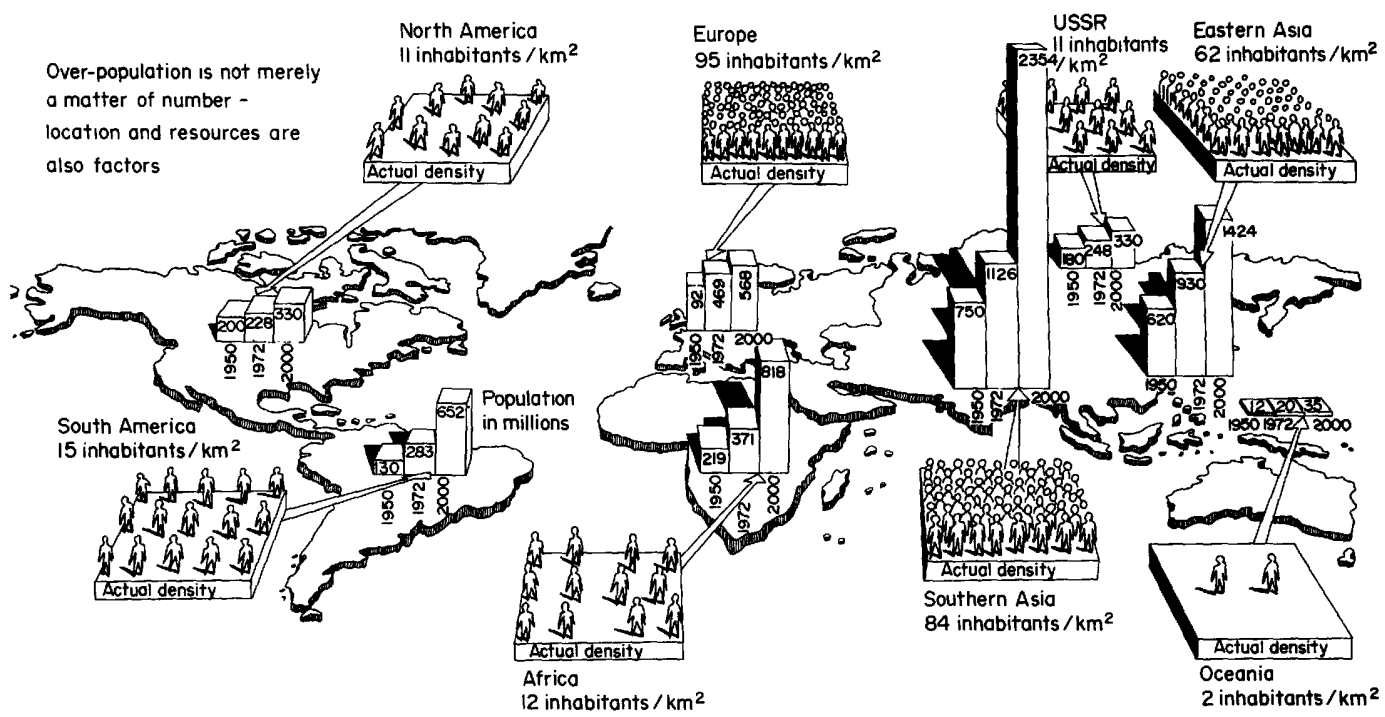

\begin{tabular}{lcc}
\hline \multicolumn{1}{c}{ Country } & $\begin{array}{c}\text { Population } \\
\text { (millions) }\end{array}$ & $\begin{array}{c}\text { Density } \\
\text { (inhabitants } / \mathrm{km}^{2} \text { ) }\end{array}$ \\
\hline China & 800 & 83 \\
India & 576 & 172 \\
USSR & 248 & 11 \\
USA & 208 & 22 \\
Indonesia & 126 & 78 \\
Japan & 107 & 284 \\
Brazil & 101 & 12 \\
Bangladesh & 72 & 524 \\
Pakistan & 64 & 74 \\
Federal Republic of Germany & 61 & 248 \\
Nigeria & 58 & 70 \\
United Kingdom & 55 & 229 \\
Italy & 54 & 180 \\
Mexico & 54 & 25 \\
France & 51 & 95 \\
Netherlands & 13 & 380 \\
Canada & 21 & 2 \\
Libya & 2 & 1 \\
\hline
\end{tabular}

Fig. 10. With 800 million inhabitants, China is four times less populated than the Federal Republic of Germany, and India two times less populated than The Netherlands. It is the Europeans who risk lack of room - the others, lack of resources. 


\section{$\checkmark$
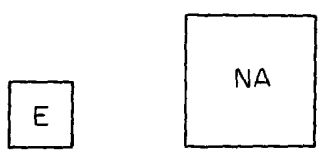 \\ Fig. 11. Space available to the inhabitants of the main developed regions: ${ }^{1}$ \\ for each person in Japan: 0.35 ha \\ for each person in the EEC: $0.60 \mathrm{ha}$ \\ for each person in North America: 4.70 ha \\ for each person in the USSR: 9.00 ha}

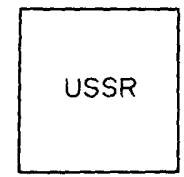

Europe's natural dimensions are not favourable to mammoth industry. When new technologies have to be tried out in wide open spaces, as is the case of military research that can have important civil spin-off, Europe is handicapped. The same is true when harmful waste needs to be recycled. Europe lacks vast continental rivers easily capable of providing cooling or process waters, hugh open spaces where air pollution is of no account, and open country with a low population which can be despoiled by mining without affecting man.

In Europe the price of land is a painful economic fact; it is difficult to set up a chemical plant, oil refinery or nuclear power station close to built-up areas. Cooling water is scarce - air and river pollution is intolerable - and the transport ol goods on main routes aggravates traffic congestion. All these factors increase industrial overheads or necessitate local authority expenditure.

The European scale of nature and the high population density appear to militate in favour of small production units, which are in any case more acceptable from the human aspect. Europe, geophysically and culturally, generally does not welcome mammoth industrial units. With mass production costs as they are today, this is an additional difficulty to be taken into account.

\section{ECONOMIC EQUILIBRIA}

Throughout history man has suffered greatly from insufficient economic capacity, lack of food, inadequate housing, poor defence against the vicissitudes of climate, and insufficient educational facilities. However, through the extent of its agricultural and artisan activities and industrial development, and through the advantages which it has obtained from its political power, Europe has experienced over the last few decades situations which were generally favourable. This has not prepared its peoples for frugality.

1 If the United States had the same population density as Western Europe, it would have 2000 million inhabitants. 


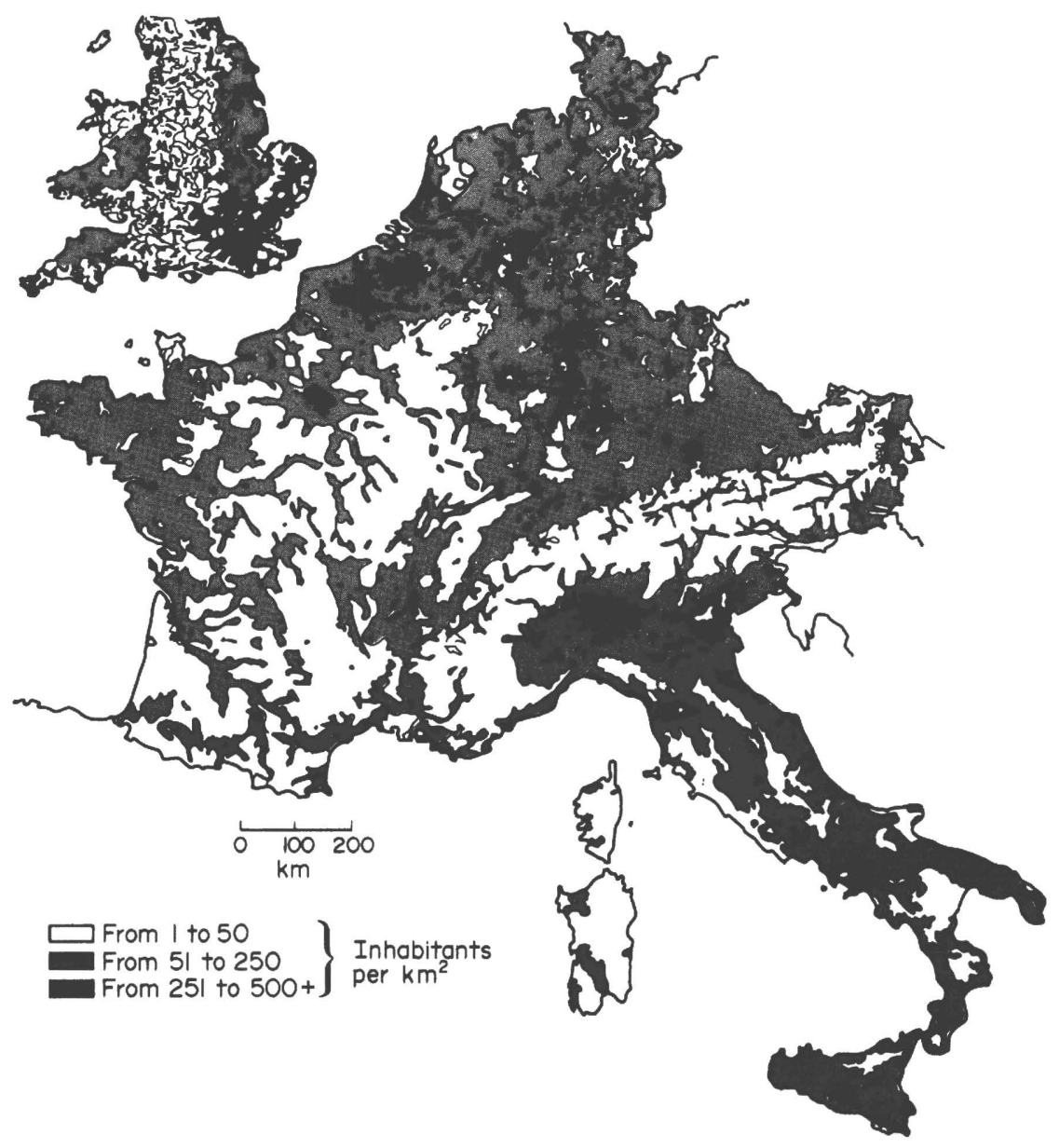

Fig. 12. Population density of the countries of central western Europe. Map compiled from the work of Professor I.B.F. Kormoss, Collège d'Europe, Bruges.

Once the pieces had been picked up after the Second World War, ${ }^{1}$ the capacity of its peoples, mobilized for industrial growth, enabled Western Europe to hoist itself again to the level of the most-favoured nations as regards potential for the consumption of all kinds of products. During the fifties and halfway through the decade thereafter the countries of Western Europe had as their real industrial competitors only the United States - itself in full expansion. Imported products, raw materials and energy were bought cheaply. Competition from Japan and South-East Asia was only beginning.

\footnotetext{
1 Largely thanks to the Marshall Plan
} 
The horizon rapidly darkened at the beginning of the sixties. Inflation and monetary disorders accompanied a break in the rate of growth in most of the industrialized countries. With effect from the autumn of 1973, Europe learned that it was going to be dictated to by certain suppliers such as those of oil and gas, and perhaps phosphates and other raw materials. In recent years, the Eastern nations re-started, under the spur of development needs, their commercial offensive, which involved a great variety of products such as steel, cars, ships, clocks and watches, radio and television receivers, electronic components and micro-processors, textiles, etc. Japan did this on the basis of its own independence. South Korea, Taiwan, Hong Kong, Singapore, and recently-independent countries, such as Indonesia, were assisted with foreign aid.

For the needs of this study the Mesarovic-Pestel (M.P.) general macroeconomic model has been used to produce forecasts regarding the deficits in food, energy, and nonferrous metals for Western Europe for the period 1975-2025. The results exhibit numerous uncertainties: they cannot take into account the unforeseeable, the unexpected changes that may occur in the political or economic order or as a result of the widespread application of the new technologies now being spawned in our laboratories. Fifty years ago, no one could seriously have predicted the consequences of biological progress on population trends nor the effects of nuclear science, electronics, and computers on our society. It is logical to believe that new surprises await us in the technological field in the next thirty years, and it is by no means sure that we will be any better able to control their effects than we have been in the past.

Because of these inadequacies in the forecasting mode1s, we give in the Annex the results obtained from the experiments with the M.P. model. The reader will find ample food for thought. Despite inevitable approximations, the results do at least indicate orders of magnitude. They show that the current deficits will steadily increase in the future in so far as scenarios can be drawn by extending statistical observations made in the recent past.

To measure the current degree of economic dependence of Europe of the Nine, it appeared more convincing to portray the situation that emerges from the statistics put out by the Directorate-General for External Affairs of the Commission of the European Communities, in the publication Community trade in 2975: changes as compared with 2974.

Table 4 shows Community trade with the rest of the world, quantifying the deficits in food, raw materials, fuel products, and primary products. Ratio ranges vary between 12 and 40\%. With all their talk of milk and butter surpluses, the Europeans have perhaps forgotten their overall food deficit. Far more alarming and worrying, however, are the energy and raw material deficits, as the volumes involved are considerable.

Figures 13 and 14, from the same document, show perhaps even more clearly the very special balances in the Community economy. They indicate that Europe serves as a sort of vast factory which makes chemicals, manufactured products, and capital goods ( $85 \%$ of its exports) for other countries, from which it purchases most of its raw materials, its energy, and much of its food requirements (58\% of its imports).

The unbalanced shares of the various member countries in the Community's trade with the rest of the world, one of the features of the current situation, add up to a general dependence on imports of primary products, as Table 5 shows (same source). 
The Balance-sheet

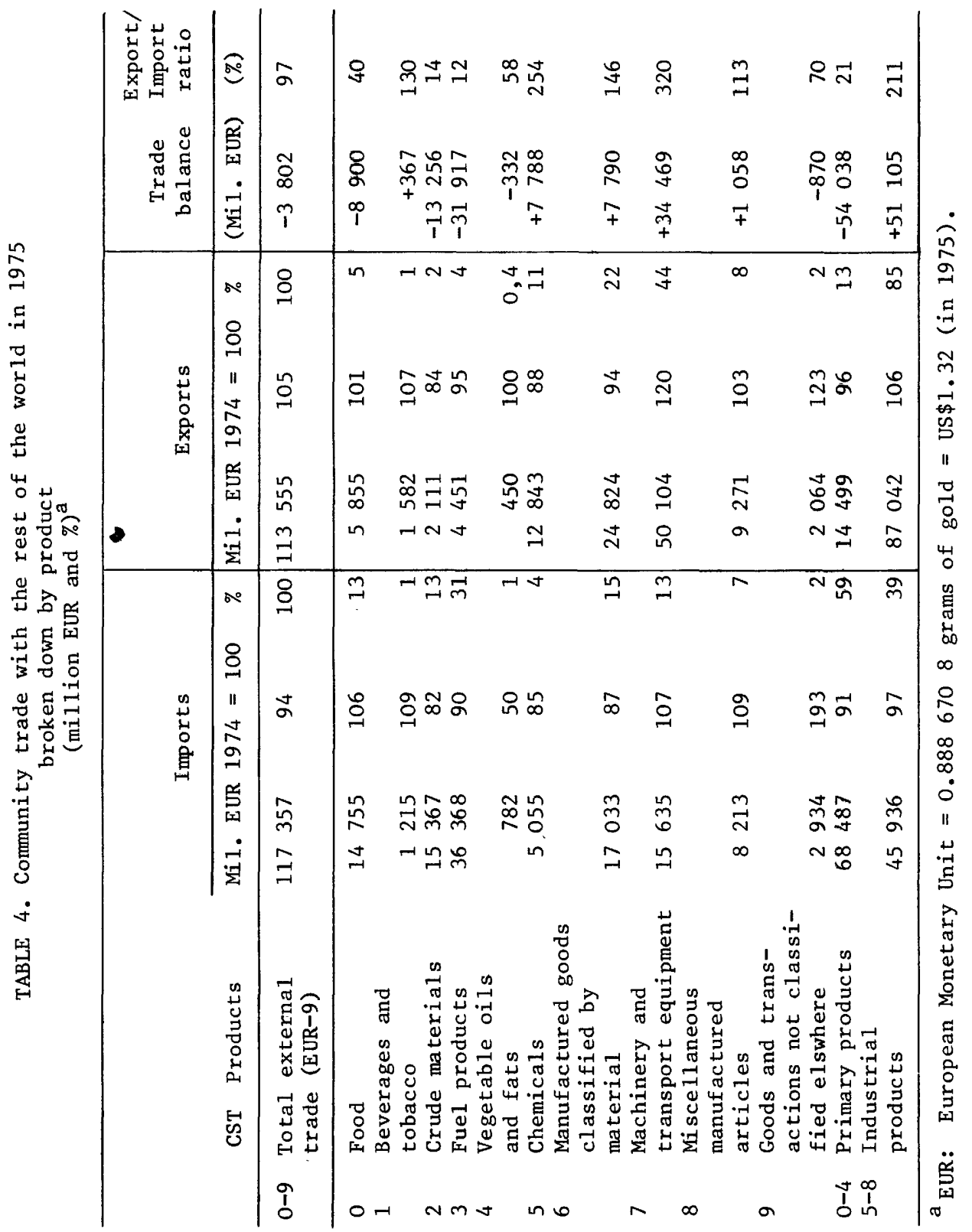



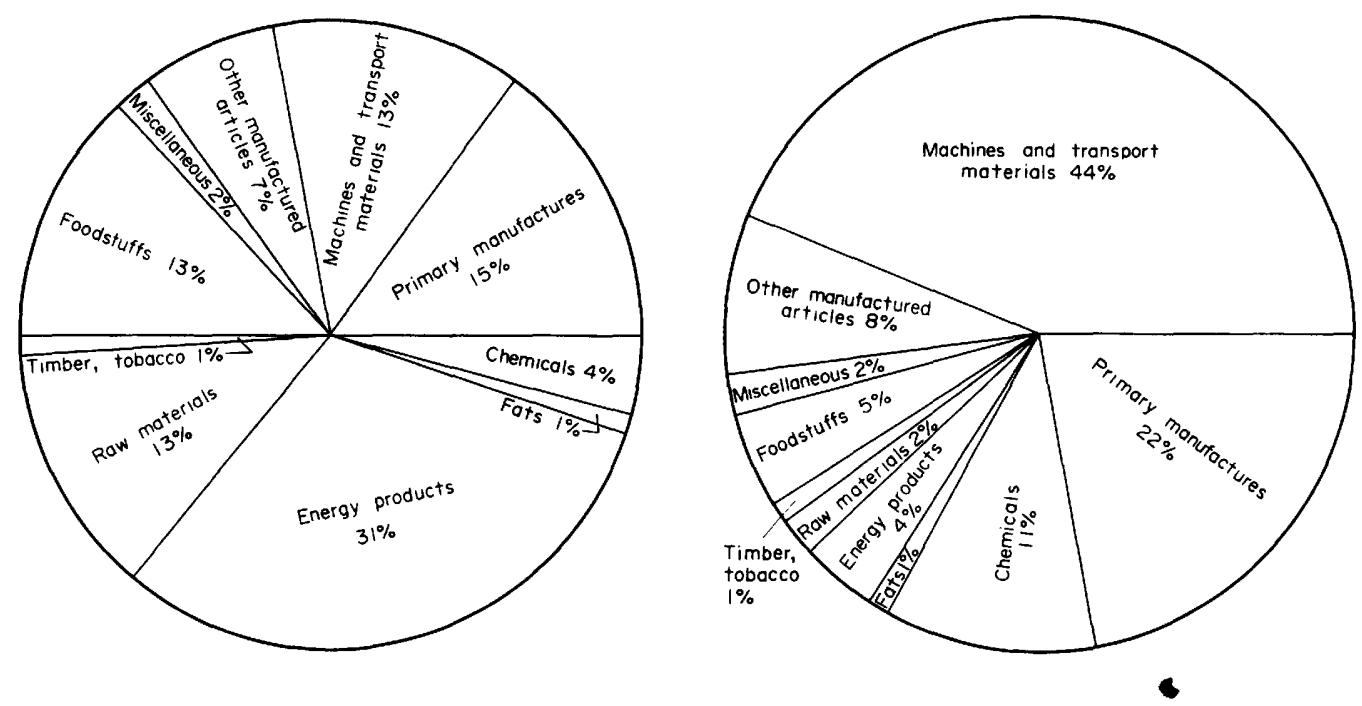

Structure of the Community's trade with the rest of the world in 1975 by groups of products

Fig. 13. Imports from outside the Community in 1975. Total: US $\$ 155 \mathrm{mrd}$.
Fig. 14. Exports from outside the Community in 1975. Total: US $\$ 155 \mathrm{mrd}$.

This demonstrates how necessary it is for Europe to maintain its ability to export manufactured products and capital goods so as to pay for the imports its inhabitants need in order to live.

One might take the view that it matters little if this trade is unbalanced; if it is marginal, we should organize ourselves to be self-sufficient. This would be a major error of interpretation. International trade is essential to the economic life of the Community. In 1975 general imports by the Nine represented $22.3 \%$ of the gross domestic product $(25.5 \%$ in 1974$)$, and the share of world trade was high at $37.6 \%$ of the total, made up of $18.2 \%$ for trade within the Community and $19.4 \%$ for trade with the rest of the world. The shares of the United States and the Soviet Union are $12 \%$ and $4.6 \%$ respectively. If circumstances compelled them to, these continent states could live within their frontiers without suffering too greatly; we Europeans could not.

With whom does this trade take place? The geographical structure of the Community's trade with the rest of the world in 1975 is shown in Table 6 . 
The Balance-sheet

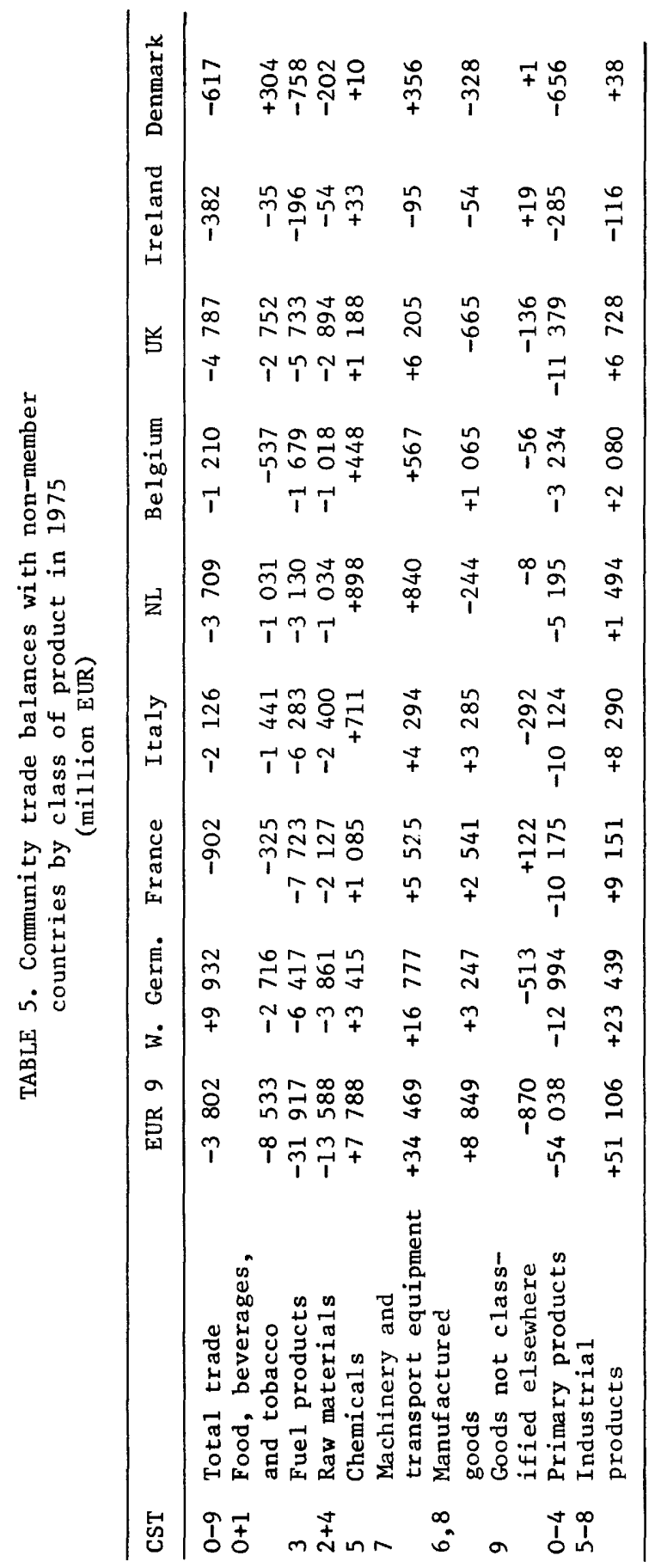


TABLE 6

\begin{tabular}{lcccc}
\hline & \multicolumn{2}{c}{ Imports } & \multicolumn{2}{c}{ Exports } \\
\cline { 2 - 5 } Origin Destination & 1975 & 1974 & 1975 & 1974 \\
\hline Total non-member & 100 & 100 & 100 & 100 \\
\hline $\begin{array}{c}\text { countries } \\
\text { of which: Industrial }\end{array}$ & 48 & 46 & 52 & 58 \\
$\begin{array}{c}\text { Developing countries } \\
\text { (Class 2) }\end{array}$ & 44 & 47 & 36 & 31 \\
$\begin{array}{c}\text { State-trading } \\
\text { countries (Class 3) }\end{array}$ & 7 & 7 & 11 & 10 \\
\begin{tabular}{l} 
Other \\
\hline
\end{tabular} & 1 & - & 1 & 1 \\
\hline
\end{tabular}

The relatively high volume of existing trade with the developing countries should be noted. They are our natural trading partners, as they are partly dependent on us for their technology, their equipment, and the training of their specialists, while we depend on them for our raw materials, energy, and tropical agricultural products. But where is there, under reassuring conditions of stability, a dialogue on Euro-Arab or Euro-African economic reciprocity? Who can guarantee the permanency of trade in the long term? Is it conceivable that a European state, however powerful and determined, can alone control these vital trade patterns when the developing countries tend ta be taken as hostages in the conflicts of interest between the more powerful?

This economic dependence on the stability of trade patterns, which are beyond our contro1, is frightening. It accounts for the fact that, in the eyes of many Europeans, American protection appears inevitable and is worth much in the way of concessions.

Although it cannot provide all the solutions, research and development can be a considerable factor in improving this situation or at the least consolidating some of the stability factors.

If our industries are competitive and our technologies in the forefront of progress, they will continue to be in demand by our customers in the countries now becoming industrialized, where we have the advantage of posing no threat of imperialism.

If technical research is called on to turn our natural resources to the best account (solar energy, processing of low-grade ores, substitute products), to conserve scarce products, and to propose consumption without waste, it can help to make Western Europe less vulnerable.

This analysis compares Europe with Japan. However, the similarity is lessened by a number of differences: the natural frugality of the Japanese people probably fits them much better than it does the Europeans for an age of economic restriction. Japan appears to have found in its deep-rooted culture and traditions cohesive forces that are lacking in Europe, and has realized unhesitatingly that it must wage a merciless economic war based on technological progress. 


\section{CAPACITY FOR INNOVATION}

As the preceding sections have clearly shown, in a world where mass effects tend to become preponderant, Europe's chances depend mainly on the quality level it can attain. That is why its capacity for innovation is so important.

For a physicist who reached maturity in 1950 and took a look backward at his past, this question of Europe's contribution to scientific and technical progress would have induced a superiority complex. Had not the laws of conventional mechanics, relativity, and wave mechanics been discovered in Europe just as the quantum theory had been worked out there and the main experiments in particle physics conducted? Did not Western Europe supply the lion's share of the inventions necessary for the production and use of electricity, automobile traction, radio and electricity, aeronautics, jet propulsion? Did not the first nuclear explosion bear the stamp of the efforts and the genius of physicists who came from Europe? And was not European superiority also decisive in the chemistry of carbon derivatives, in the synthesis of nitrogenous fertilizers, in the production of aluminium and chlorine, in medical asepsis techniques, chemotherapy, vaccination, and serum therapy; were not antibiotics born in Great Britain? Was not inventive genius in mathematics essentially European?

Twenty-five years have been sufficient to knock down this fine assurance, and al though Europe still has little doubt of its inventive capacity, it is already concerned about its capacity for translating the results obtained in its laboratories into industrial and commercial products. 1

The capacity of the European Community countries for scientific and technical innovation measures up badly today to that of the United States, Japan, and Soviet Russia, with whom Western Europe is competing under various heads, above all if an attempt is made to forecast Europe's future chances. The time and the means are not available for carrying out a detailed study of this question. It would be desirable to employ the procedure of a systematic study, a kind of stocktaking, clearly distinguishing the position for each major branch of industry because the situation varies a great deal from one sector to another. Up to what point should we be concerned at the deficiencies of countries like Federal Germany in knowhow and patent licences or of France in copyrights in the cultural field?

In the absence of a clearly defined study it must suffice to have the results available in the bibliography or derived from interviews with a number of personalities in the scientific and technical world. ${ }^{2}$

If we start at source, i.e. basic research, the general impression is not one of Europe falling behind in knowledge but rather one of lack of concern. Whereas in the United States, after a difficult period, basic research has got going again, whereas it has never been noticeably braked in the Soviet Union, and whereas Japan has decided to take the offensive, Europe's wealth has been permanently diminishing since the end of the sixties. There are certain signs of a deterioration: the United States is well ahead in original publications and Nobel prizes although, thanks to the free movement of men and ideas, there is as yet no

\footnotetext{
1 See Annex II, a list of the main scientific discoveries since the Renaissance compiled by Mr. Macioti.

2 Survey conducted by FISH (International Foundation of Human Sciences, Paris).
} 
feeling among European scientists of lagging behind intellectually. One cannot speak, therefore, of a scientific gap. It will remain to be seen whether this comfortable assessment is borne out by facts and especially whether it is not so that Europe is still living on its past impetus without yet having suffered the consequences of the reduction in its scientific effort.

If we move on from basic research to applied research, development and industrial innovation, what we see varies greatly, depending on the speciality.

\section{Europe's place in the "power specialities"}

In the "power specialities" such as those associated with political or military power, armaments, space, aeronautics, and nuclear science, the place occupied by the Community countries is remarkably satisfactory as regards the qualities shown by European technicians, although at the same time disturbing because of the inadequate economic exploitation of successful results. There are always obstacles: either the capacity for financing is lacking or the internal market is too compartmentalized or the outside market is too resistant or the desire to be in on things on a major scale is not great enough. The United Kingdom and France have been able to develop a sophisticated arsenal without outside help: their electronic industry is not inferior in terms of performance to that of the Americans. Concorde is the world's leading commercial supersonic aircraft, the satellite Symphonie is a demonstration of the Community countries' ability to solve the problems posed by space telecommunications. Europe is ahead in nuclear breeder reactor techniques for the production of electricity. However, despite these technical successes in the "power specialities", the place occupied by Europe in the volume of world achievements is remarkably humble. In commercial aviation, the place of European aircraft in the world fleet is small (Fig. 15) and Concorde's experience shows how many difficulties arise in the face of technical superiority in this sensitive field.

Judged by quantity rather than quality, the inferiority in nuclear armaments is we1l known. The same goes for conventional armaments if we consider the range of production, despite the fact that for reasons of product quality and also for reasons of political independence, the European conventional weapons industry is a great exporter.

In space, Europe's effort is modest, to say the least. It has played no significant part in the great prestige ventures of manned satellites, moon landings, and exploration of the planets by space probes. Experience has been gained on a reduced scale, as Table 7 shows.

What guarantee of independence does Europe have as regards major problems involving satellites such as telecommunications, data transmission, broadcasting and television, meteorology, remote sensing, vehicle spotting, and military information? And yet it has the skills, as is proved by the successful part it has played in some of the scientific space programmes.

In the production of electricity of nuclear origin, after some countries had abandoned their original lines, European technicians gave proof of their talent by regaining their freedom of design and engineering for the conventional types and taking a firm lead in several major techniques such as fast neutrons, the breeder reactors. However, the United States opposition to an independent export policy is reinforced by demonstrations of concern by environmentalist movements. 


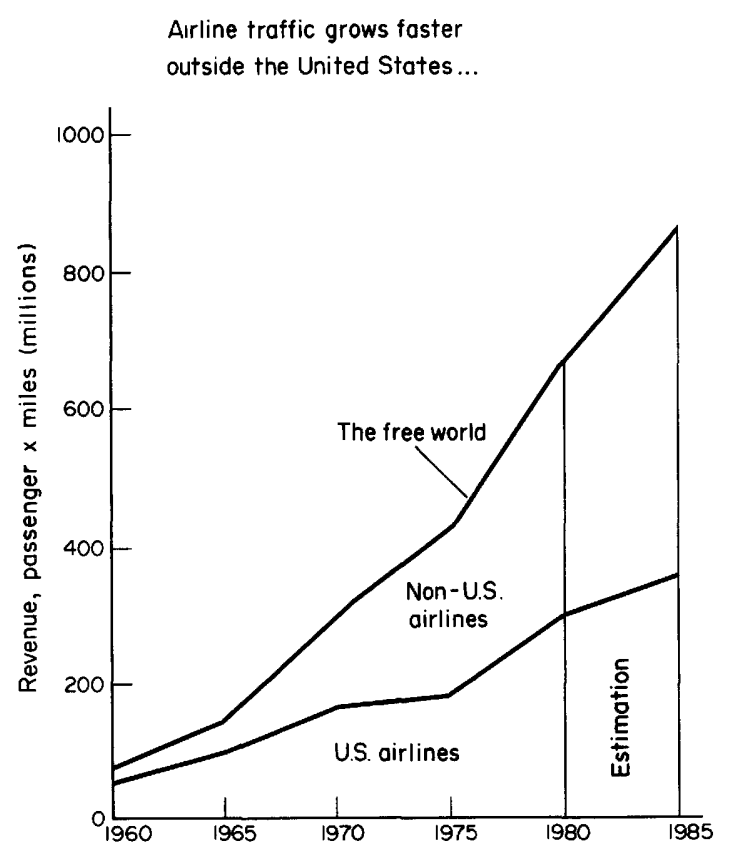

Data: Pratt and Whitney.
... so foreign plane-makers

have good sales prospects

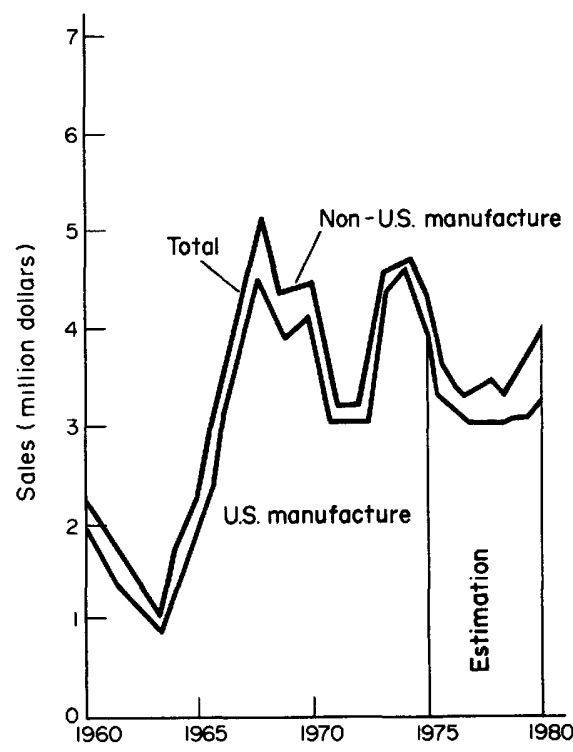

Note: USSR, PR China and non-ICAO countries.

Data: The Boeing Co.

Fig. 15. Aeronautics (Business Week, 12 April 1976).

Growth of traffic and manufacture.

Europe is probably staking its future on the availability of energy, and it is essential to overcome the existing internal obstacles; they show an inadequate understanding of the general problems to be overcome and the importance of the guarantees to be given regarding reactor safety and waste reprocessing - all problems that are being studied, it is true, both by the Community's Joint Research Centre and by various national centres. Europe's capacity to shape its own destiny and accept the risks involved will be revealingly measured by the quality of the effort it will make to produce electricity of nuclear origin and the nature of the consensus it will obtain from its peoples in understanding the balance of the risks accepted, by the level of investment to guarantee safety, and by its resolve to take part and have a say in the control of nuclear proliferation.

The exploration and opening up of the oceans (collection of deep-sea nodules, deep drilling, etc.) must also be classed among the power specialities. It is not yet clear how these will benefit Europe in the future, despite the pioneering successes obtained. During the twenty-first century, this field could play a similar role, in the economics of primary resources to that played by the discovery of the new worlds in the sixteenth century. However, this will call for human and capital resources obviously beyond the capacity of any individual community country, and it is to be expected that political obstacles will emerge similar to those encountered in the past in the control of fossil energy resources or today in the aviation, space, or nuclear markets. 
TABLE 7. Census of objects in space (at 26 December 1976) Source: North American Air Defense Command of the US Air Force

\begin{tabular}{|c|c|c|c|c|c|c|c|c|}
\hline \multirow{2}{*}{$\begin{array}{l}\text { Country/ } \\
\text { organization }\end{array}$} & \multicolumn{2}{|c|}{$\begin{array}{l}\text { Earth } \\
\text { orbits }\end{array}$} & \multicolumn{2}{|c|}{$\begin{array}{l}\text { Interplanetary } \\
\text { space }\end{array}$} & \multirow{2}{*}{ Total } & \multicolumn{2}{|c|}{$\begin{array}{c}\text { Disintegrated } \\
\text { objects }\end{array}$} & \multirow{2}{*}{ Tota1 } \\
\hline & Payloads & Debris & Payloads & Debris & & Payloads & $\overrightarrow{\text { Debris }}$ & \\
\hline United States & 401 & 2281 & 27 & 37 & 2746 & 431 & 943 & 1374 \\
\hline Soviet Union & 399 & 840 & 25 & 8 & 1272 & 691 & 3371 & 4062 \\
\hline United Kingdom & 7 & 4 & - & - & 11 & 4 & - & 4 \\
\hline Canada & 8 & - & - & - & 8 & - & - & - \\
\hline France & 13 & 42 & - & - & 55 & 1 & 23 & 24 \\
\hline ESRO & 1 & - & - & - & 1 & 6 & 3 & 9 \\
\hline Federal Germany & 2 & 4 & 2 & 1 & 9 & 2 & 1 & 3 \\
\hline Australia & 1 & - & - & - & 1 & 1 & - & 1 \\
\hline Japan & 8 & 8 & - & - & 16 & - & - & - \\
\hline P R China & 4 & 4 & - & - & 8 & 3 & 9 & 12 \\
\hline NATO & 3 & - & - & - & 3 & - & - & - \\
\hline Netherlands & 1 & - & - & - & 1 & - & 3 & 3 \\
\hline Spain & 1 & - & - & - & 1 & - & - & - \\
\hline France/Germany & 2 & - & - & - & 2 & - & - & - \\
\hline India & 1 & - & - & - & 1 & - & - & - \\
\hline Italy & - & - & - & - & - & 4 & - & 4 \\
\hline ESA & 1 & - & - & - & 1 & - & - & - \\
\hline Indonesia & 1 & - & - & - & 1 & - & - & - \\
\hline Total & 854 & 3183 & 54 & 46 & 4137 & 1143 & 4353 & 5496 \\
\hline
\end{tabular}

\section{Europe's place in information technology}

We shall see later how important everything connected with information is for the activities of the post-industrial society. It is therefore essential for Europe to be capable both of creating new technologies for the recording, transmission, or processing of information and - even more important - of making good use of them to improve the productivity of its services and industries. These new tools have to do with the human mind, intellectual processes, and relations between men, and it is therefore necessary to make their use consistent withideep-rooted cultural forces.

In this very complex field, Europe has not got off to a good start by comparison with the United States, and is tending to be overtaken by Japan. For the first time in recent history, with semi-conductors, integrated circuits, and computer software, it is in the presence of technology which does not owe its invention mainly to Europe. We must be careful not to exaggerate this verdict, derived from statistics, because it does not take into account certain possibilities of a reversal of technical and trade positions. Technical innovations in this particularly unstable field can, of course, provide surprises where the Community is still capable of seizing the initiative. However, the facts are impressive today, as is shown by the graphs which follow.

As regards the world breakdown for the installed value of computers for 1974, which constitutes a yardstick for computerization, Western Europe occupies second place, far behind the United States (Fig. 16).

If we now examine trade penetration for the supply of calculators in national markets we see a major difference between the European situation - extremely open to imports or to the multinational companies of US origin - and the Japanese situation, 
where there is a tendency to reserve for Japanese nationals the lion's share of the market ${ }^{1}$ (Figs. 17 and 18).

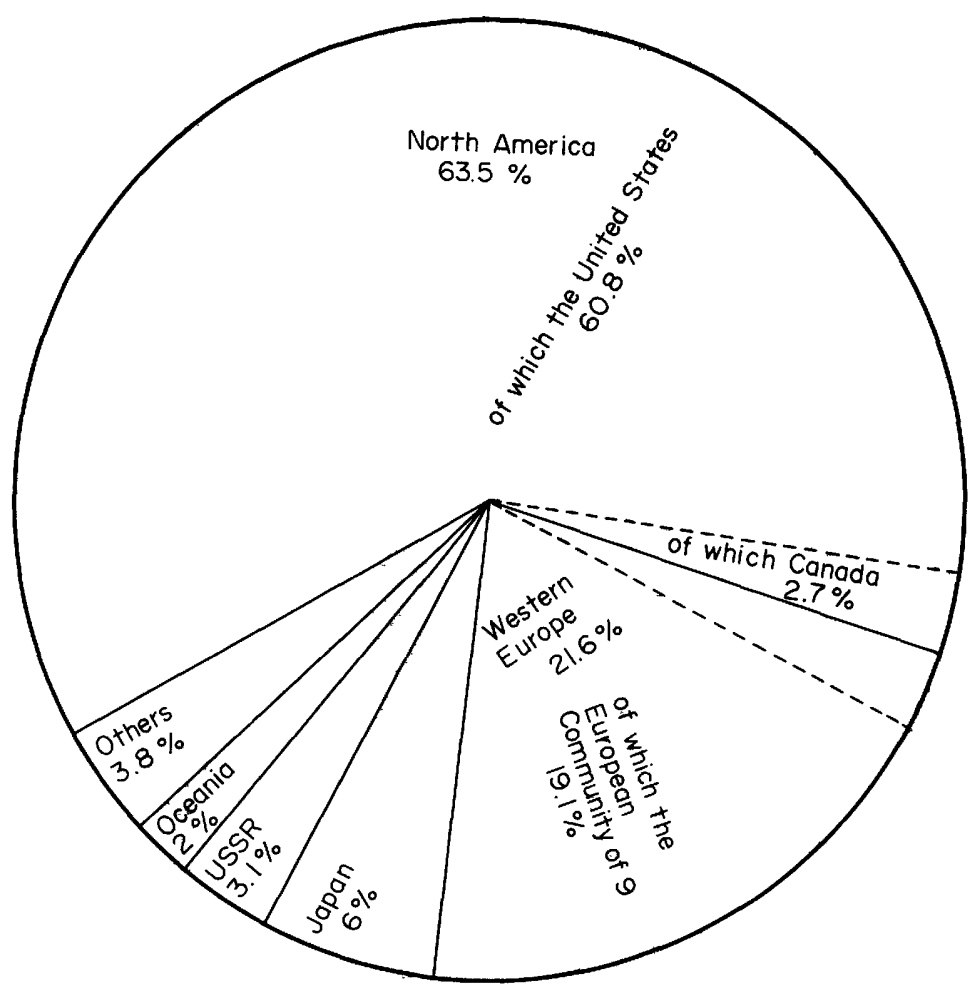

Fig. 16. World breakdown of installed computers in terms of value by major geographical areas. Source: Japanese Computer Industries SRI - USA, 1974.

A study should be carried out to ascertain the situation and trends as regards microprocessors, as these small devices may be regarded as the nerve cells of tomorrow's society. Distributed very widely, they will be used in all arithmetic operations required for trade, industry, and accounting purposes and also in all intelligent automatic systems in which they will add a memory and logic capability to the mechanical automaton. Combined with quartz they supply solutions like clockwork, combining extreme precision with low prices. These microprocessors are the result of complex physical processing operations, which means that it is economic to produce them in large numbers; female Asian labour is particularly suitable for the delicate assembly operations. In the international distribution of labour, which is unfolding before our eyes. Europe's chances would appear to be poor in comparison with US and Japanese companies, which subcontract certain finishing operations in the various South-East Asian countries open to a free market economy.

1 These graphs do not take into account changes which have occurred in France since the CII Honeywe11-Bul1 merger. 

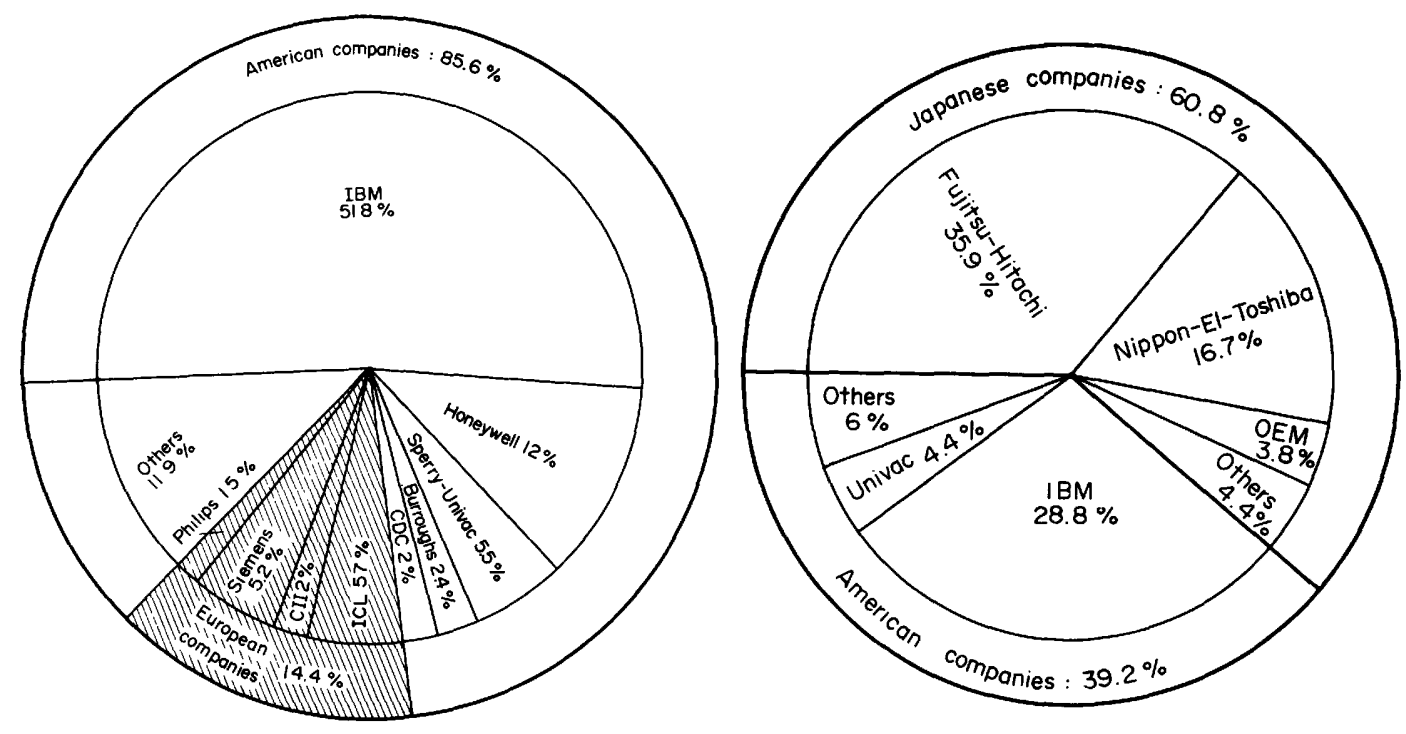

Fig. 17. American computer companies on the European market in 1975 (in terms of the value of equipment installed). 1975: Total: \$19 billion. (Source PAC.)

Fig. 18. American computer companies on the Japanese market (1974). Total: $\$ 44$ billion. (Source: MITL.)

The difficulty experienced by the European Computer industry in expanding may be put down to the excessive power of a multinational company of American origin that has acquired a de facto monopoly position as regards medium-sized and large computers. This explanation does not apply in the small computer sector, where handicaps resulting from scale effects are less serious. The information in Fig. 19 (even allowing that another source gives a slightly different picture) shows how small is the share acquired by European companies in a field vital for the automation of production and the introduction of data processing into all disciplines.

\section{Europe's place in the traditional industries}

Europe's capacity for transforming innovation into commercial success encounters fewer obstacles in the traditional industries, especially in those where Europeans have been influenced by their own characteristics. One example is the motor industry, well geared to the conditions prevailing on the home market. The dimensions of European cars, their comfort, and their fuel consumption are suited to the small confines of Europe's territory and the need to save energy. As these conditions are also encountered in many outside countries, the Community's car 
industry is a great exporter. The taste for quality is satisfied by colour television standards which were defined later than American standards but are superior. The development of health schemes has been beneficial to the pharmaceutical industry and certain specialist branches of production such as deaf aids. The German and Swiss chemical industries are predominant in some techniques, and The Netherlands has an outstanding reputation in electronic equipment for civil use. Further examples could be added in this way to demonstrate that there is not rea11y a technological gap.

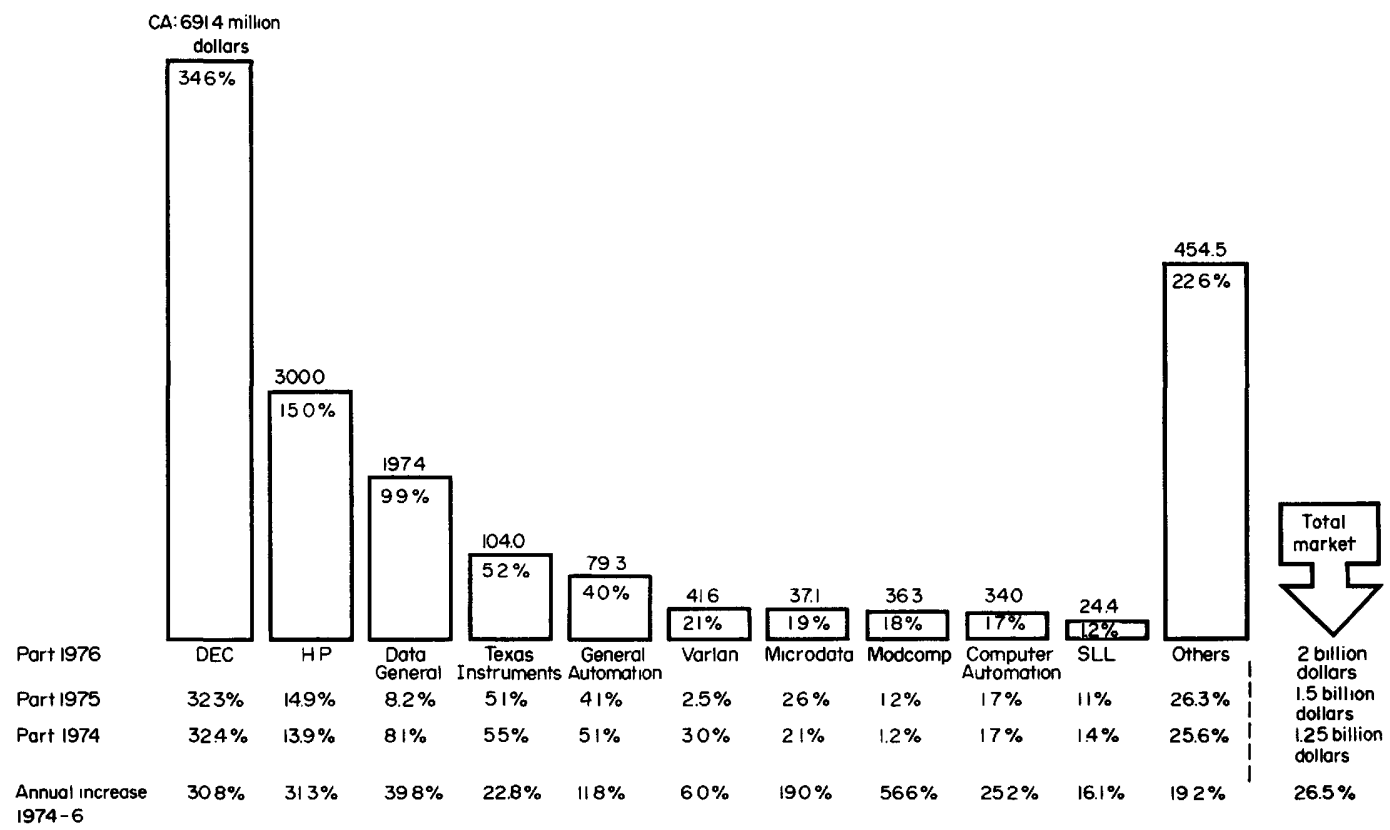

Fig. 19. Estimate of the shares of the world market for minicomputers accounted for by the main manufacturers. Source: Robertson, Colman, Siebe1, and Weisall.

However, the Community countries will in future have to keep an eye, even more than in the past, on the potential for competitive innovation of Japan, which, in the traditional industries, is putting up a redoubtable performance, especially as regards the automation of production (steel, shipbuilding) and very large-scale mass production as in the case of optical instruments, photographic and $f i 1 \mathrm{~m}$ equipment, radios, tape recorders, portable television sets, reprographic equipment, motorcycles, and cars.

This need to be more inventive as regards the automation of mass production also appears to be a major point in the textile industry, in the processing of plastics, and in certain agricultural and foodstuffs specialities in countries where the fruits of low-cost labour using conventional means may be the ruin of our industry. If domestic production were to disappear almost entirely, it is not certain that the capacity for designing, manufacturing, and exporting production equipment would survive.

If considerations of political independence could be disregarded, the basic industries, e.g., cement works, paper mills, sugar refineries, oil refineries, chemical factories for the production of plastics, manmade textiles and fertilisers, 
and aluminium works, would be better sited in areas where energy is cheap or where ore is rich or where the low population density reduces pollution hazards. Their continuation in Europe cannot, therefore, be taken for granted in the context of an international division of labour resulting from the free movement of products manufactured on the most economic sites. Only innovation making it possible to reduce the effect of pollution, to exploit low-grade ore, or to economize energy will enable them to continue on a competitive basis. This battle is far from won and a social study would be necessary in order to find out to what extent it is being waged.

To sum up, Europe is very badly placed as regards innovations in the power speciality fields, is behindhand in information techniques, and is also threatened as regards its capacity for innovation in the field of traditional industry. However, the talent and the knowledge of its specialists constitute forces which are apparently intact. Up to now the scientific and technical objectives assigned have been met.

Upon a number of occasions in the course of this study we shall be coming back to this question mark concerning Europe's capacity for innovation. We shall see, as all specialists in development, demonstration, and industrialization know quite wel1, that the principal deficiencies are by no means a lag in knowledge. It might be thought that this leeway could be made up by the purchase of licences or transfer of technology. On the contrary, these facilities contain the risk of deepening the gulf between the donor and the assisted party since the assisted party makes a saving and is ignorant, therefore, of the main part of the inventive process, consisting of the effort involved in adjusting the new product to the new market and the always gradual discovery of technical solutions which govern the lowering of the cost price. The assisted party loses the initiative as regards laying down specifications for the properties of products and their use. These are decisive factors for the acculturation of new technologies. The assisted party has, as it were, his inventive genius amputated and is unable to wage a battle on a moving front. It imports technique which is not perfectly adjusted to the peculiarities of its market. In this way, without any immediately perceptible warning, it slips into underdevelopment.

If, therefore, there is no alternative to the importation of technology, in order to make up leeway, it must be realized that, to avoid a situation of permanent dependence, the research and development effort devoted to the field concerned must be at least equal to that of the licensee whose knowhow is being purchased, so as to counterbalance its influence in the initial stages and later to become independent of it. This method of regaining one's scientific and cultural identity in respect of an imported technology has been Japan's strength, and there are numerous European examples, especially in Germany. The temptation to adopt the opposite attitude is great, however, and this is where the danger lies: it is all too easy to fall into the comfortable (for the time being) situation of the hanger-on. Those who have not had personal experience in handling these matters are il1-equipped to understand the importance of access to knowledge and the far greater importance of the capacity to acquire knowledge by one's own efforts or to add original elements to it.

\section{THE CHALLENGING OF MORAL VALUES}

There is a crisis of moral values in all industrialized countries. Europe is no exception, and it is difficult to know whether these phenomena are really deeprooted or whether the descriptions of them are no more than the expression of a mental susceptibility on the part of a fairly insignificant section of the adult and adolescent population spoilt by the comforts of the civilization of plenty. 
It appears as if a period of intoxication in which the favourable aspects of technical progress were prized to excess has given way to an exaggerated movement in the opposite direction which asserts that all is harmful in the consumer society.

Whatever the underlying reasons this crisis must be taken seriously, however, as it can sap our moral forces, those forces based on common spiritual values which nurture solidarity, hope and enterprise and forge the social consensus.

$$
* * *
$$

If this description were taken to its limit, verging on caricature, the following picture of this crisis would emerge:

(1) Youth no longer appears to believe in its future. Young couples reject life and no longer ensure that their generation is replaced. The need for a sustained effort during the period of higher education is grudgingly accepted, and badly motivated students find selection by competitive examination not to their taste. Sexuality is no longer, as it was in the course of preceding centuries, an occasion for asceticism or faithfulness to the indivisibility of the couple. On the contrary, it is the occasion for manifesting a capacity for liberty. More and more people are turning to alcohol and drugs.

(2) Certain values which counted as fundamental for previous generations have been called into question. The family is losing part of its stability. Religion is rejected, especially as regards its aspects of moral constraint and institutional organizations. There is controversy in the churches, and the idea of patriotism has ceased to be felt my many, while the spirit of national solidarity is yielding ground to regional movements.

The image conjured up by the pessimistic observers of industrialized civilization continues as follows:

(3) The man on the job is not happy. Senior staff feel they are lost in gigantic organizations which have become too complex for them really to participate in decisions. A country's own people reject manual tasks, which they entrust to immigrant workers cut off from their family and cultural environment. Workers have the impression that they are no longer recognized as people but are regarded rather as things; the dignity of labour has been lost. Power sharing is not fruitfully determined between management, the unions, and government. Ideological opposition is added to the natural difficulties involved in the period of apprenticeship in the very complex relations imposed by the organization of major enterprises. The fear of unemployment sets in.

(4) The townsman is not happy. The town is ugly, inhuman, and dangerous. Far too much of his free time is taken up by travelling. Contact with nature is lost. Communications between human beings are barren and anonymous. The lack of space in the home makes it difficult to exercise an art, to practise a craft, or just to be on one's own to think.

(5) Man is no longer "sapiens" or "faber"; he has become "consumens" and is no longer able to resist the temptations of consumption. He becomes indebted in order to buy useless objects which do not contribute to his happiness. He is no longer able to "be", so much does he wish to "have". His pleasures are passive. The greater part of his leisure time is taken up by the television set or the motor-car stuck fast in traffic jams. The radio and the press spread, above a11, bad news.

(6) The citizen prefers security to a spirit of enterprise. 
(7) The State tends to be regarded as al1-providing. It is responsible for everything which is difficult or uncertain. It guarantees order and national defence and manages communications. It must supply family allowances, health and old age insurance, guarantee permanent employment and pay the unemployed, subsidize agriculture, dispense health care and education free of charge, and control industry make it competitive and where necessary make up losses. It is responsible, in both the short term and the long term, for inflation and the external debt, for scientific and technical research, and for cultural, artistic, or sporting events. However, those who demand these measures find the taxes too heavy and individual liberty pared down too much.

(8) Violence is increasing. Juvenile delinquency, kidnapping, ransom demands, skyjacking, and bank robberies are becoming more and more frequent.

It would be unwise to exaggerate the importance of these symptoms, but it would also be rash to take them too lightly. It cannot be denied that these difficulties are being experienced to some degree by society and that the very discussion of them will aggravate the situation if the necessary answers are not found.

This malaise, the real depth of which is not at all clear, is the outer crust of the psycho-sociological crisis which Europeans are going through in adjusting themselves to a world which is changing more and more quickly and is out of their control under the pressure of technical progress. This bewilders them, not because they do not understand the intellectual machinery involved but because it destroys their balance and their habits. Well established yesterday on his land and amid his traditions, the European feels himself today uprooted in towns which he no longer understands. He does not know what social attitudes constitute the right response to these material changes. He is discovering that he is no longer the driving force and the author of history, and it goes against the grain to be nothing but the vassal of "imported" history where others decide and where, at best, he can only run along behind.

In the enthusiasm of the post-war reconstruction effort, followed by the almost fetish belief in the virtues of industrial growth, Western Europe has completely transformed itself. However, this rapid, brutal, exogenous trend in history is, for the European, a challenge for which his culture has hardly prepared him and he cannot see himself in this materialist role gorged with manufactured products, that it would impose on him. He is starting to denounce the art of economics; all this growth seems to him to be out of proportion with the human scale which his landscapes and his experience have given him. Memories and scruples are mingled within him and conjure up a nostalgia for yesterday's society. He recognizes it to have been elitist and regrets this but nevertheless attributes to it much variety, many virtues, and human values. In the mass society which he desires and yet fears he discerns not a new Athens which would be justified and which would enchant him but a new Sparta with threatening conformity, with neither privilege not individuality.

He remembers, above all, that the Renaissance started off the rational transformation of the world, which is being completed before his eyes, by launching Europe on the road of the systematic and continuous progress of knowledge which for some centuries was to guarantee its pre-eminence. The Renaissance did this, more particularly, by instituting "bachelors", that surplus of students which the universities trained and awarded diplomas without guaranteeing them, within themselves, either a place or a career. This radical and emancipatory initiative launched the new elite, at their own risk and peril, along the path of scientific, technical and even social innovation. A new spirit - the spirit of enterprise - was thus introduced into the advancement of knowledge and was to fertilize it. It is to this spirit that we owe the transition from conformity in accordance with a single thesis which we see incarnate in the 
word "university" to a pluralistic situation. Europe is well aware that it owes its glory to this, and that this is still its genius.

In entering upon the twenty-first century it is to be hoped that Europe will experience a "Second Renaissance", but this will not be possible without intellectual and social boldness. In particular, is not an important stage the assimilation of innovation by our culture, i.e. the integration of change into our society? It would be necessary, while abandoning all the old quarrels about elitism and access to knowledge, effectively to bring to life again our capacity for assimilating novelty. If it is preferred, this may be expressed as our "pedagogical function" of implementing knowledge, more particularly knowledge in the field of the human and social sciences, still so desperately trivial by comparison with the "exact" sciences.

In this crisis of moral values the European Community is now apparently characterized by mixed reactions. Some countries, economically and socially, seem to be suffering more than others. Having entered the crisis earlier, are they not that much nearer recovery? It would be wise to recognize that, overall, there is similarity in the dangers and that the discrepancies in behaviour do not indicate balances which have stabilized differently but, more probably, that certain thresholds have been crossed which everyone is near to - only some are still on the right side and others already on the wrong side.

The above description should not be allowed to discourage us. In this last half of the twentieth century there have been no extreme innovations as regards immorality, abuse of power, or alcoholism. Historians teach us that, even though violence has increased since the abnormally low level observed in the early decades of the century, it is still nothing like the violence that prevailed throughout most of our history. Illiteracy has largely disappeared together with famine and epidemics; extreme poverty is far less common, and instead of fighting each other in fratricidal wars the European nations are living in peace and seeking co-operation. The debit balance in terms of the rebellion against systems of moral values must be set against the almost triumphant achievements in public health, in the increase of purchasing power, in the eradication of poverty, and in education.

Cannot the crisis of moral values in the developed countries be interpreted as the reverse of the coin, the unfavourable aspect of a melting-down phase in preparation for a further adaptation? The right side would then be the readiness, as a result of this break with the past, to accept the construction of a new future for which only one project is still missing - the Second Renaissance.

\section{WHAT ARE THE CONCLUSIONS OF THE "BALANCE-SHEET"?}

Within the limitations of probability for the figures advanced, it is possible to draw from the above balance-sheet a number of principal points:

(1) In the space of a generation, Europe's place in the world has changed radically. It no longer controls more than one-third of the land and one-quarter of the peoples together with their wealth in the form of primary resources. The future will be determined by this change which is still masked, in the current transitional period, by certain trading habits and cultural traditions. In particular, Western Europe no longer has the capacity for taking the initiative based on political power. It is in danger of being overtaken by events instead of being their source. 
(2) In terms of its relative importance in the world population, Europe is in a continual state of decline. Towards the year 2000 the Community of the Nine will be smaller, in proportion, than one of its major members in the eighteenth century. The ageing of the population will then contrast with the youth of the southern countries where numbers will have become greater.

(3) Through its geography and climate, Europe is to be distinguished from the continental states such as the United States, the Soviet Union, and China, with whom it is competing. Restricted as regards the amount of space available, short of rich ores and fossil energy, and fragile as regards its ecology, Western Europe is ill-suited to giant-scale industry and cities. It may be distinguished, however, from Japan by its cultural traditions and the wide range of factors which make for diversity.

(4) Europe is threatened with permanent scarcities which it will be able to meet only by means of imports, which renders it economically and politically dependent. The field where it is most sensitive in this respect is energy, where the situation may become dramatic.

(5) Compelled as it is to export in order to pay for its purchases of basic products, Europe is asking itself what is left to it of its capacity for innovation, its scientific and technical primacy having first been challenged fifty years ago. It has lost the initiative in armaments and in space and is in danger of losing it in the exploitation of the oceans. Its handicap in the field of information technology is worrying, and when it does achieve breakthroughs in aeronautics or the nuclear field it has difficulty in exploiting them commercially. However, the competence of its scientists and engineers seems to be intact and leads to success whenever problems specific to the European market are dealt with.

(6) The system of values which constituted Europe's moral strength is being contested. This crisis is the manifestation of a failure to adapt culturally to the changes caused in society by the brutal advent of the new techniques. This crisis, which is affecting the whole of the industrialized world, is particularly felt in Europe. But it can be regarded as a preparation in readiness for a project, a Second Renaissance. 


\section{Chapter 2 \\ THE CULTURAL FORCES}

The major changes in the situation which have taken place since the Second World War must be seen as facts. It would be futile to regret them, or even to look for the source of the human responsibilities. The obstacle to be overcome is rather that of accepting them as being true. We are still attached to sentiments derived from a previous stage in which Western Europe was made up of an assembly of powers which were great because of their military and political strength and were wealthy in terms of human beings available for the remainder of the world. The peoples who recently became independent continue to look at us partly through the eyes of the past, and the United States, instead of fearing the complications which might ensue from our weakness, still consider us as trade adversaries.

Part of the influence which Europe still has today is 1inked with the time when we were still formidable to others. Part of the freedom with which we give vent to the expression of our national selfish feelings is derived from the fact that we have not become aware of our true standing in today's world nor of the dimensions of the problems to be solved. Our minds may be informed of the new facts while our sentiments may act as if only the facts of former times counted. When, between these two aspects a mutation takes place, misinterpretations are easy, and this is what must be avoided.

This part of the study constitutes an attempt to define the ideas and forces which emanate from European culture and the aspirations which may be deduced therefrom. Europe must not be static, but growth can no longer be anything more than essentially qualitative. In addition to the factors of evolution inherent in the various economic situations there are underlying psychological forces which, there can be no doubt, must now be clarified and used as a guide in rechannelling technological evolution.

$$
* * *
$$

The overriding idea in this chapter is that Europe's almost sole wealth lies in the quality of its inhabitants who are enclosed in a culture. This culture is part of history, and it is also part of the climate, the scale of nature, and the absence of easily accessible great material wealth. Because the confines of Europe are narrow, the density of population is great, and the level of education is high, contact between minds - and clashes between them - is facilitated. It is these factors of density of population, ease of communication and high level of education that help to maintain the quality of man in Europe. 
This culture is acceptable in the outside world because the tide of expansion of recent centuries has left behind it languages and systems of education of European origin even where the peoples are not the children of immigrants. This culture is still regarded as powerful and useful by the recently independent peoples who, in order to assimilate the new technologies, need to take as their inspiration the classic European models in the same way as the Middle Ages and the Renaissance were helped by the Greek and Roman heritage. ${ }^{l}$ It is, moreover, this very profound cultural interpenetration with certain regions in the world, especially North America, which makes it so difficult to recognize that Western Europe has its own cultural identity.

The same problems of assimilation of scientific and technological progress appear in the various industrialized countries, and the same solutions will in the end be applied, but Europe and Japan are the only countries which are today impelled by necessity. The major gain of the last fifty years was the growth in capacity for production and consumption of material goods on the part of agriculture and industry. This growth consumes a great deal of space and primary resources and gives rise to nuisances. While the available space, energy, and raw materials were considerable and while the nuisances could be absorbed by natural recycling, there was nothing to justify such growth being identified with waste. It was, on the contrary, legitimate to consider it as progress. It makes available to man wealth which is useful from the point of view of his material and immaterial needs. It is the sign of man's victory over nature. The United States, Canada, and Russia (with its Siberian appendages), Australia, and Brazil have no reason in the short term to conduct a vigorous quest for another form of balance. Their natural bounty grants them safety margins which are still considerable.

Europe and Japan are no longer at this stage. They are nearing the limits to the exploitation of arable land, to population density, to the exhaustion of their soil in terms of wealth in primary products, and to the elimination of nuisances. In this they are close to the most densely populated developing countries. What, in the new countries, is a conquest over nature is for them waste, and they have lost any chance of imposing politically their complementarity upon less-exhausted regions.

As always, when a civilization shows all the signs of success as regards prestige and power, the American model fascinates. Performance is measured by the amount of the gross domestic product, for a whole country or per copita, and the aim of all is to come as close as possible to the American figure. And yet the GDP gives no indication of the quality of life and has virtually no meaning, even in econometric terms, in the developing countries where part of the wealth is produced by family or craft activities and cannot be precisely recorded.

It is physically impossible, at least for the next thirty years, to extend average American consumption to the world as a whole. Capital formation is not fast enough and the available resources are not adequate. ${ }^{2}$ In view of the short time available to find solutions to the problems that will be caused by a population of 8 to 12000 million next century, it appears wrong to pattern the future on the existing consumption model of the industrialized nations.

1 This idea was expressed by Mr. J. Stoezel, Chairman of the Human Sciences Committee of the Commission Nationale Française pour l'UNESCO.

2 For energy, forecasts for the year 2000, taking the extreme hypotheses, give a level of consumption between 78000 and $130000 \mathrm{~m}$. tpe, about twenty times the 1972 consumption ( $5067 \mathrm{~m}$. tpe), if the American average were extended to the rest of the world. (Source: ECA document, Paris, June 1976 "Energy, Growth and Atomic Energy". m. tpe $=$ million tonnes petroleum equivalent. 
On account of its high level of development and relative poverty in terms of space and resources, Europe is the first of the "rich" regions to encounter these finite boundaries. It is obliged to innovate as regards civilization, in order to satisfy the desire of a population which is not frugal, by proposing new aims for society that are compatible with its own level of resources and its degree of economic dependence.

In order to attain these aims it must show originality by comparison with the US mode1, which is dragging it in the direction of unsuitable solutions. If Europe were to become a sort of guinea-pig region for the world, its absence of an imperialistic capability and the help it could offer in the form of its cultural bridgeheads would enable it to convince the financially rich but not yet developed countries to adopt this new model instead of the model based on growth in the consumption of material goods. The United States vitality and potential for adjustment are such that it could take over and develop on a wider scale original successes scored in the European social and economic experimental laboratory; in that case the whole world would get along better.

The modern world is characterized by the interdependence of and consequently communication between economic systems and the contagious effect of ideas. It would be entirely wrong to believe that Europe could isolate itself in order to escape what it might consider a mistaken trend in other countries, especially the United States. This is why nothing is proposed here that is incompatible with certain trends observed in industrialized nations, especially across the Atlantic. However, consideration must also be given to the pressure that will be exerted by the developing countries in the face of their difficulties; any project that did not help to reduce this pressure would be neither useful nor realistic.

\section{THE IDEA-FORCES OF WESTERN EUROPE'S CULTURE ${ }^{1}$}

There are no criteria for classifying cultures. In endeavouring to explain the principal features of Western Europe's culture we do not by any means claim that it is better than any other. Depending on climate, population, and traditions, other cultures have been born which provide a better response to local conditions and perhaps even to those for mankind in general. It would be desirable that, in the world's major homogeneous regions, such cultures should inspire objectives for development and serve to consolidate scientific and technical achievements and the new technological tools.

It appears that, with the possible exception of China, no region in the world has really tried to control the nature of its economic growth and its technological aims by making use of the wealth of its cultural identity. And yet there are elsewhere considerable philosophical values and intellectual riches, especially in regions where the peoples and their traditions are most ancient: in the Arab world, Iran, India, or Indonesia, to say nothing of the original features of the Negro culture or the remaining influences of the ancient Amerindian civilizations. None of these values is being called on, however, for the acculturation of technical progress. Japan is a special case: it has managed to industrialized by developing the same products as the most advanced nations but without abandoning the main lines of its ancestral way of 1 ife and thought. This is most probably to a large extent the secret of its success.

1 This chapter, 1ike the previous one, is based mainly on a study by FISH (Henri Cavanna) and discussions at the Luxembourg symposium organized in October 1976 at the request of the Commission of the European Communities (DG XII). 
Since it is a question here of imagining a new model for society in Europe, it is as well to attempt the exercise of trying to bring out the ideas-forces which constitute the basis of Western Europe's culture. The problem is that of highlighting what unites Europeans, the fundamental cultural values they have in common amid all that divides them in the shape of the variety of ways in which they express themselves and act. We shall revert to this later.

Western Europe is a meeting point of cultures. The Greek pattern of art and philosophy, the Hebrew heritage of religion and the Jewish diaspora, the Latin influence, particularly through Roman law, the continuous exchanges with the Arab world in the course of confrontation or co-operation, have all intermingled with Celtic and Nordic traditions to produce a "homo occidentalis" who finds it difficult to identify himself, aware as he is of these differences, even though he contains a set of likenesses that may be said to constitute his invariants.

What best characterizes Western man is probably readiness for action, participation in the turn taken by events, and the rejection of resignation. The centre for new ideas and growth of techniques was situated first of all in the Middle East and Greece, and we are the heirs of this Greek-cum-Semitic civilization. Then the initiative moved westwards, shifting at the time of the Reformation from Europe's Mediterranean axis to its north-west axis. I The European, as if impelled by some force from within, tries to act and to develop through action. Hence the concepts of the value of work and the satisfaction derived from abundance to which the European is today very much attached.

For a long time religion played a vital role in the forming of minds, although its penetration was not equally intense in the north and south of Europe. It is therefore necessary to understand the cultural message inherent in Christianity. This is not a static religion. The Holy Trinity is a god in a state of tension, essentially dynamic. That God made man means that man is God's partner in creation and is responsible, alongside Him, for evolution. Man is not religious only when in contemplation. He is religious also in what he does within a framework of personal freedom which grants him wide scope for interpretation. Man is great via his freedom. Man has a value not only as a species. Each individual is the recipient of God's infinite love. Man is not embedded in castes - his place in society is only secondary. The poor man pure in spirit is the lamb of God. Man is worth only what he gives to others in God's light. ${ }^{2}$

By projecting these values into the economic sphere, the Reformation fostered the spirit of enterprise and the reinvestment of wealth. This movement spread throughout the north and north-west of Europe and was particularly successful on the North American continent. On the other hand, the cultural content of the Counter Reformation, which was to actuate the Catholic Church up to Vatican II (1962), partially accounts for the industrial and commercial backwardness of the Latin countries, the other factor being the shortage of energy (coal).

Dechristianization, which started in the Enlightenment, and the shorter period of religious impregnation in the Scandinavian nations, did not prevent the establishment of a certain idea of man inherited from the past and common to all Europeans. This common idea strongly retains the concepts of dignity, liberty, and responsibility attached not only to human groups but also to each individual.

1 See works of Pierre Chanu.

2 Essentially the same values are found in Judaism and Islam, a civilization based on the Bible like Christianity. 
The value attributed to work is profoundly rooted in the popular conscience. The sense of effort is inculcated from childhood onwards. The concept of liberty has not ceased to progress in the midst of chaos, becoming an essential value and one which justifies the gift of life. Western Europe, which has tried everything in its long political history as regards methods of government, fundamentally rejects despotism and demands protection of the citizen by the law. Such liberty makes possible the expression of Europe's variety of languages and customs, which characterize the mosaic of regions and nations. Hence the importance attached to the Charter of Human Rights, the free movement of men and ideas, respect for religious or political opinions, and freedom of speech. To protect his freedom of thought, the Western European invented the separation of Church and State, contrary to developments where the Byzantine influence has continued.

However, the European is also a social creature. He knows that his success can be the result only of acceptance of a certain number of rules which permit and guarantee life in common. He wants justice that is not arbitrary, that is based on a law common to and respected by all. He wants to be governed democratically within rules that are sometimes implicit but generally explicit, within the framework of a constitution. He demands the right to work and the abolition of excessive inequalities.

The European is firmly anchored in a permanent and subtle interplay between freedom and reason - freedom which would grant him the right to do anything, even what is asocial, or even deliberately to be a cheat or libertine. Reason, which induces him to give a privileged place to aspirations towards an organized 1ife, makes him respect the civic spirit, gives him a taste for effort, and, at certain times and in some countries, encourages asceticism and puritanism. This conflict between liberty and reason takes different forms in the north and south, but is ever-present, and its brutal or excessive arbitration is never tolerated for long. In short the European is an idealist, very much incarnate, who accepts this as one of his fundamental values. ${ }^{1}$

The incarnation is a biological one. It comes from natural selection, aggressiveness in the struggle for life and evolution, with the elimination of the weakest by the strongest. This interplay has for a long time made of the European a warrior - which he may no longer be - and the cry for liberty is often confused with this desire to be able to give vent to aggressive strength, either individual1y or in groups. However the idealism compensates, in a permanent state of internal tension, for giving vent to aggressive feelings. It imposes a minimum threshold of justice and compliance with a set of social constraints.

How are the subtle interplay between freedom and reason, this need for individualism counteracted by the concept of the general interest, this need for aggressive action, tempered by the social conscience, understood in our society, transformed as it has been by technological progress? How can these tensions between humanism and the spirit of enterprise find expression within the complexity of our post-industrial social setups? All these are fundamental questions to which it is perhaps premature to try to find a reply. However, the result of this analysis is that no blueprint for society can be proposed to tomorrow's Europeans if it does not give some scope to the biological forces of growth and the spiritual forces of the civic spirit, and if a wide margin of freedom is not granted to the permanent and painful quest for a state of balance between social idealism and the right to be aggressive.

1 The historical behaviour of Europeans, cruel in their internal wars, destroyers of remote civilizations and sometimes guilty of deplorable mass crimes, does not invalidate the aspirations to idealism, to moral and aesthetic values. It does, however, reveal the enormity of the contradictions in human nature. 
This represents a pull in the direction of progress or, if a less-optimistic expression is preferred, a pull in the direction of adjustment to environmental conditions.

Like all the civilizations that preceded our own, Europe has until now been an elitist society. The European elite, which gradually expanded to include a part of the upper middle class and then more recently some of the middle class, has acquired a highly developed sense of material pleasures as a result of the abundance of agricultural and industrial goods. It had also learned to live amid cultural wealth, in an intellectually and artistically sophisticated Universe, among old stones embellished with ornaments and rich in history, and in luxury of the spirit. The sensuous values impregnated life. The European's contact with the treasures of painting, sculpture, or music; the fact that he moved in cities, which were themselves museums, and prayed in churches, which were art treasures; and the potential of literary production available to him or being created, developed the aesthetic feelings of a growing proportion of the population. Europe spread forth $i t s$ art and culture. It maintained its diversity. Must not any blueprint for Europe incorporate, as a useful force, these spiritual needs while extending enjoyment of them to the greatest number without, as in the past, reserving them for a minority?

Without expressing this aspiration in formal fashion, the European is manifestly looking for a form of society giving to all what was formerly reserved for a few. This underlying desire in the direction of egalitarianism from the top downwards has many manifestations. It is at the root of the claims of the workers' unions. It explains the desire on the part of personnel in undertakings to be associated with the workings of management. It partly justifies the desire for overconsumption. It is apparent in the form of the refusal to carry out manual tasks. Europe is dreaming of a society in which the class struggle will have become devoid of content because the disappearance of elitism will have caused the solidarity of the privileged few to extend to all the citizens. However, this aspiration is blocked by social structures, certain excesses by way of social inequalities, and general incomprehension in the face of economic and technical constraints. The European does not understand the society in which he lives. He does not tolerate its limitations, its complexity, and its interdependence. He is afraid of social innovation. This gives rise to conflicts exacerbated by support for opposing ideologies, stoked by misunderstandings resulting from language differences, fanned by the conflicting experiences of the various social groups, each of which has frequently lost any sense of the general interest.

These conflicts may be regarded as a symptom of decadence, a weakening of cohesive forces, but they may also be interpreted as a painful and difficult effort to move in the direction of social progress, towards which opponents are tending to converge without realizing it themselves. Is the objective of a genuinely non-elitist civilization, less excessively unequal than all its predecessors, where the most humble would feel that they were recognized and given consideration, a utopian ideal, a dead end, or the great hope of the human race?

Depending on how pessimistic or optimistic he may be, the observer could choose any one of these possibilities, but Europe appears to be making more headway in this effort than the United States, perhaps because its climate, dimensions, and traditions are less virile, less brutal, its peoples are more concerned, and the feeling that an era of economic difficulty is approaching is more acute and more alarming. 
Diversity is a feature of Western Europe. The ancient Ce1tic, Scandinavian, Germanic, or Latin cultures have persisted to a degree that varies from one place to another; the influences of the Greco-Roman and Jewish worlds and of Christianity vary greatly in extent; there is separation into areas with Protestant or Catholic majorities; a further division is caused by legal concepts (Romano-Germanic or common 1aw); there are countries with strong or weak colonial, maritime, or continental traditions; varying degrees of industria1, commercial, or financial specialization; unequal levels of development in different regions; traditions of trade with different parts of the world.

Amongst Europeans there is no end to the diversities rooted in history and consolidated by language. The language problem is enormous, especially from the viewpoint of the accession of new member countries to the Community; however, apart from regional dialects to which some ethnic groups are particularly attached, the languages spoken fall into only two families, Germanic and Latin. I

Diversity is also found in the educational systems. Young Europeans are educated in systems that differ in structure and content. The same historical events are of ten explained quite differently.

The FISH survey on which this study is based shows that the European is extremely attached to these diversities. He is so receptive to this awareness of difference that he finds it difficult to describe similar features and define his identity.

One of the most difficult problems to be overcome by the European Community is to profit from this diversity as a collective asset and, at the same time, to foster the awareness that a European identity really exists, transcending a mere association of economic interests.

Depending on background and geographical location, the attachment to diversity finds expression in a variety of ways. To some, patriotism bound up with the concept of the nation is an essential value that must not under any circumstances be diminished by the formation of Europe. To others, the basic cell to be respected is the Region, with its traditions, its language, and its specific culture. Very few Europeans are prepared to be merged into a political entity that would eliminate a part, however small, of their diversity. Feelings on this subject are generally expressed vehemently; intellectual reasoning is rapidly over-ruled by passion. ${ }^{2}$

This situation must be accepted as a fact, on the basis of which a political structure of a new pattern, not hierarchical, suited to complexity, confederal rather than supranational, may be devised for Europe. These concepts are readily grasped by experts in systems analysis; ${ }^{3}$ they realize that this view does not in any way diminish the importance and power of the confederal authority. However, these "systems" ideas, although in no way intellectual but merely the outcome of experimental observation of living systems, are too new to be easily communicated.

1 This fact indicates that machine translation (or machine-aided translation) by computer might not be unattainable.

2 During the survey conducted by FISH this was one of the rare points on which those interviewed quickly lost their composure, showing the extent to which Europe would be harmed if it did not respect these attachments.

3 See Fontanet, Le Social et le Vivant, Plon, 1977. 
They will have to be put into practice by successive approaches; an evident maturity will gradually emerge from this apprenticeship. In the second part of this study we propose that a start be made on this apprenticeship by formulating and implementing a scientific and technical policy.

It may be said in passing that nothing, or almost nothing, has been done to he1p young Europeans to realize that they are both specific to their country of origin and specific to a Community. For example, history is still taught as if the great phenomena were national antagonisms, whereas the important facts are to be found in the development of certain social classes, the content of education, the ideas and legislation on employment, the status of women, and many other factors which have developed simultaneously in Europe and have shaped the society of today. 


\section{Chapter 3}

\section{ASPIRATIONS TO A NEW DEVELOPMENT}

The "quality of life". What content could the European attribute to this fashionable expression, rich in sentimental value but surprisingly difficult to measure? In relation to what values, on the basis of what criteria, can the quality of life be judged?

At a loss when faced with this problem, the best thing is once again to stick to the facts and draw up a balance-sheet of what we know of or what we could do with:

(1) the time available to us in our lifetime;

(2) our communications facilities;

(3) our aspirations to growth;

(4) the new economic aims proposed to us;

(5) our working conditions and competitive situation.

FREE TIME; THE HOPE FOR A NEW DEVELOPMENT

Man's time is limited and he knows he has to die. Hence, is not his most precious capital the time which each has at his disposal? Is not the most important reflection in considering the criterion of the quality of life that which results in the best possible use being made of the time granted us?

All civilizations have indulged in such speculation. For the ancients enjoyment merged with "otium", free time, time which was noble, time for culture and reflection, in contrast to "negotium", which was time for business. This concept was widespread up to the advent of industrial Europe. It has constantly been in conflict with the entrepreneurial need, the need to develop through action, the need to participate in the production and business game. Indeed, otium was reserved for the elite. It was the reward for power and wealth. In certain degenerate forms such as idleness it became, especially in the Latin countries, the sign that the person enjoying it belonged to the elite. The amount of free time available to the few was but the result of arduous labour on the part of the majority.

1 This chapter is based on a study by Mr Andre Bonnet (IRIA, Rocquencourt) with the help of documents and advice supplied by INED, Paris. The statistics are based on observations for France, but the trends can be extended to the whole of Western Europe. 


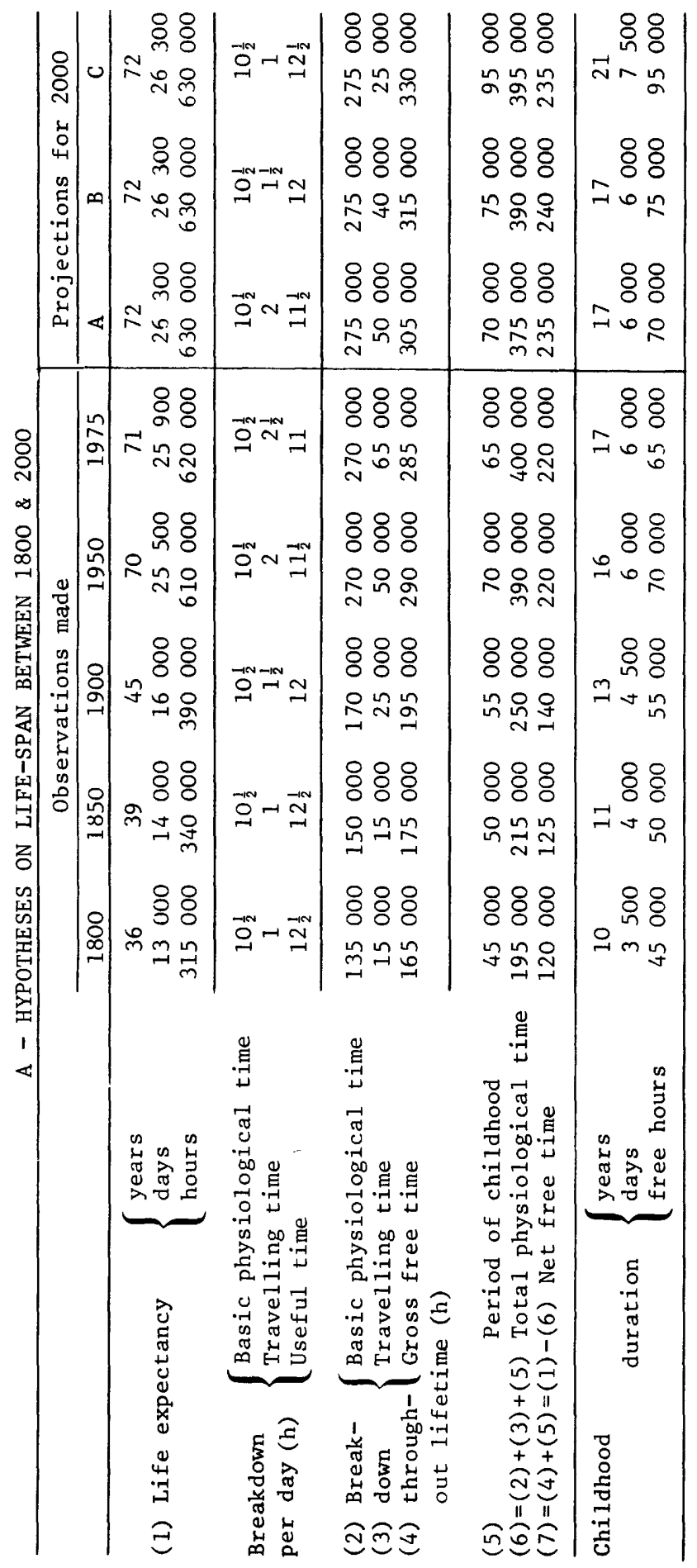


Aspirations to a New Development

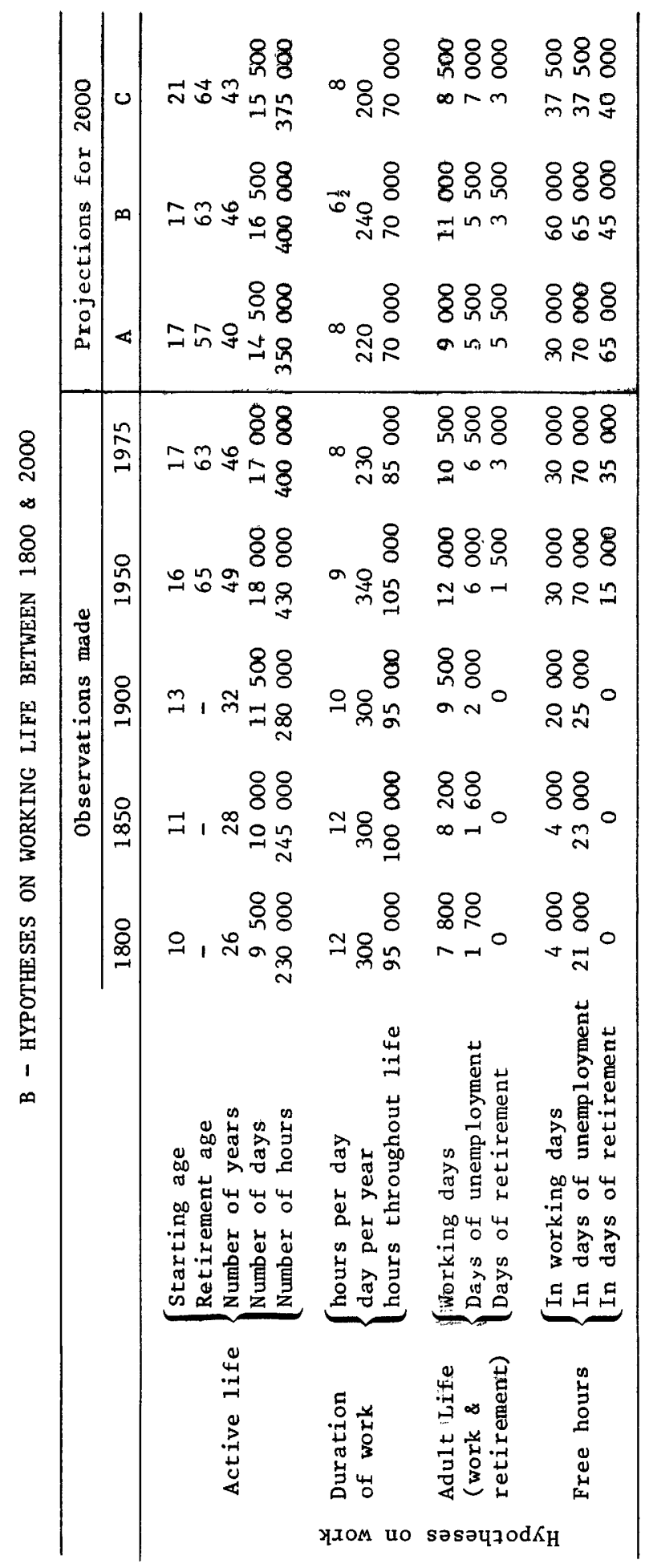




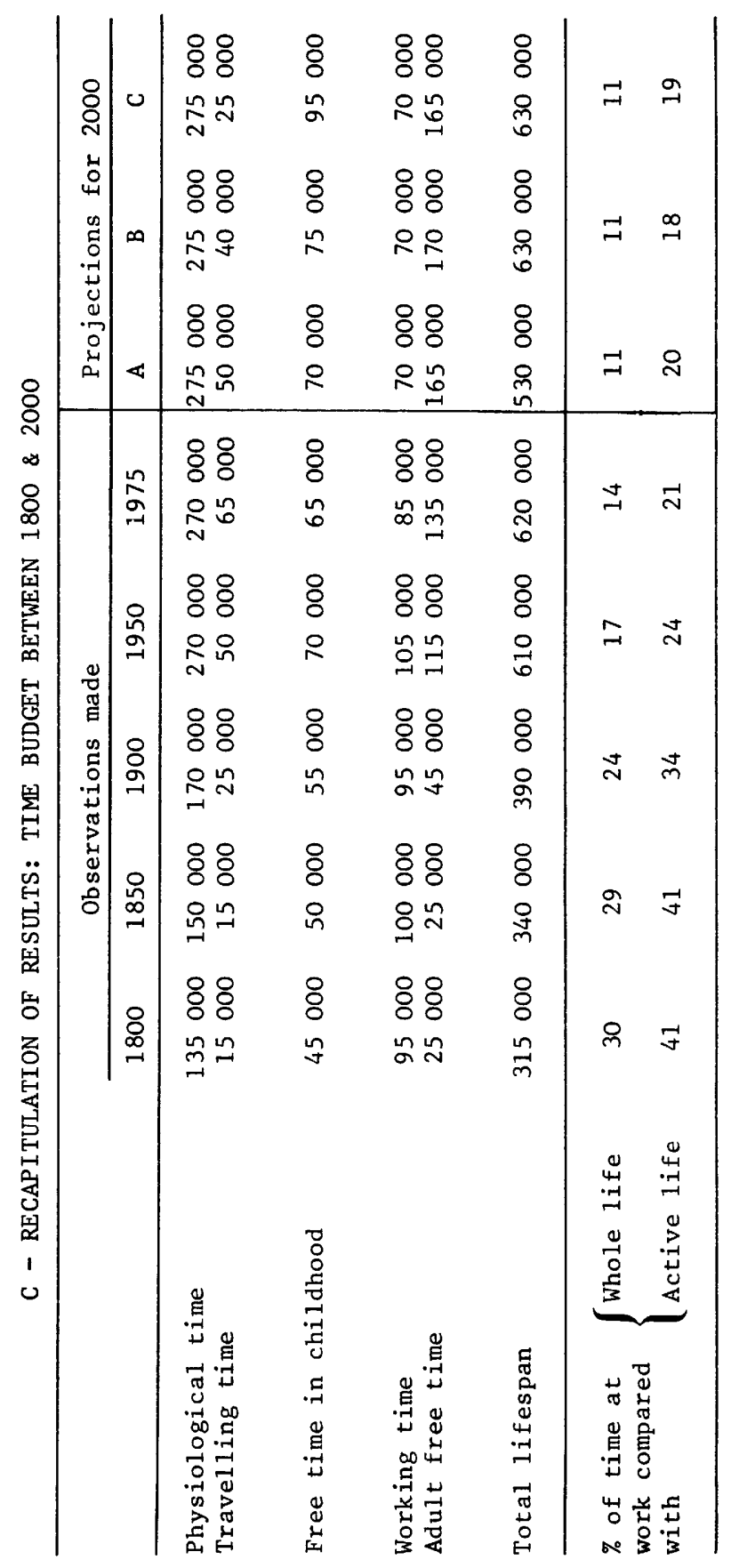


How do matters stand today? On the basis of average figures and extrapolations of trends observed in the past fifty years, there have been very curious changes in the time budget.

On average, and this is one of the most important consequences of technical progess from 1800 until the present day in Europe, life expectancy has risen from 36 to 72 years, i.e. from 315000 to 630000 hours. What has man done in qualitative terms with this gift in the form of life? In this field, too, the post-industrial civilization brings profound changes.

Physiological time (Fig. 20) is that devoted to sleep, nutrition, hygiene, and a minimum of repose in the waking state. The specialists estimate that the average for physiological time in a lifetime is $10 \frac{1}{2}$ hours per day. In the whole of this chapter we are talking of course, about averages per average individual (men and women) who attain, but no more, the average expectation of life. Taking into account his longer total lifetime, the average individual would have spent 135000 hours on physiological needs if he was born in 1800 and 270000 hours if he was born in 1950 .

Travelling time in the urban environment (Fig. 22) has steadily increased during the twentieth century. The specialists attribute to this head, on average, one hour per day up to about 1850, the figure rising to $1 \frac{1}{2}$ hours in 1900,2 hours in 1950 , and $2 \frac{1}{2}$ hours in 1975 . So the average man of 1975 will have wasted 65000 hours of his life on travelling as opposed to 15000 for a man in 1850 (in 71 years, of course, instead of 39).

"Prolonged childhood" has steadily increased in the form of successive extensions of the period preceding initiation into working life. On average it was ten years in 1800 and seventeen years in 1975. The principal change came between 1920 and 1950. It was during this period that the school-leaving age was raised, on average, to beyond the age of puberty.

The amount of time devoted to work remained, on the whole, stable from 1800 to 1960 at around 100 000 hours for a total lifetime, despite the doubling of the average expectation of life. If fell off markedly from the period 1955-1965, reaching 85000 hours in 1975. Extrapolation of the variations recorded over the last twenty years and observation of what is happening in the United States leads to the assumption that, if the trend is not reversed, total working hours per lifetime will have been reduced to 70000 by the year 2000 . The factors which serve to reduce working hours are known, i.e. a longer childhood, appearance of retirement schemes, the holiday periods allotted, and a shorter working day.

The biggest change is taking place with regard to adult free time which includes, in addition to the whole of the retirement period, minus physiological time, free periods in the working life not devoted to sleep, nutrition, hygiene, and travel. The "free time capital" granted to the average male and female population in 1800 was only 25000 hours in a lifetime. Between 1920 and 1975 a prodigious increase was experienced and the figure rose from 45000 hours to 135000 hours.

Extrapolation to the year 2000 gives an estimate of close on 145000 , which could rise to 170000 if the waste in the form of travelling time were reduced from $2 \frac{1}{2}$ hours to 1 hour daily.

Even admitting that these figures have to be corrected by a fatigue coefficient which has reportedly been on the increase since 1945 on account of the reduced quality of the environment, making it necessary to increase by 1 hour per day the amount of physiological time spent on indispensable additional rest, it is seen that the major phenomenon of the last half century has been the increase in the free time available to adults for things other than their elementary needs and paid work. 


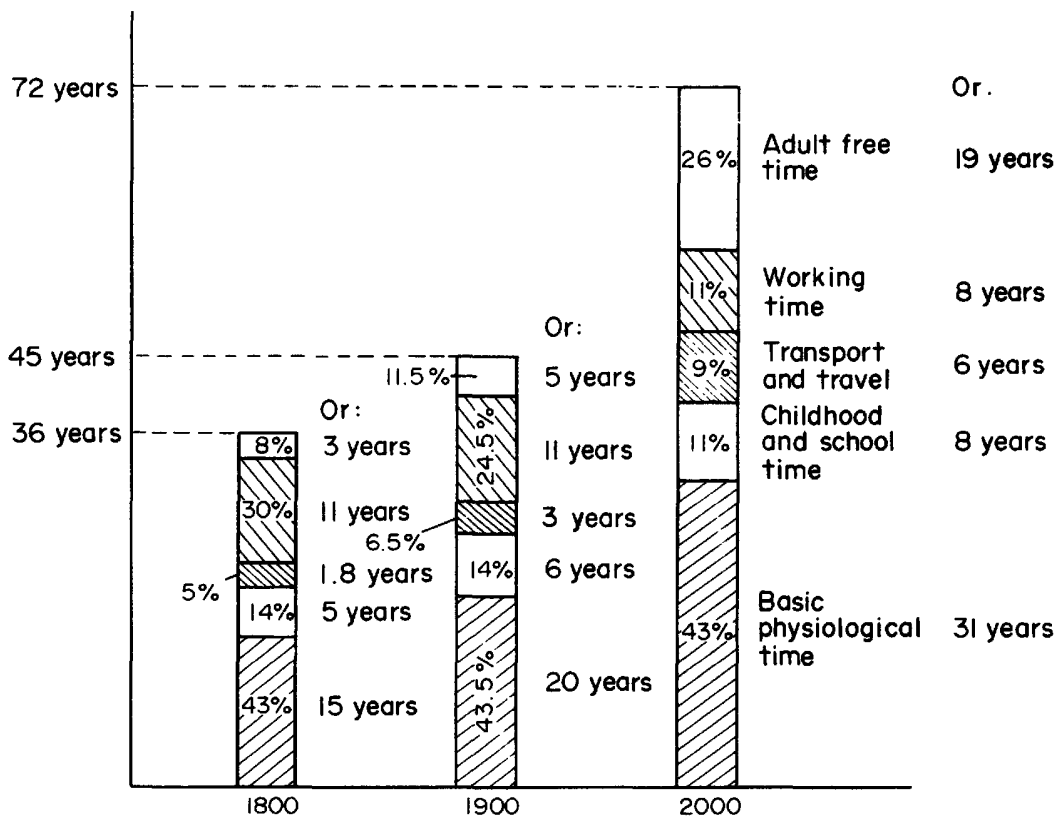

Fig. 20. Trend in the time budget of an average individua 1 - France. (Source: INED.)

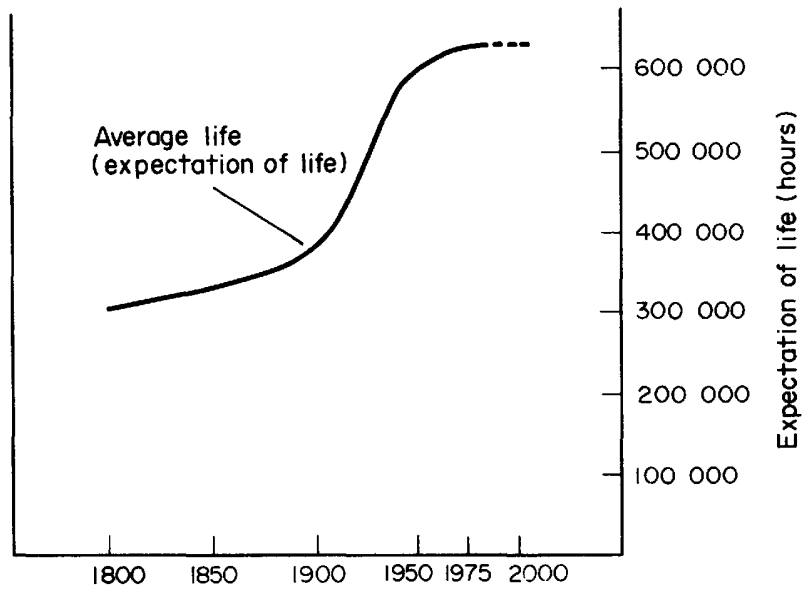

Fig. 21. Life expectancy. 


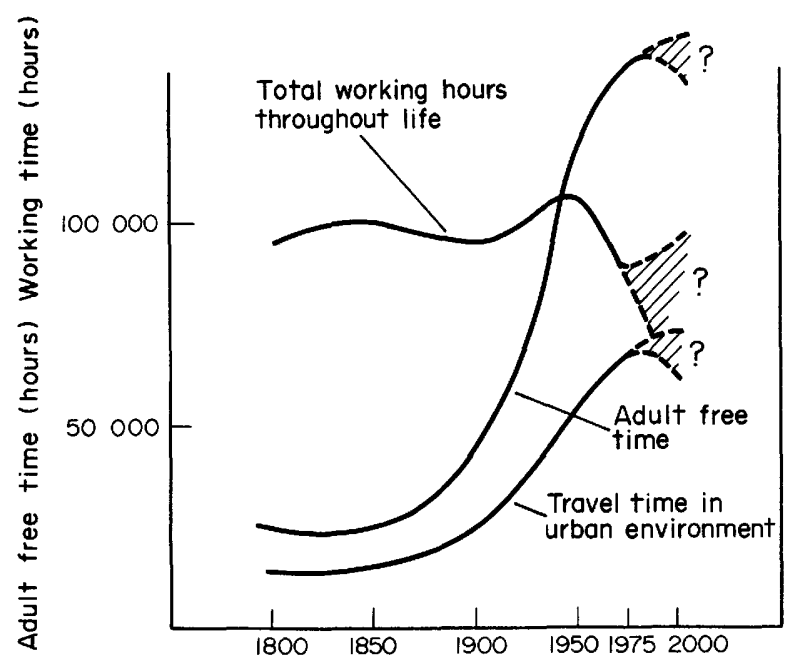

Fig. 22. Use of life.

These observations call for some comments if they are viewed in the context of an attempt to improve the quality of life.

Is it a good thing to extend childhood very much beyond puberty? Is not a late start in social life and in accepting responsibility a serious factor in creating lack of understanding and inability to adapt? Would it not be better if the acquisition of knowledge were not concentrated in a specialized educational and training period lasting well beyond adolescence but, after a certain initial education, took place in stages throughout the individual's life?

Should not one of the decisive steps forward in modern technology be to reduce travel time? Should this not be by means of an improvement of public transport, and of town and country planning which gives priority to the reduction of commuter distances by transporting not persons but information or products or means of production?

Should adult free time continue to increase? How will it be used? Can the proposal be made to people that they should spend their leisure time on increasing their knowledge, their culture, the spiritual content of their lives, and producing goods and services under conditions of free choice and with constraints which cannot be other than foreign to paid employment? Will man be happier if he adds to his breadwinning activity a productive activity, a source of additional income, taking an artisan, or artistic, or even utilitarian form such as cultivating his garden or building his house?

In a Europe poor in resources by comparison with many of its world competitors and yet desirous of procuring for its peoples a high standard of living, should the total number of working hours in a lifetime continue to decrease? At what price in terms of automation in industry and increased productivity in services would this be? Can free-time activities, orientated towards the creation of products and services, make up sufficiently for the reduced purchasing power which will probably accompany the further reduction of paid work? Does not the aspiration towards a better life call for thought regarding free time, its breakdown over the day, the week, the year, the lifetime? 
Increased expectation of life (Fig. 21) is accompanied by the appearance of a category of very aged persons which was negligible in terms of numbers in the recent past, but it is now close to $3.7 \%$ of the population in 1975 and will reach more than $5.5 \%$ in the year 2000 . Should society devote its attention now to the problems they will cause?

$$
\text { * * * }
$$

These questions probably help us to a better understanding of the problem of the quality of life. If the trends towards reduced working hours could be prolonged and if a consensus could be reached to the effect that most of an adult's available time would be spent on productive activities or activities in the direction of individual further training, an immense field for growth of a new type would be opened up in handicrafts, the minor and major arts and the further acquisition of knowledge on the part of adults in all disciplines.

Free-time activities do not consume much energy or raw materials. They are therefore compatible with Europe's relative poverty as regards primary resources. Of course, there could be no question of a return to the processes in use in cottage industry, activities typical of the pre-industrial centuries. Production at home would be fed at source by an industry specializing in prefabricated products or specialist tools, but it is to be supposed that a not inconsiderable added value would be supplied by the labour contributed by users themselves or by their relatives and friends.

If the reader were to meditate on the following list he could perhaps add some lines to it? What would he like to do if he had the time and the facilities? What new or further knowledge would he like to acquire? What special subject would he like to add to the obviously incomplete list given here of the various sources of production at home or self-study? In these free-time activities, how could he introduce the sort of conviviality which is not feasible in industry, trade, or administration because of productivity requirements?

\section{Free-time activities (unpaid)}

(1)

\section{Games and entertainment}

Individual, team, and parlour games and pastimes. Family celebrations, office or group outings or parties, etc. Keeping up local traditions.

\section{(2) Arts taking the form of personal expression}

Writing of all kinds (novels, poetry, essays, memoirs, etc.). The plastic arts (drawing, painting, sculpture, engraving, etc.). Scenic arts (music, singing, choral singing, dancing, theatre, puppets and marionettes, etc.). Audiovisual arts (photography, filming, sound recording, etc.). The applied arts (decoration, cabinet-making, ceramics, tapestry, etc.). The culinary art (gastronomy).

(3) The further acquisition of personal knowledge

Lifelong education. Vocational retraining or further training. The acquisition of social and economic culture (knowledge of society). Travel for cultural purposes. Participation in archaeological, ethnological, ecological, or historical research. Learning a personal activity (art, craft, sport). Preparation for political or social work. Learning a foreign language. 
(4) Contribution towards the acquisition of knowledge

Participation in study circles, clubs, scientific societies, etc. Scientific research without costly equipment. Voluntary work in non-profit-making organizations Educational activities (courses, lectures, demonstrations).

(5) Civic, religious, and spiritual activities

Political or trade union work. Practice of a religion; pilgrimages; study of religions. Philosophical meditation; spiritualism; parapsychology. Participation in psycho-sociological survey.

\section{(6) Aid to the developing world}

Participation in study groups, collection of aid funds. Welcoming activities for nationals of developing countries. Participation in friendly missions, technical assistance, missions, etc.

\section{(7) Social and family life}

Participation in local life (organizations, local authorities, regions). First aid. Child care and education. Care of various kinds (the sick, the elderly, the handicapped). Assistance in the rehabilitation of the injured. Participation in the management of facilities for the young, the old, the handicapped, etc. Prison welfare work. Assistance with leisure activities for the elderly.

\section{(8) Sports}

Gymnastics and open-air activities (swimming, walking, climbing). Leisure sports (fishing, shooting, riding, boating, etc.). Competitive sports. Team sports. Rambling, cycling, trekking on horseback, etc.

\section{(9) Crafts and handwork}

Do-it-yourself building, house improvements, furniture-making, construction of heavy sports equipment (aircraft, boats). Carpetmaking, tapestry, basketwork, pottery, ceramics, enamelling, mosaics, bookbinding, carpentry, cabinet-making, marquetry, etc. Weaving, dressmaking, lacemaking, knitting; making and restoration of traditional costumes, fancy dress, etc. Working of wood, leather, ivory, plastics, precious metals; making of costume jewellery. Toymaking. Horticulture, gardening, poultry rearing, stockbreeding, etc., for one's own use. Do-it-yourself activities and maintenance work (electricity, plumbing, wallpapering, car, etc.). Restoration of furniture, curios, clocks, frames, pictures, musical instruments, etc. Restoration of ancient monuments and historical sites, participation in archaeological digs. Assembly from kits of radios, hi-fi systems, TV sets, radionavigation equipment, sound and light equipment, burglar alarm systems, calculators, etc.

The provision of a development framework for free-time activities in order to channel them towards production in the home would more or less amount to guiding and legalizing what is today known as "moonlighting", which appears to meet a general desire on the part of the peoples of Eastern Europe and also in some members of the Community of the Nine. This work on the side partly accounts for the resistance to loss of earnings where strikes and unemployment greatly reduce official output. The success of this type of work also shows that there is a strong movement in favour of a productive activity even when circumstances favour idleness and passive free-time activities, provided there is a serious economic incentive combined with a feeling of liberty. 
The above statistics on the time budget are mean figures, which implies that particular cases are not really taken into account. The organization of free time may be considered to vary throughout a person's life: part-time working, early retirement, sabbatical years for vocational training, reduction in weekly working hours. A la carte arrangements of this kind would probably bring back to work a large proportion of the non-working female population, which would meet a deep-felt desire. The working population would then be greater in number but each individual would work shorter hours.

It is necessary to re-emphasize, however, the major difficulty already pointed out. The hard industrial and commercial competition that Europe will have to face, combined with its natural economic handicaps, will not allow existing standards of living to be preserved without a considerable effort on the part of its peoples. The extrapolation of the tendency towards a reduction in working hours that emerges from today's statistics would be dangerously utopian if the following two conditions are not met in the future:

(1) substantial further improvement in the productivity of industry and services;

(2) effective contribution made by free-time production to economic wealth by the provision of products of arts and crafts that are useful in everyday life or serve the purpose of cultural enrichment.

There are other reasons for devoting serious thought to the question of free time:

(1) Modern society lacks facilities for communal life such as were provided by the village or parish in earlier times, and consequently a greater burden in the care of the individual falls on the home and on the place of work. Inevitably, there will be conflicts in the relations between people. This emotional overburdening at home and at the place of work is a hazard that may disrupt them both.

(2) The unsuitability of higher education to meet real requirements, rampant unemployment, and illegal immigration are all factors encouraging drop-outs; post-industrial society in its present form creates drop-outs. Might not the idea of free-time activities extended to the production of cultural goods or official recognition of what is today "moonlighting" help to improve this very dangerous situation?

The risk of an increase in passivity, or still worse in alcoholism, drug-taking, and the crime rate must be set against these optimistic ideas on free-time activities. What resources can the human sciences employ to generate a new social consensus, new systems of values that will enable us to overcome the difficulties while respecting individual freedom?

These reflections on the time budget give rise to many questions to which there is still no answer for lack of sufficient information, but we must act quickly as everything points to the fact that in the area of working hours and the development of production in the home, prudence calls for a spirit of enterprise and the taking of a calculated risk. 


\section{INFORMATION ACTIVITIES: FREE SCOPE FOR NEW GROWTH GROWTH ${ }^{1}$}

Up to the nineteenth century civilization was mainly rural. Agriculture occupied the greater part of the working population. Then came industry. It developed at first without noticeably changing agricultural work - the working population had become more numerous as a result of the flareup in the birth rate. Then competition started and this obliged farmers to mechanize in order to step up consider ably their productivity per man employed. The rural population dwindled. The developed countries became urban. The proportion of persons working in industry increased greatly at the expense of all other forms of activity. Society became rapidly more complex and this made necessary the creation of services and information processing of all kinds, i.e. administrative, financial, commercial, and technical. It called into being new specialities in the acquisition of knowledge and its communication.

More recently the productivity of agriculture and industry has been making prodigious progress, freeing jobs and increasing complexity. Labour is shifting to the services sectors. For the United States, which is ahead of Europe in this process, the percentage curves for the working population on an annual basis are shown in Fig. 23, A distinction is drawn between three types of activity: agriculture, industry, and services.

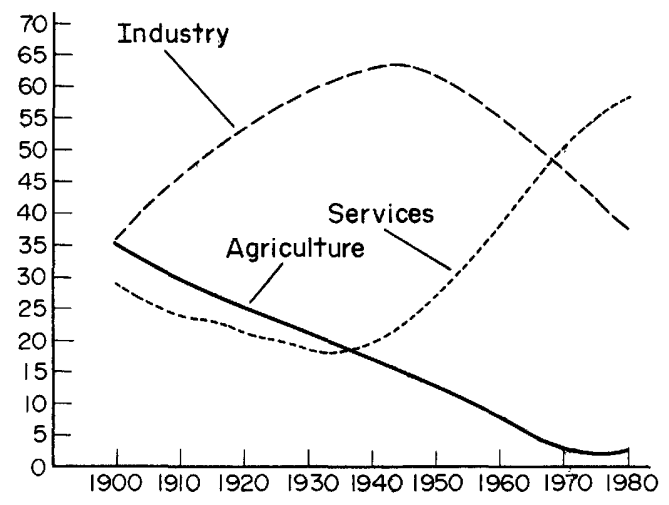

Figure 23. Working population of the United States: percentage breakdown into three sectors.

Edwin Parker proposes, following upon Mark Porat, to hive off from each category of workers above those who specialize in the collection, processing, and spreading of information. ${ }^{2}$ He distinguishes four sectors: the three conventional sectors excluding all operations on information plus a fourth information sector. The curves showing the proportion of employed persons since 1900 for the United States are given in Fig.24. They show a real change in the nature of employment which became apparent in the period 1955-1965.

\footnotetext{
1 This chapter is largely based on the lecture given by Professor Edwin Parker at the OECD on 4 February 1975 (OECD Document DSTI/CUG/75, 1, 27 January 1975).

2 "Information" here is used in a fairly wide sense of statistical data, general knowledge, news information, thought, etc.
} 


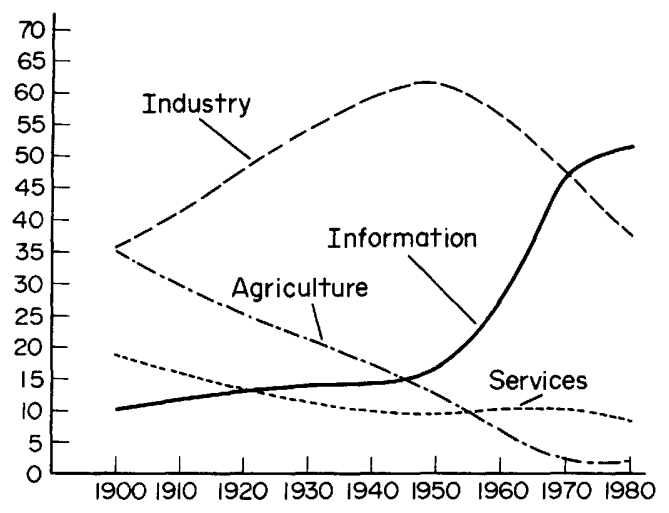

Figure 24. Working population of the United States: percentage breakdown into four sectors.

One can see that, in the decade 1970-80, those actively employed in information activities will exceed those employed in work exclusively of an agricultural, industrial, or service nature.

As far as these phenomena are concerned it is true that the trend in Western Europe is behind that in the United States, but events are following the same course. The delay may be estimated at from five to ten years. It is legitimate to say, therefore, that, by the nature of things, if the trend is not nipped in the bud by an excessively severe economic crisis, it will impel us in the direction of an economy where the main proportion of activities will be linked with information. For Europe, if this comes to pass, the observation is fundamental, for the collection, processing, and dissemination of information does not consume much energy or raw materials but it does require numerous brains of a high quality.

There follows a list, obviously not exhaustive, of the main specialities coming under the head "information activities". It is obvious that most of these fit in remarkably well with the resources and aspirations of European culture, as already analysed previously. At professional level, they overlap some of the free-time activities studied in the previous chapter and in some cases provide technical or logistic support for them.

\section{Principal Information Activities}

\section{(1) Acquisition, storage, and transmission of information}

Scientific and technical research. Documentation, libraries, data banks.

Training, education, communication of cultural, scientific, and technical knowledge in all its forms (further training, language laboratories, etc.). Learning a craft.

Intellectual and artistic creation: literature, painting, sculpture, music, etc.

Entertainment (theatre, circus, cinema, etc.).

Museums, exhibitions, trade fairs, etc.

Audiovisual activities (broadcasting, television, audio and video reproduction, etc.). 
Written and spoken press, advertising.

(2) Acquisition and processing of information

Applied mathematics.

Forward studies, planning, market research.

Statistical observations, modelling (in economics, town and country planning, transport, etc.).

Standardization.

Project studies.

Technological innovations (development, demonstration, promotion, patents). Exercise of a political or trade union responsibility; management of a collective; conduct of an administration or a public service; management of an enterprise (executive and supervisory staff).

Drawing up laws and regulations, justice.

Medicine, health.

Meteorology.

(3) Services based on information

Printing.

Postal and telecommunications services.

Banks, financial services, stock exchange.

Social security.

Insurance.

Organization of spare time.

Assistance to developing countries, transfer of technology.

(4) Support industries (Specialist equipment and supplies)

E1ectronic components.

Printing presses, tele-typesetting.

Reprography, telereproduction, photography, sound recording.

Telephone, telex, videophone, teleconferencing, electronic mail.

Electronics: broadcasting, and television (transmitters, studios, receivers),

radio links, tape recorders, hi-fi, sound proofing, etc.

Computers, teleprocessing, networks, microcomputers.

Automation (sensors, microprocessors, etc.).

Scientific instruments.

Information media (photographs, films, discs, memory, etc.).

Software industry; computer service activities.

\section{THE CALL FOR A NEW DEVELOPMENT}

It is necessary to have experienced the rapid growth of an industry to realize what enthusiasm is generated in a management team by an increase in turnover, the launching of new products, the employment of an ever-increasing work force, or the conquest of new markets. Growth cures or masks all diseases; it leads to full employment, gives everyone a feeling that progress is being made, even if accompanied by inequalities, overcomes financial obstacles, gives rise to enormous productivity gains, and, even more important, gives man the feeling that he is useful, that he is participating in a major undertaking, and that the effort called for is something of a pioneering venture. The post-war generation experienced this exaltation of growth to the highest degree in the industrialized countries up to the end of the 1960s. The intensification of the drive for material power was the continuation of a long progression. 
Observations over the past centuries of history show that growth is a typical phenomenon of the human race as the ravages of catastrophes, famine, epidemics, and wars have always been rapidly repaired. Globally, all curves are ascending: population, capacity and number of production tools, capacity of economic production, knowledge of nature and of man, communications facilities in the way of transport and telecommunications, acquisitions of a cultural, aesthetic, and philosophical nature, destructive power of arms, etc. This overlapping of growth phenomena is known collectively as development. In the rich countries the rate of development has speeded up surprisingly since the Second World War but in an imbalanced manner; technological progress has moved apace, breaking away to some extent from a cultural evolution characterized by the continuance of concepts derived from the past. Growth has no longer taken place primarily in the intellectual sphere, but in the field of material consumption, not without bringing in its wake an increase in all the phenomena of complexity and interdependence.

The Club of Romel must be given great credit for having dared to announce that we were approaching the limits to exponential growth in the consumption of scarce materials and energy, that the world had finite dimensions, and that we were coming very close to those limits. And even if the mathematical model used to demonstrate these findings was marred by undoubted errors, much of what the message announced was true. But this warning disrupted the comfort guaranteed by the growth mystique; contrary to its author's intentions, it was interpreted as reflecting a deep pessimism.

Recent years have helped to define the limits of the dangers. ${ }^{2}$ The risks of shortages of primary resources are small in the short term, with the exception of two - unfortunately essential - items: petroleum and, for the peoples of the tropical and equatorial belts, foot. Experts agree that pollution could be contained within acceptable limits if 2 to $2.5 \%$ of the gross national product were devoted to its control. However, for some products such as phosphates, mercury, silver, chromium, and a few others, the scarcity of easily mined high-grade ores could lead to serious price increases. Nothing fundamentally tragic for humanity results from this analysis; the younger generation must not view the future as inevitably destined to produce apocalyptic catastrophes, but the warning is a serious one. In the present state of technology and the possibilities for capital formation, the spread of the American consumption pattern to the rest of the world would lead to enormous wastage. And yet the American successes are taken today as a yardstick and aim by almost all governments implementing a deliberate development policy.

Europe must give serious consideration to the question of growth as the finite nature of the world and its interdependence have a profound and immediate meaning for it: they recall its cruel shortage of primary products and its dependence on suppliers over which, as we have already seen, it no longer has any political control.

In recent years thinking in intellectual circles has appeared to fluctuate between two extreme solutions, both of which are impractical: the restimulation at all costs of consumption growth as experienced for rather more than twenty years after the Second World War and, at the opposite pole, zero growth.

1 The founder of which, Dr. Aurelio Peccei, is a member of CERD.

2 See in particular the symposium organized by FISH on the terrors of the year 2000 in September 1975, in Jouy-en-Josas. 


\section{Rejection of Zero Growth}

The choice is shown fairly clearly in Fig. 25. Zero growth would mean that the curve representing economic activity would lie between curves $I$ and $I$ bis. For the first time in the history of humanity, apart from temporary short-lived economic crises, the second-order derivative of the function economic activity would take on negative values and would remain negative. It is by no means certain that we would be able to handle a situation of this kind, demanding reflexes so different from all that we have acquired in recent decades. And it is difficult to imagine what a society compelled to embark on deceleration would be like. In all probability, an economy of this kind would necessitate the freezing of existing structures and a great rigidity of society. Instead of continuous1y encouraging individual opportunity and rewarding a spirit of enterprise, it would enclose people in fixed organizations in which advancement would depend solely on seniority. Society would probably evolve by moving towards crystallization into a structure with no mobility. The absence of reward would not encourage effort. The freedom of individuals and groups would be greatly reduced by the fragility of the static balance, whereas the adaptability of dynamic growth balances easily absorbs errors and flourishes on successful endeavours.

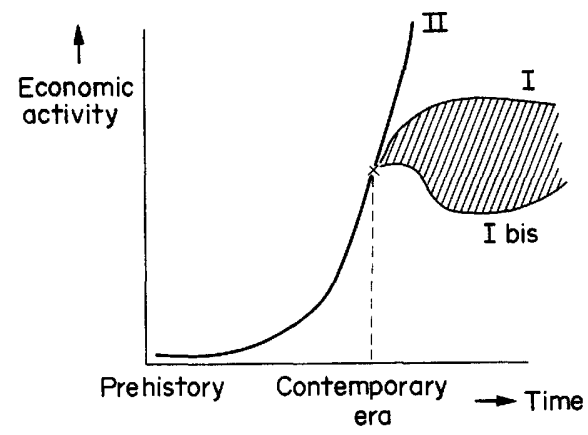

Fig. 25. Growth in economic activity.

Would this sedimented society be based on a system of egalitarian distribution, with neither wealth nor poverty, or on a caste organization established by compulsion? Either of these formulae could be adopted, depending on the country or circumstances.

Zero growth means seeking a static equilibrium. Engineers know that there can be balance only in a combination of dynamic forces, and biologists have proved that life is essentially movement, happening, revival, conflict, surprise. But static equilibrium is attractive to many minds; it appears endowed with capacity for refinement that would enable perfection to be attained; it would guarantee everyone security, would eliminate conflicts of interests because these would become pointless. It is the temptation of nothingness, the fascination with death to which man is so sensitive. It is to be expected, therefore, that we will encounter in the future the manifestation of dreams rooted in the past, myths of the return to a rural civilization within closed geographical frontiers. As a result, the tendency towards authoritarian organizations in which the State, with all powers concentrated in it, would decide on the happiness of its citizens, is a likely outcome, as the positive constraints emerging from a collective desire for development can be replaced only by political constraints. 


\section{Discovery of the Sources of a New Development}

The European needs to develop through action, as we have said: he is unable to divorce thought from action; he is not prepared to merge his personality in the mass. A programme of aims must therefore be proposed to him. However, this programme must turn its back on excessive consumption of energy and raw materials, must avoid waste and attacks on the environment. It is necessary to invent a new development. Only by proving that it is feasible to enter a phase of development of an entirely new nature will it be possible to create the necessary willingness, give new impetus to the spirit of enterprise, and release the forces of change. This will overcome opposition to further productivity increases at work because the fear of unemployment will be gone. The announcement that a new growth model is in sight is the only way of giving youth faith in its future and persuading it to sacrifice the time and effort necessary to achieve success. This is an essential condition for the rehabilitation of the concept of progress.

All these ideas are in the air; they have been expressed in many countries and in a variety of environments but have not brought matters much further forward. One would have to be extremely vain to claim to have found solutions; at the most one may hope to foster emulation, to set brains working, and to arouse criticism from which constructive proposals will emerge.

In the course of the two previous chapters, two fields have emerged as possible growth areas which have no scarcity constraints and are in line with the drive towards psychism typical of evolution. Man fulfils himself by making a judicious use of free time; he increases his ability to communicate with his fellows and with his environment by means of information activities. These are the new poles of growth but, for economists, it will be clear that these aims will not be sufficient to trigger off a movement towards a Second Renaissance. Two considerations underlie this scepticism:

(1) Never in history have men succeeded in uniting their economic forces for the sole aim of improving their lot, the drive towards comfort and pleasure arising from the cultivation of the senses and of the mind is not a rallying force; perhaps men are still too primitive and too unequally cultivated?

(2) Assuming that these aims are acknowledged as desirable by a large majority of the population, resources to finance the transitional phase are inadequate. Europe does not create enough capital to pay for the new communal and individual investments; it does not derive sufficient surpluses from its economic activities to absorb the costs of the social and commercial imbalances generated by a transition from a type of civilization essentially based on the production of material goods to a civilization of communication and of the mind. That is why it is urgent to devise a third pole of growth of a more familiar kind, more in line with industrial investment and the technical resources available in the industrialized countries. If this third pole of growth were indeed to be able to continue to foster productivity increases, and if these increases could generate sufficient economic surpluses, then the financing of the transition towards a Renaissance would no longer be an insurmountable obstacle. Prospects of a society more richly endowed with humanity would no longer be merely Utopian but would become a project. 
Asking this question is tantamount to pondering on the market: where are the real needs? The reply is clear: the real needs for an increase in consumption may be found amongst the 2,000 million (who will shortly number 4,000 million) who are today deprived.

\section{EURO-SOUTH SOLIDARITY}

It is not possible in a short chapter to deal with the vast question of the economic takeoff of the poor countries. However, it is impossible to speak of the economic future of Europe without referring to the enormous development possibilities, for the Community itself, which would be opened up by financing, if this were possible, the equipment in capital goods of the countries in the process of industrialization. A new growth extending over thirty to fifty years would be open to European companies. If this process could be triggered off, it would bring about a fantastic economic spin-off in the wake of which the evolution towards a new quality of 1 ife, which appears Utopian today, could become reality.

Although the order of magnitude of the circumstances and the complications involved are not comparable, the situation has some similarities with the picking up of the economic pieces of Europe and Japan after 1945, in particular thanks to the loans under the Marshall Plan and their extensions. This act of solidarity was not only generous. Was it in fact dictated by generosity? However, it was intelligent and in recompense, directly and indirectly, the United States has received as a contribution to its own development several times the amount of the initial financing.

Many ideas are in the air today about the remission of the debts now crippling the economy of the developing countries, Sweden having just provided one example. There is talk of the financing of joint development, as proposed by $\mathrm{Mr}$. P. Cheysson in particular; of a standstill on armaments which today scandalously consume an appreciable proportion of the economic growth potential of the poor peoples. Perhaps we are not far from the point of no return, the transition from theory to action?

Even if no great policy can be put on foot, however, the purchasing power derived from the increase in prices to suppliers of products that have become scarce (petroleum, gas, ores, tropical food products, etc.) is starting, at least in certain geographical areas, to stimulate takeoff. Europe is directly involved; it must see that its own development shares in this trend.

\section{COMPETITIVENESS AND SIZE}

Western man is not characterized by frugality. 1 He is used to an abundance of material goods, to civilized comfort, to a car, and a colour television set. His diet is rich. He aspires to a second house or dreams of travelling to far-off places or going to the theatre or the museum or practising winter or seaside sports. He considers it legitimate to enjoy a long retirement, calm and well financed. He intends to preserve his health by means of curative and preventive treatment. He wishes his children to study for prolonged periods of time and, if

\footnotetext{
1 With the exception, however, of a poor sub-proletariat benefiting but slightly from the advantages gained through technological progress, the existence of which is a permanent insult to the ethics on which the industrialized society would like to pride itself.
} 
possible, to prepare for a career associated with non-manual tasks. He wishes to be guaranteed against loss of his job and against the consequences of illness. If he does not have the benefit of these he feels deprived.

This situation is due to the progress made in the productivity of the mass manufacture or consumer society, also known as the society of abundance. No government would dare to let it be understood that the objective is progressively to abandon what has been achieved because Europe's position in the world has changed so much that it is no longer able to grant its populations such favourable treatment. . However, let it be said to all those with no political attachment who are devoting their attention to Europe's fate that all these current advantages are extremely fragile and if they are to continue it can only be as a result of considerable efforts consented to by the population at all levels. The balance-sheet for Europe drawn up in the first part of this document is sufficiently explicit to demonstrate how remote the chances are. To be without any great political power in a world characterized by a pitiless competitive struggle in the division of labour, when one has no natural advantage save the quality of one's population, does not make for commercial victories without an iron will and a broad social consensus.

Europe must therefore continue to increase the productivity of its agriculture, industry, and services in order to remain competitive. It must also pursue its effort in the direction of innovation in order to surprise its competitors by its technical progress. On this basis it will be able to continue exporting in order to import energy and the other raw materials which are indispensable for its economic life. However, the inhabitants of Western Europe must understand that every year they will feel weighing more heavily upon their shoulders the burden of a finite world, the scarcity of primary resources, the need to eliminate pollution. In this effort, one of the main weapons will be innovation.

Innovation is the result of scientific research. In this field it would be well for Western Europe to choose its ground, in keeping with its specific resources, its dimensions, and its own cultural genius. We shall come back to this later.

\section{Productivity and Size}

As far as productivity is concerned, the European Community must not forget the implacable rules of the economy of scale. When a product or a service can be obtained by means of a mass-production process its cost price is in inverse ratio to the quantity manufactured. Figure 26 explains this Law.

Depending on how far artisan manufacture is developed or whether it is partly or completely automated, the price of a specific product will decrease in accordance with a curve which looks like a hyperbola; the more sophisticated the manufacturing methods, the lower its asymptote, the ultimate price. However, it should be noted that in the case of short-run production rustic methods are the most economical. In other words, not only is the price a function of market breadth but also of the degree of sophistication characterizing production.

Most of the good and evil attributed to the consumer society is contained in these curves, namely:

(1) the considerable gains in terms of productivity and the spectacular lowering of sales prices;

(2) the strong trend towards giant production units; 
(3) the success of the multinationals;

(4) the pressure exerted on customers for increased consumption of products;

(5) the growth of development and engineering expenditure;

(6) the tendency towards a lowering of quality standards, especially at the expense of durability;

(7) the difficulties experienced in transferring rich country technology to poor countries whose domestic market is too small ünless they are made into exporters with a controlled foreign market (neo-colonialism);

(8) inflationary tendencies which are partly derived from the fact that the industrial cost price is deceptively low because the giant production units pass on to society a large proportion of their overheads in the form of the elimination of nuisances, transport of personnel, giant-scale urbanization, etc.;

(9) the difficulties experienced in regaining a market once lost for a certain time (electronic components, microprocessors, computers, quartz watches, etc.).

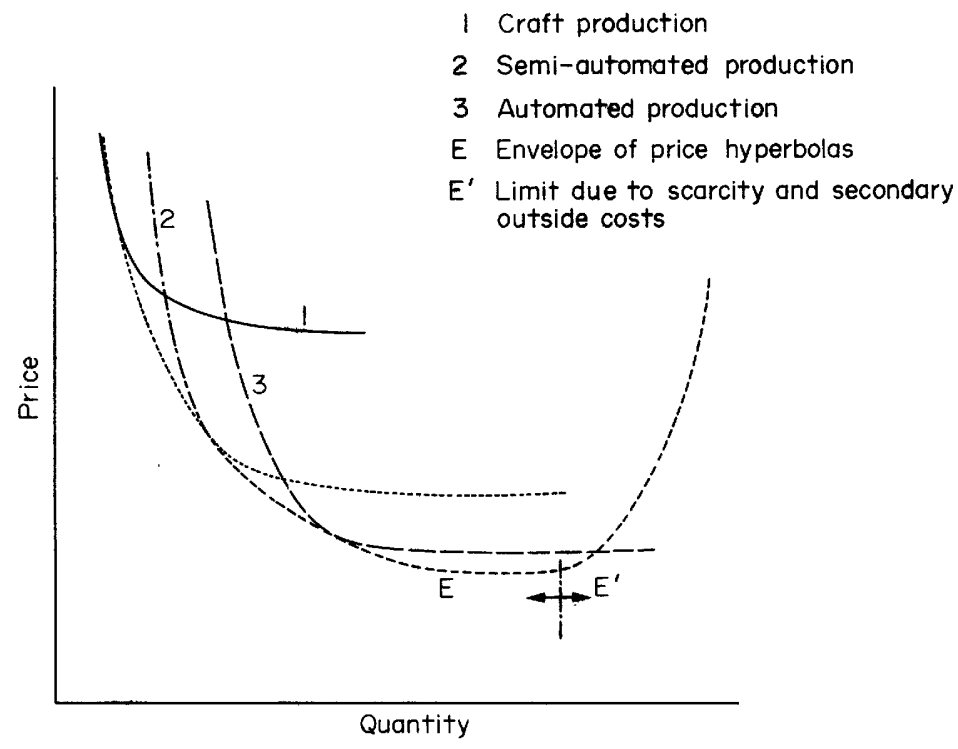

Fig.26. Mass production: price-quantity function.

European industry is finding itself confronted with the implacable nature of this law which lays down that price decreases with the quantity manufactured and, unlike Japan which exploits all aspects of this remarkably well, it seems that the Community has a special propensity for falling into all the traps which accompany these phenomena.

In the first place, the Community takes no advantage of its size. As a result of the direct or indirect control of the Member States over the main markets for 
innovation such as national defence, health, telecommunications, education, and the nuclear field, despite the theoretical freedom of movement for products, national producers are given preference. Thus what should constitute a single market of 250 million consumers with a high purchasing power and a much richer potential than Japan, almost as powerful indeed as the US market, is broken up into separate national units. However, although Europe is singularly unable to derive an advantage from economies of scale it is not able to combat the dangers thereof. In particular, it is allowing itself to be dragged into the production of goods with a short lifetime intended to be thrown away and not repaired; this is in no way suited to its relative poverty in terms of energy and raw materials. No great efforts have been made to recycle waste.

In addition the Community has paid little attention to real cost prices. This must include both direct industrial costs and expenditure outside the undertaking necessitated by the growth of high-density urbanization and the vulnerability of the environment.

It is therefore not only in the field of customs that Europe, as is often said, is borrowing from the United States the worst without taking the best. It is also true, in many respects, in the economic field.

From this glance at the economy of scale it must be deduced that Europe will not maintain the purchasing power of its peoples in international competition if it does not accept certain constraints which are imposed by the laws governing price formation in mass production and particularly if it does not unify its main markets for the products of innovation. With the help of technical standardization and regulations, it should introduce new constraints in line with its special characteristics and should, among other things, steer its industry in the direction of products with a long lifetime, which can be repaired and are not rapidly consumed, and products designed so that the scarce raw materials embodied in them can easily be recycled. Its efforts should also be directed towards a closer approach to true prices so that the protection of its social and ecological balance, which is particularly delicate, can be allowed for.

\section{The Concentration of the Large European Undertaking and the Challenge} of Multinational Business

As many observers have commented, the need to become competitive by increasing the scale of operations and the shock caused by the Treaty of Rome have led not to intra-European concentration, as might have been expected, but to mergers between rival groups within member countries. Examples probably come to mind readily in Germany, France, and the United Kingdom, where the chemical, electrical engineering, steel, and other industries set to work to form powerful national groups. A similar course was adopted in Italy by the State financial trusts IMI and ENI. Instead of market interpenetration, the formation of these oligopolies has resulted in a strengthening of specific national features - exactly the opposite of what should have been done to offset the power of the major American or Japanese industrial groups. As a result, with, of course, a few exceptions, real transnationality within the Common Market has been achieved only by European companies based in the small countries (Netherlands, Sweden, Switzerland) on the strength of the momentum acquired from their long-established location and by the ventures of American companies. The latter, inward-looking right up to 1957 , were suddenly stimulated by the rebirth of Europe to engage in ventures outside their traditional home markets.

1 This statement can be disputed; it is not true of all industrial products. This controversy shows the need for serious studies on this subject. 
The question that arises concerns not only industrial competitiveness but also the dissemination of innovation. The development of modern techniques is so expensive that the costs of research and development, demonstration, and sales promotion must be recovered on the markets of several major consumer countries simu1taneous1y. Here Europe is faced with a problem that has not yet been properly solved and that comes under both the industrial and the scientific and technical po1 icy.

These reflections on the economy of scale provide an opportunity to illustrate a contradiction. To remain competitive, which means merely to survive, European industry is forced to accept certain trends towards mammoth industry. And yet, as we have seen, mammoth production units are not at all in keeping with the geographical characteristics of Western Europe and all that we have said of social aspirations and cultural forces does not indicate any natural predisposition to succeed in large concentrations. The difficulty cannot be resolved by an all-ornothing choice. There are fields where Europe is obliged to accept mammothism. It can succeed if it wants to. But the ideal would be to develop consumption models that are suited to production in small units; in this field the Common Market countries would probably be winners. This offers a promising line for research.

\section{WORK AND QUALITY OF LIFE}

The ideology that has accompanied the work results from a conflict between two concepts which sometimes coexist in the mind of one and the same person. Work is a curse - the sign of man's imperfection. Work is a matter of dignity; man achieves greatness in work. Depending on where one stands geographically or socially, or the point in history one considers, one of these concepts takes precedence over the other. Nevertheless, work and effort have been regarded as basic values of society throughout the industrialization period, and the concept of dignity through work is still widely prevalent. Only the youth of today question this, but their challenge is perhaps directed not so much at the principle in itself as at the fact that attractive aims on which to focus their effort are no longer offered to them. It is fair to say that as long as the tasks involved in paid employment are, rightly or wrongly, regarded as repugnant by a considerable proportion of the working population, there will be no satisfactory reconciliation between the citizen and society.

The place of work is generally the "undertaking", viewed in the broadest sense of the word. This is a human community specializing in a group of specific tasks. The undertaking may be an industrial and commercial company, but it may also be a non-profit-making venture; it may also be the administration of a university, hospital, or local authority.

We shall not here go into the conflicts of ideas on profit and its distribution except to warn against the risks of misleading simplification. The complexity of the modern world does not allow such simplification; in particular, it is wrong to regard profit as the sole aim of the industrial and commercial company. As for power, because of the complexity of the situation, it depends far more on information than on ownership.

Here we are interested in the quality of life of the man at work: it is recognized that this must be improved both in the public services and in private companies and, according to our observations, in both free and planned economies. 
Considerable research into means of further progress here is currently underway in all the Community countries. Because this is done, everywhere, in a state of tension and sometimes in the face of trade union and employer antagonism, and because it is accompanied here and there by apparent anarchy due to confusion as to who is competent, it tends to be disturbing. It would be more constructive to ensure that all the questions start off by being well formulated and that individual solutions get as far as experimentation.

On the basis of what has already been achieved until today it is possible to classify the problems into two broad categories:

(1) understanding of an undertaking's objectives and constraints and association with decision-making machinery;

elimination of distasteful tasks.

\section{Understanding of the Undertaking and Participation in Decisions}

Although the concepts that follow correspond to a level of information which is not very widespread, men of goodwill are beginning to agree on concepts for industrial, commercial, or service undertakings which differ noticeably from the image inherited from the past.

The undertaking must be recognized as the principal centre for the production of wealth. Its aims are complex and essentially economic and social. The undertaking processes raw materials or information in order to procure goods for its customers, purchasing power for its employees, a return on capital for its shareholders and creditors, while swelling the resources of the community via a number of tax levies to which it is subject. The undertaking also provides its suppliers with a living. Profit is an indicator of good adaptation; a brake if it is negative and an accelerator if positive.

The undertaking is, by its very essence, a place of tensions and conflicts. The interests of its personnel, which are to be as well paid as possible with working conditions, guarantees, and holidays which are likewise as good as possible; the interests of its customers who seek the best quality at the lowest price; and the interests of its creditors and of its suppliers, are obviously in conflict. The strategy of the undertaking, biological in nature, is to try to provide an optimum response to all these conflicting forces in the presence of competitors who are pursuing a similar strategy but whose responses are not necessarily identical. This interplay of conflicts demonstrates both the need for liberty and that for evolution and creation which, as we have seen in a preceding chapter, are profoundly anchored in Western culture. The undertaking presents risks which seriously commit its members' future since the stake is growth or disappearance. Participation in this game may be seized upon for the benefit of a few leaders, but it must not lead to the dilution of authority, in the absence of which there could no longer be any arbitration between the inevitable antagonisms.

The undertaking must be the place par excellence for apprenticeship to social life. If its mechanisms were explained to him, the employee would learn to understand the modern world's complexity; its implications in terms of finiteness and interdependence; and the need to regard inevitable certain economic and social constraints. The undertaking has replaced the parish or the village as the forum of social communication, a situation which imposes an additional emotional burden on it.

This description does not solve the problems but it does indicate avenues towards 
a solution based on reconciling man with his work. Comprehension must be facilitated by reducing complexity through decentralization. Undertakings must be broken up into as many sub-undertakings as are necessary to arrive at production units or data-processing centres corresponding with the human scale. This decentralization should be accompanied by far-reaching delegation of powers in such a way that the largest possible number of employees is associated with the quest for the optimum, which is the undertaking's response to the pressures within and the antagonistic forces which are the expression of its environment. It is along this line of thinking that numerous experiments are underway, especially in Germany, The Netherlands, and Sweden. It will be necessary to follow up the successes and the failures while understanding them and promulgating the solutions.

In addition, it is necessary to give back to man in his work a maximum of responsibility in executive tasks while providing favourable conditions for team decisions. Experiments conducted, inter alia, in Italy, inside pilot workshops where only the overall task is defined, the breakdown of subsidiary tasks being decided upon by the team actually responsible for doing the job, are a step forward in the quest for new systems for the sharing of responsibilities which are so necessary for the cultural genius of Western Europeans. It is necessary to overcome the contradictions between this search for progress and the maintenance of productivity; this calls for both caution and experiment.

\section{The Elimination of Distasteful Tasks}

Our citizens have a distaste for certain manual tasks, which they now entrust to several million immigrant workers who are cut off from their cultural and family links. The existence of such a large mass of workers, living as it were in a deported state, is a scandal in the face of the cultural values boasted of by Europeans. The scandal is all the more striking in that it exists alongside another, no less painful, namely the presence of an almost equal number of European unemployed.

By means of better organization of labour and more frequent recourse to machines or automation it would be technically possible today, provided massive investments in research and development and production equipment were made, to eliminate a large proportion of the tasks entrusted to what can only be called a "subproletariat". For the irreducible residue it would probably be desirable either to upgrade various forms of manual work in such a way that it was accepted by aboriginals, or to entrust to the developing countries which have excess labour on-the-spot execution of certain manufacturing processes. The workers would at least experience the immense advantage of finding themselves in their normal family and cultural environment.

This objective of reducing the number of distasteful tasks ought to be considered as a first priority by the Community. It would have the additional advantage that, once the organizational and mechanization effort had been accomplished, European industry would have made great gains in competitivity. It would have progressed from work done by man to work done by machine which, with a few exceptions, is more productive when optimization is properly calculated.

\section{Reducing the Fear of Unemployment; Ensuring Virtually Full Employment}

The existence of a large brigade of unemployed is not compatible with the ethics of the dignity of labour and effort. Reducing unemployment must therefore be among those social objectives which enjoy priority. 
Studies proposing new solutions ought to be conducted on this subject. It must not be believed that a solution is to be found in simply getting the consumption of material goods under way again. It is necessary to reconsider the balance of society, and in particular to study the direct and indirect consequences (not always as common sense would lead one to imagine) of reducing working hours. The development of free-time activities could, under certain conditions - in particular as regards the time and facilities devoted to adult education - help to provide solutions.

Two mistakes are to be avoided at all costs:

(1) belief that the peoples of Europe tolerate as readily as the Americans a high rate of unemployment;

(2) failing to increase productivity, despite the technical possibilities of doing so, on the pretext that this would aggravate unemployment, especially in the services sector. Europe would become less competitive and so would import and consume less and unemployment would increase.

\section{MASTERY OF COMPLEXITY}

One of the principal traits of the post-industrial civilization is complexity. No longer is any social, economic, or political phenomenon an isolated one. A whole train of secondary effects accompanies it. Sometimes they are more considerable than the initial effect. The fact that the modern world constitutes a finite system - in the sense that no new territories remain to be discovered - adds further to the complexity. Decisions, so to speak, bounce back when they encounter the boundaries of the economic and social universe. The environment is changed by reason of the very fact that an adjustment has been made to it.

This increasing complexity explains the growth in information activities. In so far as this complexity represents progress in co-operation among human beings and the sign of an improvement in the acquisition and communication of knowledge, we should rejoice at what we see. However, when it is a question of growth in parasitic activity under Parkinson's law, an effort must be made to combat it because man's' liberty suffers as a result and it represents a tremendous waste of effort.

In this field, too, it might be thought that Europeans are bending backwards to import from the United States factors making for ossification which the Americans manage not to amplify, by decentralizing powers and responsibilities, by delegation of trust, with a smaller workload for the Administration. In this respect, the organization of the Commission of the European Communities and its decision-making channels constitute something which is by way of being a masterpiece of paralysing complexity .

We must realize that although progress as regards productivity has been considerable in agriculture and industry, it has been slight in the field of services and the machinery for collecting information.

In order to improve the quality of life but at the same time reduce collective overheads, it is indispensable to develop two further subjects by study: reduction of complexity wherever it is not indispensable and increase in the productivity of services and of information activities.

The incomprehension born of complexity in its turn gives rise to a feeling of insecurity. To compensate, men try to build up systems offering security which, in the current state of affairs, merely adds to the red tape. In Europe in general, 
and more acutely in the Latin countries, citizens tend to turn to the State and expect it to behave as an ever-present provider. This desire for security must be regarded as a major phenomenon of our society. The responses, however, merely tend to add to the profusion of information, already too voluminous to master, that dehumanizes relations between administrations and those they administer and the public services and those who use them. The free citizen is tending to become a person in receipt of assistance and is thus losing part of his identity; frequently he becomes a "file" rather than a human being.

Fortunately, as always when a new problem emerges, new tools for tackling it are being developed. Systems analysis is a new technique that can grasp these phenomena, help to understand them, provide training by means of simulation, and indicate possible solutions. However, the decision-makers of the current generation have not been trained in the use of such ways of thought and instead of showing interest and endeavouring to make use of them they are generally distrustful of such intellectual prowess and those who practise it.

\section{COMPLEXITY AND POLICY}

The use of systems analysis to examine this complexity leads us to discard the two extreme courses of complete economic freedom and centralized planning and to select a middle road which in fact already exists. There is some reluctance to use terms such as capitalism and socialism as these expressions mean different things to different people and are charged with ideological implications.

The very complex system needs to be regulated or, more precisely, to be endowed with internal self-regulating mechanisms. In these mechanisms, time constants play the most important role and in an initial analysis, since reality is a little less simple than its description would indicate, two coexisting systems of regulation must be distinguished:

(1) a set of quick-response microregulating devices giving multiple and permanent reactions in real time and operating as closely as possible to the initial sources of information:

(2) a set of microregulating devices corresponding to high-inertia general phenomena. The microregulating subsystem must have some degree of freedom in relation to the macroregulating system. In other words, it must have its own constraints and its own ways of optimizing the responses it has to supply at any moment to the demands of the environment, without being excessively predetermined by the macroregulating system. It must also pass on information to the latter and possibly stimulate development.

Adoption of the middle road means that it has been possible to establish fruitful coexistence of the two regulating systems with neither an excess of planning that would not give sufficient free rein to microeconomic phenomena, nor complete liberty for these phenomena where the sum of the individual movements cannot possibly lead to acceptable macroregulation in a very complex situation.

These general aspects naturally leave very great scope for choices that will differ according to political options, some preferring a relatively high degree of planning while others favour greater freedom of competition. The important point to remember is that it is not possible to achieve anything without giving plenty of scope to both these forms of regulation. If the Europeans can conduct studies on this subject, relating them to the scientific field so as to rid the debate of some of the ideological passion obscuring the issues, great progress cauld be made in the social consensus. 


\section{CONCLUSIONS TO PART I}

Many personal elements have been introduced into this dynamic study of Western Europe: moral and cultural forces moving through history, extrapolations of observations and trends. descriptions of aspirations or projects. The reader will perhaps find it excessively subjective and imbued with a French rather than European culture; he should not let this put him off as it is here that we come up against the difficulties inherent in European diversity.

The opposite reproach could also be made: this analysis shows a lack of imagination as it really does no more than extrapolate the curves of the past. This is true of the aspirations to economic growth, the extension of the trends towards the reduction of working hours, the observance of mass production constraints, the increase in specialized jobs in information processing or communications compared with agricultural and industrial jobs and more generally respect for the cultural heritage as it is generally understood. Although apparently daring, this paper is fundamentally in line with the forces and trends that have emerged in recent years. What is more, the "aspirations and projects" proposed for Europe would flourish more readily in the United States of America, which is richer, less vulnerable, and already more committed to some of the courses described, if America were driven by need.

A11 this is true, and the reader seeking the seeds of a revolution in the construction of Europe will have to take a different course. Nevertheless, the extent of the evolution which is proposed must not be underestimated.

A move towards production of durable and repairable goods and the adoption of a systematic energy conservation policy would involve radical changes in the industrial system that would jeopardize its structures, its methods of winning customers, and of course the technical specifications for the objects manufactured.

If it were considered realistic to reduce working hours to the equivalent of 32 hours per week (this could be done in a variety of ways, ranging from halving the working day to the four-day week, sabbatical years, or early retirement), it would first be necessary to make a prodigious effort to increase productivity in order to offset the corresponding economic losses and radically to change customs and habits as the proportion of the non-working population, the unemployed, and those having no trade, would probably have to be very much lower than today. 
If information activitiès were to become one of the driving forces for growth, Europe would have to make up its leeway on the United States and face up to competition with Japan which is already extensively comitted in this special sector.

If free-time activities were regarded as a factor for economic enrichment as well as a factor for the development of human values, there would have to be a greatly developed sense of responsibility as regards the correct use of freedom, new economic and tax incentives, an extensive adult education campaign, a new "cottage" industry, increased pressure for the reduction of time wasted in travelling, and a new housing policy.

If the transfers of technology to developing countries, together with the associated supplies, were to become one of the major spearheads of the Community's export effort, it would be necessary both to establish reciprocal arrangements to provide some of Europe's customers with finance for their imports and to accept that in the long term this would lead to the establishment of fresh competition that would rival us even in the field of advanced technologies.

If consumption habits were to change, with the ambition to succeed by free personal work triumphing over the illusory accumulation of assets, we would move from a civilization of waste and envy, of never-satisfied desires, to a civilization of the self-fulfilled man, responsible and aware of the reward he will receive for his work and his talent, acts and feelings which, in past history, were the privilege of a very small elite.

And if all these projects were to converge, man would be prepared for a civilization which, although relatively frugal in material terms, would have a prodigality of spirit - probably the only practicable solution for a world population numbering 12,000 million amongst whom inequal:ties would be less caandalously rampant.

These would be the outlines, aims and means of the Second Renaissance.

$$
\text { * * * }
$$

Why such lyricism now when the first part of this study reached almost discouraging conclusions on Europe's weakness? Essentially, in order to show that it is not true that the future holds nothing and is bound to be disappointing. It is not true that we are condemed to zero growth on the way towards underdevelopment. It is not true that there is no longer any social hope; it is not true that the future is predetermined by the present and must lead to dependence, the absence of a political role, and the loss of hope; it is not true that we are moving irreversibly towards the control of complexity by dictatorship.

But it is true that a generation has never been called upon to make such an effort to avert a likely decadence. The nations of Europe have no chance to achieve this recovery in isolation; they have neither the dimension nor the stamina. But could not a new impetus be given to the Community with this as its aim?

Pending the implementation of a Grand Project, could we not start with the part that is politically least sensitive but perhaps the most effective in terms of the future, i.e. scientific research and innovation? 
Part II

PROPOSALS FOR MILD TREATMENT

A COMMUNITY SCIENTIFIC AND TECHNICAL POLICY 


\section{INTRODUCTION}

In the light of the European balance-sheet, the dangers threatening Europe, and the ambitions that could be nurtured for a new development, many might be tempted to press on with a change in structure and policy. The economic war is upon us, they will say; it has replaced the military war that was the major factor in the lives of the peoples and their leaders in past history. The battalions of scientists and technicians waging this war for position in the international division of labour and for control of the salient points in economic power are similar to the battle forces of the Napoleonic wars. The United States, the Soviet Union, and Japan have unified their commands; let us mobilize Europe, let us unite, let us, too, gather our forces and commit them unequivocably to the fight since it is inevitable. Let us start by concentrating formidable powers at Community level.

We must beware of so radical an analysis. There is every reason to propose more subtle solutions because the European governments and peoples are far from prepared for a concentration of political forces.

The European is ill-prepared for vigorous treatment. He would like to believe that his difficulties are benign; he would like to hear that his crises are passing annoyances and balks at recognizing them as symptoms of deep-rooted phenomena calling for a change of mentality and effort of will. He is therefore prepared to accept local treatment, administered as far as possible by independent doctors, but reluctant to accept a vigorous all-embracing approach. Does this attitude convey sound common sense. a balanced judgement of the real significance of events? Is it a mere inability to understand the situation as it is? Is it the fear of changing from a not very effective structure to an even less relevant one? Only time will show the right answer to these questions. Europe today has need to mature.

This need to mature does not mean inaction but an effort to prepare the way by means of mild, well-tolerated treatment exemplary enough to serve as a basis for wider ambitions when circumstances are ripe. We propose that a start be made with the Community scientific and technical policy. Why? We see two justifications:

(1) One is of a practical nature. Research is a long-term affair. Decisions on preparations for the future are either electorally favourable ${ }^{l}$ or not very sensitive. They do not involve irreversible commitments; freedom of choice, in the final resort, is preserved. Whatever their difficulties, the Common Market partners should therefore find scientific and technical policy one of the fields in which co-operation will be easiest provided they do not expect the Community organization to take up a position of superiority over national policies and attempt to arbitrate, something which no one appears to find acceptable.

(2) The other reason was set out in the foreword. The driving force for evolution today is scientific research and technological innovation. The agents of mutation are no longer genetic accidents but our laboratories and schools of thought. Evolution has shifted to the domain of technology and its social implications. By guiding and organizing the research apparatus we increase our control over evolution; we also give additional scope to freedom of choice in so far as - and we must be cautious on this point - man is capable of choosing.

\footnotetext{
1 Result of opinion polls on the receptiveness shown by European public opinion to science problems (Eurobarometre, December 1977).
} 
It is because of technological innovation that a villager of 1877 would believe he was seeing a visitor from Mars if he encountered a 1977 camper's caravan with its transistor radio, television set, cine cameras, washing machine, pocket calculator, frog suit, canned foods, medicines, and airline timetables. A mutation of this kind probably establishes irreversible differentiations, ${ }^{1}$ which brings up the problem of the Third World in particularly dramatic terms. The quality and intensity of the research and innovation effort will decide Europe's place amongst the front runners of the "mutants". That is why it is a fundamental phenomenon; we shall have an opportunity to revert to these ideas later.

The whole game is being played out in an atmosphere of competition which greatly resembles the struggle for natural selection. The European has no choice: to dispute the reality of this competition is of no practical significance as his opinion will not influence that of his rivals, but he could perhaps show initiative by selecting his own ground, that of the well-being of man and of social progress where he is particularly well equipped to win.

\section{IS EUROPEAN RESEARCH COMPETITIVE? IS IT CORRECTLY ORIENTED?}

Man finds it distasteful to feel that he is dominated by Darwinian-type forces of biological selection. He feels that he is and wants to be responsible for his own evolution. This is one of the rare values that humanists, Christians, and marxists have in common; it must be admitted that it is deeply rooted in the heart of man. To forget this pressure towards the voluntary construction of a better world would be to commit a grave error in the interpretation of human nature.

It is sufficient to observe the world around us objectively: selection by competition comes into all compartments of life and more particularly into the rivalries between commercial firms and between states. One of the weapons is technological innovation. And this race is not about to slow down since, rightly or wrongly, the tendency to make up for population imbalances by technical superiority is so strong in some of the developed peoples.

Consequently, the situation in Europe cannot be judged in isolation. It must be compared with that of its main competitors - the United States and Japan; for the time being at least, the USSR only comes into the picture as regards space and armaments and does not play much of a part in the conquest of capital goods and consumer markets nor in the international division of labour, although perhaps this situation is only temporary.

How can the European effort be measured in relation to that of its main rivals quantitatively, qualitatively, and specifically with reference to the European identity, its characteristics, and aspirations?

\section{Comparison of Quantitative Effort}

Although in scientific research considerations of quality are far more important than those of quantity, the degree of commitment on the part of political decisionmakers and the economic circles involved can be measured quite significantly by the expenditure incurred.

The comparison of the budgets of the Europe of the Nine with those of its main

1 These differentiations are not relative to an individual regarded as an educable person but to man as a centre of communication with his fellows. It is the group behaviour and not the individual genetic identity that is mutated, but is this not just as serious? 
market-economy rivals reveals the harsh truth that, relatively speaking, on the basis of the money involved, Europe is in a very poor position.

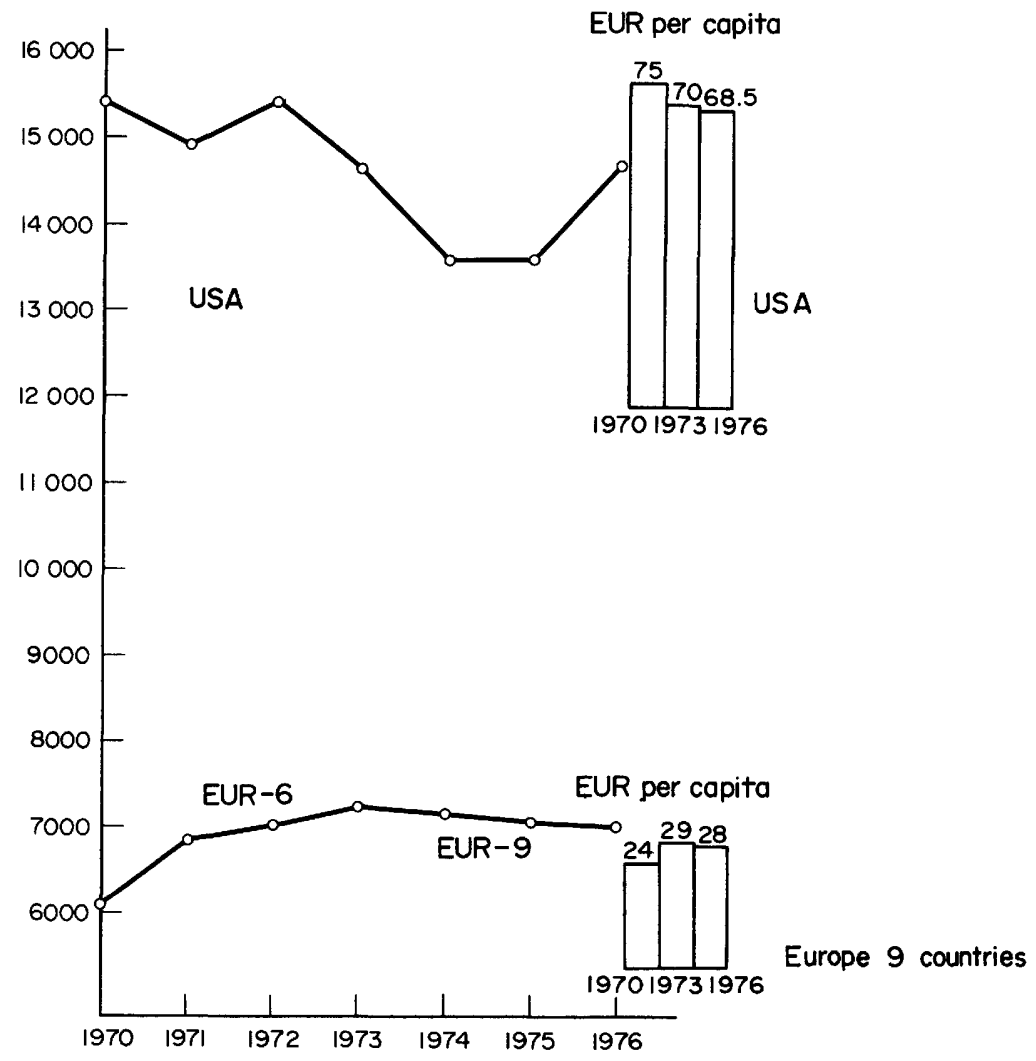

Fig. 27. Public R\&D appropriations USA/EUR-9, 1970-6. 1970 prices and exchange rates. (Source: CEC.)

Notes: (1) By using the EUR as the monetary unit it has been possible on the graphs to correct the values for the consequences of monetary erosion and consequently to make the investment effort by volume comparable for the United States and Europe of the Nine, despite fluctuations in exchange rates.

(2) 1 EUR $=0.8886708$ gram go1d $=$ US $\$ 1.32$ (in 1975). 


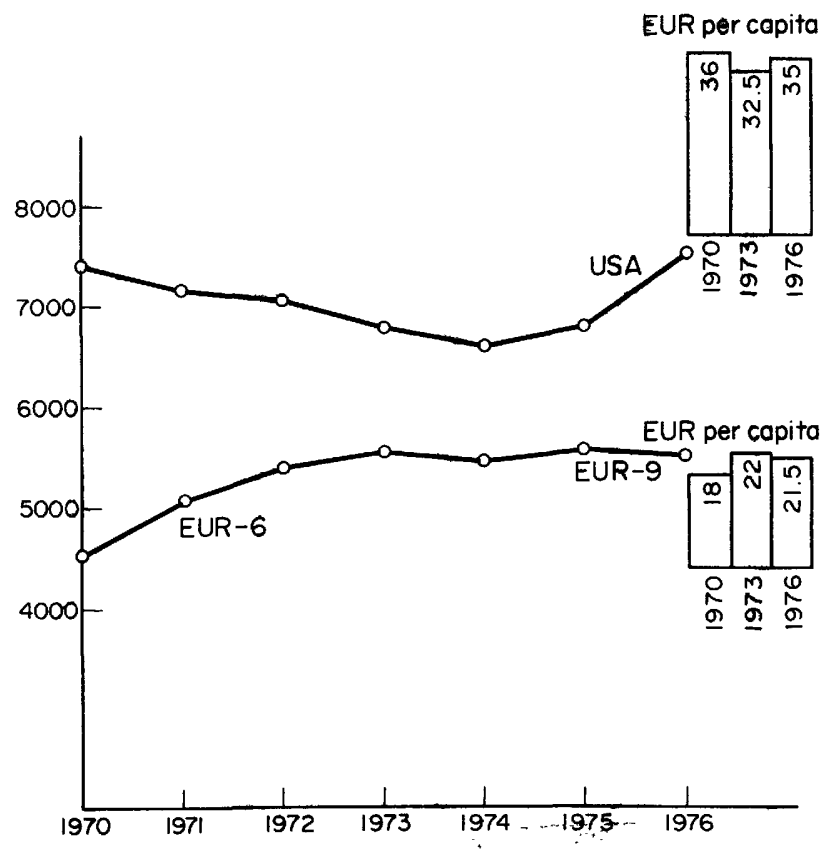

FIG. 28. Public civil research appropriations, USA/EUR-9, 1970-6. 1970 prices and exchange rates. (Source: CEC.) Notes (as for Fig. 27.)

Table 8 Comparison of budget estimates for 1977

\section{United States}

Government-sponsored research

(of which military research)

Industrial and other research estimated at

Total
Million dollars

23500

12000

20500

44000

Equivalent to $2.3 \%$ of the GDP

\section{Europe of the Nine}

Public expenditure: 10400 million EUR

$$
\text { or approximately }
$$

Expenditure by companies and non-profit-making associations: estimated at 10,000 million EUR or approximately

Equivalent to $1.6 \%$ of the GDP 
Between Western Europe and the United States the figures shown in Table 8 reflect the volume of expenditure fairly accurately as the costs per research scientist employed in Europe are today very close to the American level. As the United States has a smaller population than Europe of the Nine, the comparison of per capita expenditure is even less favourable, as Figs. 27 and 28 show. As a rough approximation, the volume of Research and Development investment per European is less than half the American level.

If budget trends in recent years and estimates for 1978 are examined, the situation is found to be worsening; the United States has been stepping up its research effort since 1976 while the Nine have been tending to cut theirs or at best to keep it constant, because of the priority given to the fight against inflation (see Figs. 29 and 30 for the American estimates).

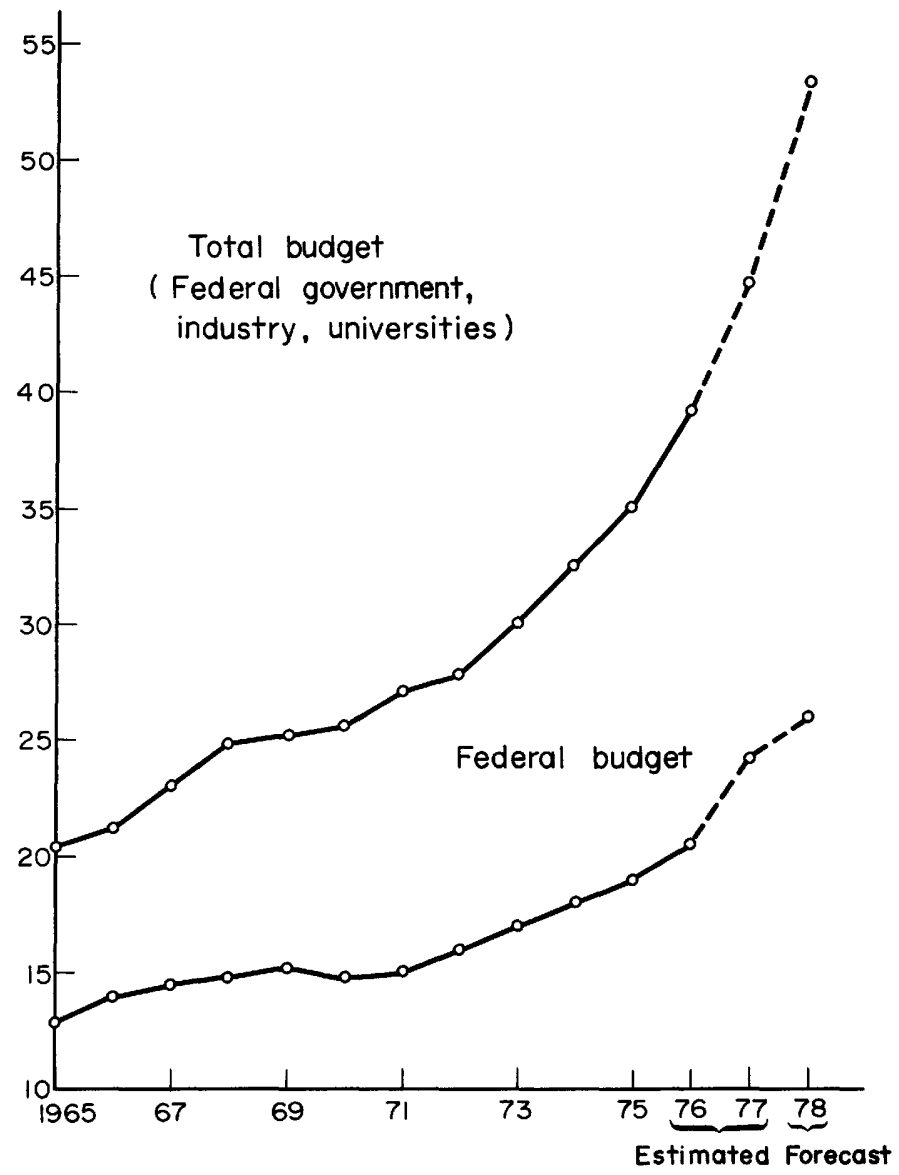

Fig. 29. United States R\&D budget (current dollars) since 1965. Equipment and operations, excluding construction. (Source: NSF, Battelle Institute.) 


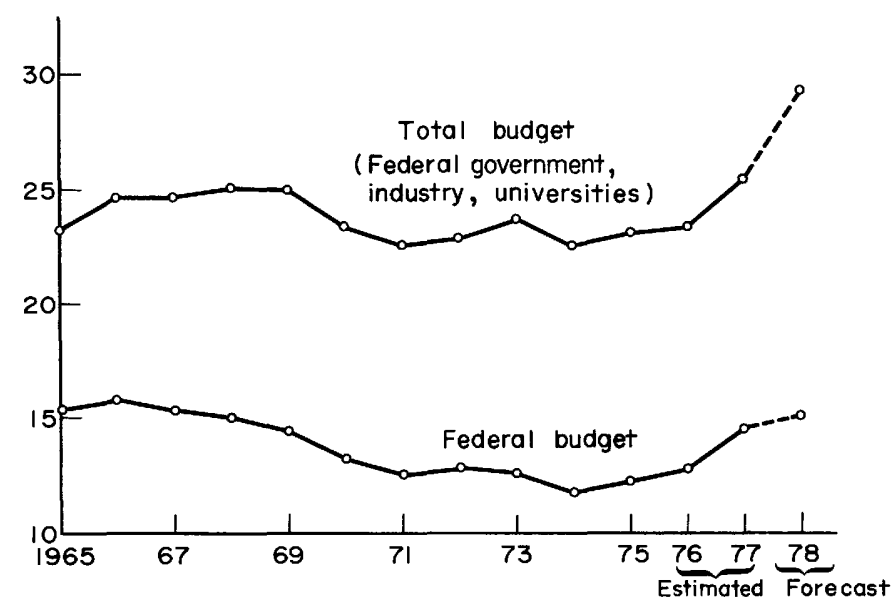

Fig. 30. United States R\&D budget (constant dollars, $1968=1$ ) since 1975. Equipment and operations, excluding construction. (Source: NSF, Battelle Institute.)

A valid comparison with Japan cannot be made on the basis of budget appropriations as for various reasons the apparent unit cost of a Japanese research scientist is very much lower than the cost of a European or American research scientist. To have an idea of the effort expended, the number of persons employed provides the best basis for comparison (Table 9).

Table 9. Comparison of the number of specialists working on R\&D

\begin{tabular}{lcc}
\hline & Japan (year 1975) & Europe of the Nine \\
\hline Research scientists & 255000 & 260 000 to 290000 \\
Research assistants & 84000 & \\
Technicians & 88000 & approximate1y 300000 \\
Other & 64000 & approximately 570000 \\
\hline Total & 491000 & 258500000 \\
\hline $\begin{array}{l}\text { Population } \\
\text { Number of research }\end{array}$ & 111000000 & $0.11 \%$ \\
\hline scientists per capita & $0.23 \%$ & \\
\hline
\end{tabular}

Sources: Japan - French Embassy in Tokyo. Europe of the Nine - Commission of the EC.

I It is, however, important to know the total sum allocated in 1975 to research and development (DIBRD). This was 2979000 million yens, or approximately $\$ 10000$ million. 
Official documents reveal two typical features of the Japanese effort. One is the very sma11, not to say non-existent, share of innovation for military purposes, and the other the speed of growth. In the five years 1971-1975, 61000 new scientists started work in Japan, a number approximately equivalent to the total research staff employed in each of the major Community countries. Japan's priorities are fairly clearly revealed by the major items in its budget appropriations: nuclear science, information technologies (space, telecommunications, informatics; envi ronment, oceanology. In the information technologies a large part is played by studies of automation and robotics to improve the productivity of industries and services.

\section{Can the Quality of European Research be Evaluated?}

A qualitative comparison is more difficult and, of course, more open to challenge. Consequently the opinions given should not be too dogmatic. However, the general agreement accorded to President Sune Bergstrom's warning justifies the following long quotation. This speech was made on 10 December 1976 at the traditional Nobel prize-giving ceremony in Stockholm. ${ }^{1}$

"The distribution of prizes amongst the various countries is an interesting reflection of the changes that have occurred at international level in the work on a research subject. A review is even more interesting this year in that a11 the prizes including the economics prize in memory of Alfred Nobel went to citizens of the United States.

"The world press has commented widely on this fact in terms going well beyond ordinary information for the general public. For example, some authors have concluded that the Nobel Foundation wished to contribute to the Bicentenary celebrations in the United States, while others saw it as a political move by the new Swedish Government. ...

"How do the changes in the distribution of the prizes reflect changes in research activities throughout the world since 1901? In the early decades of the century, the large majority of the prize winners were Europeans. Only four of the eighty-four prizes awarded in the first twenty-five years went to Americans. The number of American winners began to increase in the thirties, and no less than forty-eight of the hundred prizes awarded in the last twenty-five years have gone to them.

"Since the war the United States has received at least one prize every year, with two exceptions. Four times they have taken all three prizes for physics, chemistry, and medicine. In terms of pure probability, it is therefore hardly surprising that the literature prize - already awarded eight times to American writers in the past fifty years - and the economics prize in memory of Nobel should also go to the United States at the same time as the scientific prizes, as was the case this year.

"There are, of course, many reasons for the great predominance of American research since the thirties, quite apart from the ravages of two world wars and their numerous political consequences that have greatly hampered developments in Europe.

"In the mid-thirties, the American Government began to be aware of the importance of research for economic development, and as a result Congress voted a substantial increase in the funds earmarked for research activities by the

1 In 1976 all the Nobel prizes went to Americans: chemistry to W.N. Lipcomb; physics to B. Richter and S. Ting; medicine to B.S. Blumberg and D.C. Gajdusek; economics to M. Friedman; and literature to S. Bellow. 
Federal authorities.

"The United States opened up its lead mainly during the Second World War with the successful results of research and development work backed by military organizations, culminating in the atomic bomb, radar, antibiotics, etc. In the twenty years after the war, the experience gained led to an unprecedented development of civil research in the United States by the National Science Foundation and, in the biomedical field, by the National Health Institute.

"For a quarter of a century these efforts have put the United States in the forefront of research in many fields. Quite apart from these economic conditions, however, other factors have played a great part in America's rapid growth in the research sector and are perhaps of special interest to Europeans. Universities developed rapidly in the fifties and sixties all over the world. In many countries, starting with Europe, this development took place within the traditional rigid hierarchical structures.

"In the United States, on the other hand, the growth of university research took place in a dynamic and outward-looking atmosphere and in a form that might be termed democratic as far as research workers were concerned. Many of those who visited American institutes and attended scientific congresses after the war were struck by the natural manner in which teaching staff and students held scientific discussions on an equal footing and were surprised by the practice of entrusting young scientists at the beginning of their careers with responsibility for independent research activities within large bodies.

"The second important factor for the United States was quite simply the size of the country and the resulting high mobility - it is easy for a young scientist to find a research group or context that suits him, particularly at a time when the mobility that had earlier existed between European countries had almost totally disappeared.

"A11 these factors, combined with liberal immigration laws, made the United States a refuge for numerous scientists who left their own countries for political reasons or because of lack of support or of favourable working conditions.

"A large number of European scientists therefore emigrated to the United States especially in the thirties and forties. Some of them, and more recently some of their pupils, are to be found amongst the U.S. prize winners.

"In the past ten years, however, there has been considerable progress in Europe - as elsewhere - in the understanding and appreciation of science. The results are already evident, although much remains to be done.

"The American predominance has most probably reached its peak and it is to be expected that in the coming decades the other industrialized countries will increase their research and development potential. A pointer in this direction is the fact that one of this year's physics prize winners did much of his work at CERN, the European Nuclear Research Centre in Geneva."

Should Europeans see the moderation of his words and the relative optimism of his conclusion rather as a desire to be courteous than as holding out real hope for their future?

If, leaving basic research, we now turn to industrial research and its links with university research, the findings are not much more reassuring, as we have already seen. 
Judged on the criteria of mobility, links with the economic sector, and communication structures, the conditions under which European researchers work are on average inferior to those enjoyed by their American colleagues. As regards dissemination of innovation and its profitable exploitation, the U.S. market, which is unified and remarkably well protected among the advanced technologies, constitutes a sort of echo chamber or amplification system which is missing in the divided and compartmentalized European market. The latter seems incapable of organizing temporary protection to foster the endogenous development of certain sensitive products. These handicaps are aggravated by the development of multinational companies. As already mentioned, these companies are excellent instruments for the exploitation and dissemination of innovation, but whereas they were almost exclusively European up to 1950, now American or Japanese companies tend to predominate.

Japan has up to now been remarkably successful in combining its innovation effort with the implementation of an industrial strategy designed to concentrate its endeavours on climbing to the top of the tree in several key sectors in turn. On the other hand, the European Community has been incapable of adopting an industrial policy.

As against this, more optimistic arguments can be put forward without too much fear of contradiction. The intellectual seedbed of Europe, nurtured over several generations, is still remarkably fertile; the level of knowledge is extremely high. Whenever ambitious targets have been set and adequate material resources provided, the projects have proved successful, at least up to prototype or preproduction stage (nuclear science, aviation, chemistry, pharmacy, etc.).

These successes prove that there is a resource available. They show that all is still possible and that Europe is capable of recovery. However, if investment remains at ha1f that of its main rivals and if quality is not improved, this relative wealth will drop to the point where Europe can no longer remain competitive. This serious warning is given without reservation.

\section{Are the Aims of European Innovation Policy in Line with the} Characteristics of the European Identity and its Aspirations?

It is difficult to reply to this question because there is no declared European policy on scientific and technical research. The Commission of the European Communities handles research appropriations equivalent to less than $0.6 \%$ of the total expenditure; on this basis it obviously cannot conduct a policy. Most of the Member States have not published guidelines for their innovation effort. This lack of theoretical planning does not necessarily mean that there are no practical guidelines.

It appears consistent with market economy principles for a substantial part of the innovation effort to be carried out by industrial and commercial companies. Research and development planning is carried out at company level; this means that it is a part of the strategy of commercial operators covered by trade secrecy. Rivals endeavour to use the weapon of technological progress to surprise their competitors by launching new products and introducing more productive methods.

It is obvious that these strategic factors step up the pressure towards innovation in order to solve problems of competitiveness in the short and medium term. It is not at all obvious that the combination of these activities could cause society to evolve towards the fulfilment of projects involving better adaptation to the conditions of the social or economic environment that can be foreseen for the 
long term. That is why governments participate in the funding of research and development; they wish to attain certain objectives regarded as being in the national interest.

During the period 1938-1945 the war effort took up most of the resources assigned to applied research and the development of prototypes and preproduction models in pursuit of the aims of national defence and attainment of a self-sufficient economy. With the coming of peace it appeared that the initiative in the way of technical innovation would once again fall to private investors. In fact this has only partly been the case; in the Western industrialized countries the government's share amounts to approximately $50 \%$ of total expenditure, both in the United States and in most European countries. This 50/50 estimate, which is no more than approximate ${ }^{l}$ shows that a State scientific and technical policy accompanies, and in some cases replaces, the strategy of the private companies. Funds from government budgets go without distinction to public and private laboratories. Going to the extreme, one could imagine research budgeting deriving primarily from public funds while the work was carried out for the most part by firms or private non-profitmaking associations. Europe differs from the United States and Japan in that a larger proportion of its research work is carried out in research centres that are either state owned or under the direct responsibility of the State. Paradoxically, this situation reduces both the power of the Government to select objectives and the efficiency of the transfer of the knowledge acquired in the laboratory to those responsible for economic and social utilization of the results. We shall revert to this paradox later.

In this interaction of private enterprise and state policies, what can be said in respect of quality as regards the direction of the European innovation effort?

A look at the priorities adopted for the various programmes reveals the predominant influence of two main factors: sensitiveness to the scientific and technical mode that has come from the United States and, especially since 1973, the concern with survival.

It is difficult to affirm a European identity in the face of the American influence, radiating an extraordinary success, because Europe, culturally very close to its American daughter, is caught up in a technological and social mutation of a similar nature. The European Community could take on the task of injecting specific information as a type of hormone to protect itself against identification with the United States whose problems, as we have seen, are different at almost all the practical levels: politics, geography, natural resources, economics. The aim would not be to engage in a struggle to affirm an identity in a manner antagonistic to the United States but to throw light on and promote points that are complementary. Insufficient efforts are being made on these lines today; they appear only in isolated areas of national policies or in the course of some international co-operative projects.

Since 1973 a policy of "survival above al1" has been developing in Europe, but the serious oil threat has not resulted in any combined mobilization of material

\footnotetext{
${ }^{1}$ Innovation depends on basic or fundamental research; it then goes through the stages of applied research and applications research, followed by development, after which the mock-up, prototype, or preproduction stage is reached. The process continues with demonstration and sales promotion. It is pointless to try to demarcate strictly these various stages; they overlap and intersect, forming a continuous process with frequent feedbacks. This is why it is so difficult to agree on how to express the cost of research or even the number of research workers. However, comparisons are valid in terms of orders of magnitude.
} 
and human resources that would have impressed the rest of the world.

The effort to survive is essential, but this defensive attitude is not sufficient; it creates no enthusiasm, and experience shows that it does not rally forces. Poorly understood by public opinion, it does not prepare the way for the sacrifices that should be made today for the benefit of tomorrow. It does not encourage financial investors hostile to anything lacking in ambition and future prospects. That is why we consider it so necessary to add the idea of an offensive movement aimed at surviving to live a better life. We shall see how this idea can be taken up in the selection of priorities, but we must first try to understand why the European decision-makers appear to have little liking for scientific and technical effort. Are there reasons for challenging science?

\section{SCIENCE CHALLENGED}

\section{The Facts}

The need to make savings so as to support currencies, improve trade balances, and reduce State spending does not fully account for the fact that budget appropriations for scientific and technical research in Western Europe have remained stationary or even declined since the beginning of the 1960s. Other factors that deserve some consideration have helped to strengthen this trend. It is difficult to understand why Europe as it is today, with all the threats hovering over it, should take the risk of being outstripped by its rivals in the only specialized field where it is not serious1y handicapped - brainwork and inventive capacity.

It cannot be denied that science and technology no longer enjoy the untroubled atmosphere of the immediate post-war years.

Some scientists are concerned at the use made of their discoveries, in particular as regards the destructive power of weapons.

Public opinion is alarmed by the environmentalist movement, the sentimental force of which should not be underestimated. However, the ecologists' messages are not always properly understood; their warnings that priority should be given to safety are too frequently seen as a rejection of technological development which is identified as the cause of hazards.

After the scientific craze of the 1960 s, governments have been disappointed at the low return they have received both from the scientists themselves and from their results in the way of solving economic crises and the problems of society.

What is more, Europe is once again imitating the United States while running several years behind; this lack of initiative will eventually ruin it. The U.S. Government cut back its research and development effort in about 1970. Instead of catching it on the wrong foot and moving into the attack, most of the Community Member States have followed the fashion set across the Atlantic. However, this fashion never caught on in American industry, and two years ago its direction changed; have the Europeans noticed this?

\section{Questions}

This situation gives rise to a number of questions: 
(1) How can we learn to attribute due importance to long-term preparations? Market economies and democracies are particularly vulnerable to the temptation to live for the moment. Heads of companies have to pay great attention to their end-of-year balance-sheet, while politicians have to submit themselves frequently to the whims of the electorate. Would not one way of overcoming this obstacle be to base scientific and technical policy on organisational structures attached to the highest level of government and business and to make multi-annual budgets a regular practice? At the highest levels there is a particularly keen sense of responsibility for the future; decisions in favour of long-term investment are the most readily given. If, in addition, the public were kept adequately informed, scientific and technical policy would be expressed in terms of electoral concern. Is this wishful thinking?

(2) How is it possible to prevent the misgivings of research scientists being confused with the unrest in the universities? The latter difficulties stem from the fact that the universities are ill-suited for mass education; the phenomenon is largely independent of research.

Researchers will always be sensitive. They are by nature inclined to judge the present by what they expect of it for the future; consequently their opinions are not a matter of common sense. They must at all times fight to protect their originality; their ideas on liberty are particularly intransigent, as is clear in countries where there is not complete freedom of movements or expression.

The misgivings of research workers aré also expressed in defensive reactions. If a serious opinion poll is carried out amongst circles close to - but outside research, the corporative egoism of researchers is criticized. "Career security", it is said, "is of greater interest to them than their duty to society". "They work to satisfy their own curiosity rather than to serve others whose future depends on their work."

This might appear a mere extravagance of language that is difficult to understand and still more to accept, but unfortunately it does express the true feelings of those who are responsible for formulating political and economic decisions. ${ }^{1}$ When a research centre has gone through a crisis and when the crisis has been overcome by creating public awareness - the history of the Ispr Joint Centre provides an example - it is extremely difficult to erase the memor of the difficulties from the minds of observers.

Is it not up to researchers themselves to come to grips with this situation and examine its foundations? Important movements are afoot to study the responsibility of scientists to society; should they not be encouraged by demanding that all aspects of responsibility be taken into account, including the immovable constraints arising from the economic environment?

(3) What should be the response to the attacks of those who believe technology to be dangerously extravagant or who regard technological development as contrary to the interests of man? Two arguments are readily developed; they are heard quite frequently in intellectual circles and amongst members of the liberal professions. They encourage public opinion to reach disparaging judgements on scientific research; they provide decision-makers with justification for cutting budget appropriations for research and development.

1 opinions of this kind are expressed both in the West and in the East. 
Some consider that technology is coming to the end of the easy production stage; the richest veins of science have been exhausted, and to exploit a lower grade of ore the sums to be invested are too large in relation to the expected yield.

Others consider that technological development has been too fast; it is no longer progress, but threatens to destroy the equilibria of the living world. It does not improve man because it proposes ways of life that cut him off from his cultural roots.

Should not scientists and technologists encourage discussion on these matters? They are serious; in some respects they raise real problems which are not unconnected with the concerns expressed in the first two parts of this study.

To respond with adequate information it would be necessary to bring the current situation of science and technology to the knowledge of all in a suitably drafted form without using the jargon that makes communication so difficult. This is not the purpose of this study, and consequently I merely refer the reader to the following list, obviously not exhaustive, of the scientific specialities that at the present time hold out great hopes for the future.

The following are fields in which major technical breakthroughs are to be expected in the next thirty years (with no claim to be exhaustive):

\section{Energy}

New sources: solar, geothermal, wind, waves, etc.

Hydrogen (transport, storage).

Nuclear (fast neutrons, breeder reactors, fusion).

Coal: gasification, synthetic oils, new mining and transport techniques, etc.

Bituminous shale.

Bio-energy .

Energy conservation: insulation, recycling, etc.

Use of lasers as local sources of energy, fusion, transport, regulation, etc.

\section{Oceans}

Mining of the ocean bed (mineral nodules, etc.)

Mining of the continental shelves.

Aquaculture and photosynthesis in a marine environment.

Desalination of sea water.

\section{Space}

Applications for telecommunications, broadcasting, television, and data transmission.

Applications for remote sensing.

Meteorology.

Navigation aids.

Scientific experiments in space.

other (solar energy, production of extremely pure products, etc.)

\section{Preservation of the ecology, conservation of natural resources}

New recycling techniques applied to industrial and household waste, precious metals, etc.

Biodegradation and bioregeneration techniques. 
Antipollution devices at source (vehicles, factories, etc.). Systems analysis applied to the cycles of scarce raw materials, pollution study, etc.

\section{Understanding of major natural phenomena}

Seismology, vulcanology, meteorology.

Theory of the earth's tides, tectonic structures, etc.

Climatology, study of solar tides.

Study of the phenomena that protect the upper atmosphere and the ionosphere. Theory of atmosphere/ocean exchanges, global energy balances, etc.

Monsoon analysis and prediction.

\section{Life sciences - biology, medicine, agronomy}

Development of recent acquisitions of biology (molecular biology, genetics, enzymology, etc.).

Virology, immunology, etc.

Animal and plant hybridism.

Tropical agriculture.

Emergence of the bio-industries (pharmacology, nutrition, biological synthesis products, etc.).

Evolution of medicine under the influence of micro-engineering, model building, computers, electronics, etc., and as a field for the application of biological advances.

\section{Information technologies}

Application of new materials and components: glass fibre, lasers, microwave and opto-electronic components, high-speed macro-memories, highly integrated circuits, holograms, etc. Microprocessors; computer networks.

Artificial intelligence, robotics.

Automation of work in the services sector and office work.

Teleconferencing, electronic mail, facsimile reproduction, teletypesetting, videophones, etc.

Audiovisual techniques (video-discs, tapes, cartridges, etc.)

\section{Transport}

Supersonic and/or low noise aircraft.

New levitation devices (air cushions, magnetic fields, etc.).

Systems analysis applied to public transport, traffic control, etc.

Application of electronics and computers to the motor-vehicle.

New safety techniques.

Multimode urban transport systems.

\section{Organization - planning - social life - communications}

Scientific study of social organizations.

Applications of systems analysis to the study of regional planning and housing (humanization of the urban environment, optimization of the cost of sites, construction and maintenance, etc.).

Creation of new economic indicators expressing the degree to which human requirements are satisfied, the quality of life, etc.

Study of economic phenomena (inflation, currencies, etc.).

Study of procedures to combat unemployment.

Modelling of resources problems (population, nutrition, energy, raw materials, 
etc.) and development of forward studies based on scientific methods and computer facilities.

Progress in sociology, psychosociology, political science.

Use of tools (mathematics, computers, etc.), to aid decision-making.

Studies on new methods of education, teaching, learning, etc.

Application of statistical analysis and computers to human sciences, historical studies, linguistics, law, etc.

Tools for the machine translation of languages.

New man-machine communication methods (speech recognition and synthesis, automatic document reading, etc.).

A point-by-point examination of these special subjects would lead to the following conclusions, which we ask the reader to take on trust:

(1) It is incorrect to say that science has exhausted its most fruitful resources. On the contrary, we are experiencing the emergence of the "life sciences"l which are concerned with the action of micro-energy phenomena. These life and information sciences can be studied by small teams, and yet most probably herald new and far-reaching developments in a wide variety of applications at low cost.

(2) Another very fruitful area is multidisciplinary research which brings together several special subjects. Examples are the combinations of electronics, data processing, applied mathematics, and health techniques; of biology and chemistry; of mathematics, systems analysis, data processing, and the human sciences, etc.

(3) At the present stage in human development, with the 8 to 12000 million people that will populate the earth in the next century, only technical progress can counter the genuine threats of imbalances. The solution cannot be to stop short; this would be equivalent to standing in mid-stream in the most vulnerable position. Nor can we retrace our steps, however rosy (and this is open to discussion) the past may appear. The only course that offers any hope of providing a decent life for such a large population is to make rapid progress in numerous fields: nutrition, new sources of energy, better protection of the environment, conservation and recycling of scarce resources. A new surge forward in scientific knowledge and correct application of technical innovation are the only ways of attaining this.

To bring this home to public opinion, should not scientists devote much of their time to information, education, communication of their knowledge in terms that can be understood by all? A technological breathing space, which would deliberately delay practical utilization of scientific results, would run counter to the humanitarian intentions of those who advocate it, as it would aggravate the crisis caused by the population explosion and the deterioration of the environment. How can this be put across?

(4) What reply should be given to those who advocate marking time so as to leave the financial burden of innovation to our economic rivals, later selecting

1 The term life sciences will be used on several occasions in this study. It applies to those sciences which study living systems in both their biological and their societal forms (societies of insects, human societies, individual and social patterns of behaviour) using systems analysis and modelling. 
from their results those which would be most useful to us? This apparently intelligent economic calculation conceals a tragic error. To reveal this error, researchers, innovators, and manufacturers have no arguments to fall back on other than their own experience, which in part is impossible to put across. One must have had firsthand experience of the ups and downs of the competitive struggle for innovation to realize that it is very difficult to jump on a moving train. This is not merely intuition acquired on the job. It is a fact that can be expressed in specialized technical language, case by case, and above all in econometric terms. However, this specific technical language inhibits communication with those who have to be convinced, the man in the street who reflects public opinion, the mass media which form that opinion, and political decision-makers who are distrustful of specialist vocabulary. Perhaps examples will be sufficient to make the point. Past experience with Japanese electronic watches, steel, and shipbuilding, with American computers and electronic components demonstrates more convincingly than any talk that a place on the rungs of the ladder of the international division of labour are hard won and that it is very difficult to dislodge those who gain the first foothold in markets which they have won by their own pioneering efforts.

In brief, there is no justification for rejecting the scientific and technical research effort.

(1) The source of technological development has not dried up and drawing on it is no less rewarding now than in the past. ${ }^{1}$ On the contrary, the prospects offered by the emergence of the life and information sciences and of multidisciplinary research are particularly well-suited to the European bent.

(2) Everything militates in favour of a policy reflecting initiative and pioneering spirit. By taking the offensive, we avoid being left behind, sometimes with no hope of catching up; we oblige others to follow us and we preserve our liberty.

(3) There is no future in deliberately bringing scientific progress to a standstill and blocking innovation.

These conclusions are not derived from theory but from an analysis of the facts. The author would have been very happy to propose a method that is less costly, in terms of the sacrifices to be made, to prepare for the long term at the expense of the short term; he would have liked to invent a shortcut avoiding the need to run the full distance. Unfortunately, facts are more compelling than desired. It is necessary to learn once again to relish research, to associate it with a project, and to select priorities.

\section{The Gap Between the Assessment of Intellectuals and Public Opinion}

An opinion poll carried out under the auspices of the Commission of the European Communities, following a proposal by Professor Prigogine, ${ }^{2}$ has shown that European public opinion is more or less unanimously in favour of scientific research. Faith in the virtues of science as an instrument for human progress is

I It must be acknowledged, however, that with the increasingly cumbersome administrative structure of research and the high level of international competition it is becoming increasingly difficult to acquire superiority in the order of knowledge.

21977 Nobel prize for chemistry - member of CERD. 
deeply rooted in the minds of the people, whatever the age, background, or nationality of the Europeans concerned. At the same time, however, a majority opinion is expressed in respect of dangers created by technological innovation. This desire for research to continue, heavily subsidized by the states and receiving substantial aid from the Community, contrasts strangely with the scepticism expressed in some intellectual circles and the lack of interest shown by political decision-makers. Who would dare to say in this instance that public opinion is wrong? In that case, why regard it as of such little significance?

\section{AN ATTEMPT TO DEVISE A STRATEGY OF PRIORITIES}

As regards research objectives, the desire of any political authority, probably shared by public opinion, is to determine a limited number of priority fields. The task would be easier if it were possible to eliminate once and for all exhausting and constantly criticized choices between medical research, progress in agriculture, in data processing, telecommunications and electronics, new sources of energy, and a hundred other varied subjects, all supported by pressure groups. Unfortunately, the development of the technical society is accompanied by a widespread growth in very varied fields, none of which can be ignored. To accept this complexity is the first useful step in thinking about science and European innovation.

The European Community is a vast consumer market, second only to the United States in quality and quantity. There is an immense diversity of traditions, trade patterns, and requirements. It would, therefore, be wrong to make choices by exclusion. The Europe of the Nine cannot simplify by substraction; it must conduct scientific research in all specialized fields, at least from a defensive and vigilant position if not from an offensive position of creative originality.

A scientific and technical research policy cannot ignore the diversity; it will, therefore, have to support a minimum effort in all specialized fields. In particular, it will, at national or community level, have to devote sufficient funds to basic research, which is essential for good-quality higher education and is the source of all innovation.

It is, however, necessary to go still further. Without being diverted by the storm of protest that any proposal of this kind is bound to provoke, we could try out the following procedure for selecting priorities.

(1) Some subjects hold out rich promise of innovation potential because recent discoveries in the area of fundamental knowledge have opened up further possibilities of applications in the near future. They may be said to offer virgin land for man to conquer. In 1978 this applies to everything concerning the life sciences and information technologies.

(2) Some subjects are very critical to our economic survival.

(3) Another set of priorities is relevant to the aim of ensuring a better life.

Before clarifying the content of these three categories of objectives by going into greater detail, it may be advisable to take an overall view. This is summarized in Table 10. 
Table 10 Contents and criteria of the priority fields

\begin{tabular}{|c|c|c|}
\hline $\begin{array}{l}\text { Category of } \\
\text { objective }\end{array}$ & $\begin{array}{c}\text { Content } \\
\text { in order of importance }\end{array}$ & $\begin{array}{c}\text { Major criteria } \\
\text { justifying priority }\end{array}$ \\
\hline $\begin{array}{l}\text { I } \\
\text { To profit from the } \\
\text { upswing in the } \\
\text { life and infor- } \\
\text { mation sciences }\end{array}$ & $\begin{array}{l}\text { 1. Biology } \\
\text { 2. Applications of } \\
\text { mathematics, systems } \\
\text { analysis, statistical } \\
\text { analysis, and data } \\
\text { processing to futur- } \\
\text { ology and } \\
\text { decision-making } \\
\text { 3. Social sciences }\end{array}$ & $\begin{array}{l}\text { Resources required are moderate } \\
\text { Guarantee of success provided } \\
\text { by the enormous European cultural } \\
\text { heritage } \\
\text { Relevant scientific research on } \\
\text { the verge of decisive progress in } \\
\text { methods or results } \\
\text { Specialized subjects likely to } \\
\text { promote new industries with a } \\
\text { low consumption of scarce materials }\end{array}$ \\
\hline $\begin{array}{l}\text { II } \\
\text { To organize sur- } \\
\text { vival }\end{array}$ & $\begin{array}{l}\text { 1. Energy } \\
\text { 2. Improvement in ser- } \\
\text { vice productivity } \\
\text { 3. Competitiveness of } \\
\text { agriculture and } \\
\text { industry }\end{array}$ & $\begin{array}{l}\text { Reduction of economic dependence } \\
\text { Reduction of costs and mastery } \\
\text { of complexity } \\
\text { Innovations specific to the } \\
\text { European identity (shortage } \\
\text { of space, vulnerability of the } \\
\text { environment, shortage of raw } \\
\text { materials) }\end{array}$ \\
\hline III & $\begin{array}{l}\text { Establishment of recip- } \\
\text { rocal economic links } \\
\text { with the developing } \\
\text { countries }\end{array}$ & $\begin{array}{l}\text { Stimulation of Europe's economic } \\
\text { growth by the development trends } \\
\text { in countries that are today } \\
\text { economically poor but are rich in } \\
\text { real requirements }\end{array}$ \\
\hline a better life & $\begin{array}{l}\text { 1. Information techno- } \\
\text { logies } \\
\text { 2. Development of } \\
\text { economic freetime } \\
\text { activities }\end{array}$ & $\begin{array}{l}\text { Meeting specific needs of highly } \\
\text { industrialized countries } \\
\text { Activities in which the value } \\
\text { added by brain power is high } \\
\text { and the consumption of scarce } \\
\text { materials low } \\
\text { The emergence of new consumption } \\
\text { models }\end{array}$ \\
\hline
\end{tabular}

In Table 10 participation in the progress of the developing countries comes under both the "survival" and "better life" headings. There is probably no need to justify this. In actual fact, the three categories are inseparable. The life sciences will supply the keys for the new innovating industries and for the improvement of social life, whereas "survival" is obviously an essential condition for a "better life". The author believes, however, that the fight for survival will never be truly won unless the European peoples ean be given the hope of a better life.

Means of Profiting from the Upswing in the Life Sciences

Reference has already been made to the emergence of the life sciences, which are concerned in particular with the nature and behaviour of animate beings. At elementary leve1, these sciences are concerned with phenomena controlled by low 
energy changes, unlike the natural sciences, of which physics and chemistry are the major branches. This concept of energy is extremely useful in understanding their special nature. When important mechanisms are triggered by very low energy transitions, as is the case, for example, in genetic memory or the functioning of the nerve cel1, the dominant phenomena are no longer governed by global behaviour but by fluctuations ${ }^{1}$ This accounts for the fact that the life sciences cannot be reduced to simplifying apparently immutable laws like the mechanics of celestial bodies or the physical chemistry of minerals, but are sciences of change, complexity, and interreactions; the laws of thermodynamics are, of course, observed but do not in any way help to predict individual modes of behaviour which are, by their very essence, uncertain. What is involved here is indeed a combination of change and necessity; we shall have an opportunity to revert to the conclusions that can be drawn from this concerning the structure and mode of action of scientific research.

Biology is the first expression of these sciences of complex energy microphenomena but, by extension, it is not artificial to include among them the human sciences that also embody systems characterized by complexity of interreactions and by change. For long a tool of the physicist, mathematics is starting to tackle the description and modelling of these phenomena, which involves it in a radical transformation. This leads to a development of tools and concepts that hold out hope of very great progress in fields that up to now have been restricted to observation.

There is every indication that recent biological discoveries hold out hope of applications of enormous scope. Prospects are comparable to those offered by physics at the beginning of the century. The breakthrough must be followed up, and it would be all the more unpardonable for Europe to show no ambition to succeed here since the financial resources called for are relatively modest compared to those required for other fields of research such as high-energy physics, the economic and human impact of which are less obvious.

Incidentally, it is extremely fortunate that these life sciences - or sciences of change and complexity - are holding out such excellent prospects at the very time when the post-industrial society is becoming bogged down in an excess of complexity and a failure to understand change.

Generally speaking, the advent of the life sciences will once again make sma11, highly motivated teams efficient; the large laboratory organized more or less like a factory is now valid only in exceptional circumstances. Multidisciplinary organization will prove most fertile. If knowledge is to progress, calls must be made on many disciplines: mathematics, model-making, scientific calculation, electronic and optical instrumentation, chemical analysis, psychology, sociology, etc. The best results will, therefore, be obtained by ad hoc operational groups, task forces set up to organize "Laboratories without walls" cutting across organic research units so as temporarily to bring together experts working in different disciplines. This meeting between basic and applied researchers of various origins, who will have to learn each others' languages and pool their knowledge, will not come about spontaneously. It must be catalysed. If this catalysis is done judiciously, enthusiasm, discovery, and invention will spring forth from stocks of knowledge that are barren in isolation. We shall come back to the structures required for the catalysis of scientific and technical research.

1 Fluctuation means the sudden appearance of an unlikely phenomenon constituting a significant departure from the normal. This anomaly can have appreciable secondary effects, e.g. cause genetic mutation or disturb a delicate structural balance. It is not generally possible to predict a significant fluctuation, to evaluate its probability, or to imagine its consequences. 
Is there any need to say that Europe, with its high population density, the communication facilities that geography and history have provided for its peoples, and the wealth of its cultural heritage, appears remarkably well placed to succeed in these disciplines? There are still many obstacles to be overcome, however. These include the individualistic nature of the European research scientist and his reluctance to accept the constraints of the "1aboratories without wa11s"; the gulf in Europe between scientific discovery and utilization of the results by industry; misunderstandings regarding the concept of multidisciplinary research; and the remoteness of research in social sciences from the real problems of 1 ife in industry and the public service and the tendency of such research to resort to intellectual concepts that are difficult to put across to non-specialists and are perhaps pointless.

Giving priority to these special subjects means providing the means to overcome all these obstacles, which will not be possible without allocating extensive human and financial resources.

\section{Organization of Economic Survival}

\section{(1) New energy sources and energy conservation}

Whatever standpoint one adopts, energy will be in the forefront. The main factors justifying this priority include:

(a) Dependence resulting from the cost of oil imports.

(b) Growing scarcity (20 to 50 years) of liquid and gaseous fuel resources with a low cost of extraction, and the vulnerability of their political environment.

(c) The Community's specific requirements: high agricultural productivity, automation of production, automation of the services sector, use of low-grade ores and production of substitute products, pollution control, and recycling of scarce materials. In the present state of technology all these requirements can be met only by a high level of energy consumption.

There are three further reasons for urgently undertaking extensive research and studies in the energy sectors:

(d) the fact, that according to past experience, for a new energy source the lead time elapsing from the design stage through the model stage to large-scale exploitation is extremely long, approximately 15 years in the most favourable cases or otherwise 25 to 30 years;

(e) the need to overcome ancillary problems, such as the deterioration of the countryside and the human environment by the extraction, production, transport, or large-scale conversion of energy;

(f) the need to find ways of allaying, by demonstration and information, public concern about the relative dangers, which the layman cannot assess, of the consequences of an energy shortage, of pollution by hydrocarbons and waste, and of the risk of accidents in nuclear power stations.

This energy problem continuously emerges as the main physical factor in the minds of all those who feel committed to the future. CERD provides good evidence of this concern. A specialized working party has been entrusted to Professor Della Porta. The first chairman of CERD, Professor Casimir, has demonstrated some of the risks 
to which a civilization based on excessive consumption would be exposed. Professor Meyer, a member of CERD, has been commissioned to carry out a study on a model for a low-energy-consumption society. Its results can be compared with those reported by the US Commission on Energy Conservation: Figs. 31 and 32 show the results. They indicate that average per capita consumption and total consumption are increasing at a greater or lesser rate depending on the hypotheses adopted, even in cases where there is a strong political resolve to make maximum savings in energy consumption.

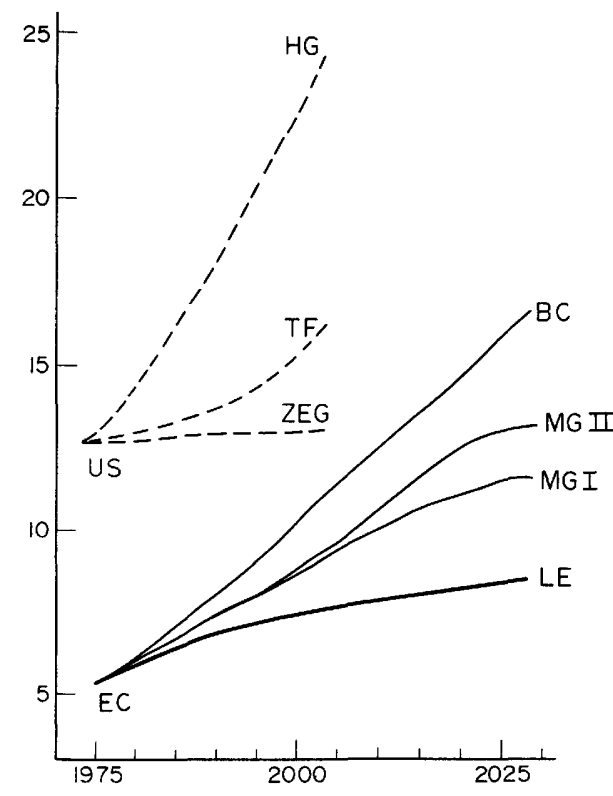

Fig. 31. Scenarios for the development of the per capita energy demand in the EC, 1973-2025, and the US, 1973-2000. EC: base case scenario. MGI, moderate growth scenario I. MG II, moderate growth scenario II (with stabilizing population). LE, low-energy scenario. US: HG, historical growth scenario. TF, technical fix scenario. ZEG, zero energy growth scenario.

These conclusions show that with the knowledge we have at present and with our current outlook we are unable to devise a society which would be highly productive in agriculture, industry, and services and at the same time have a low energy consumption.

In 1971 the average annual per capita energy consumption was 11.5 tce in the United States and 4.7 tce $^{l}$ in Europe. It has increased continuously since that time, although there was a substantial slowdown after the 1973 events. It would be useful to study the model of a society that would preserve the existing standard of living while reducing average energy consumption in the industrialized countries to 5 tce per inhabitant per annum. At the present time, however, we are unable to imagine practical ways and means of achieving this result.

\footnotetext{
1 tce $=$ tonnes coal equivalent
} 


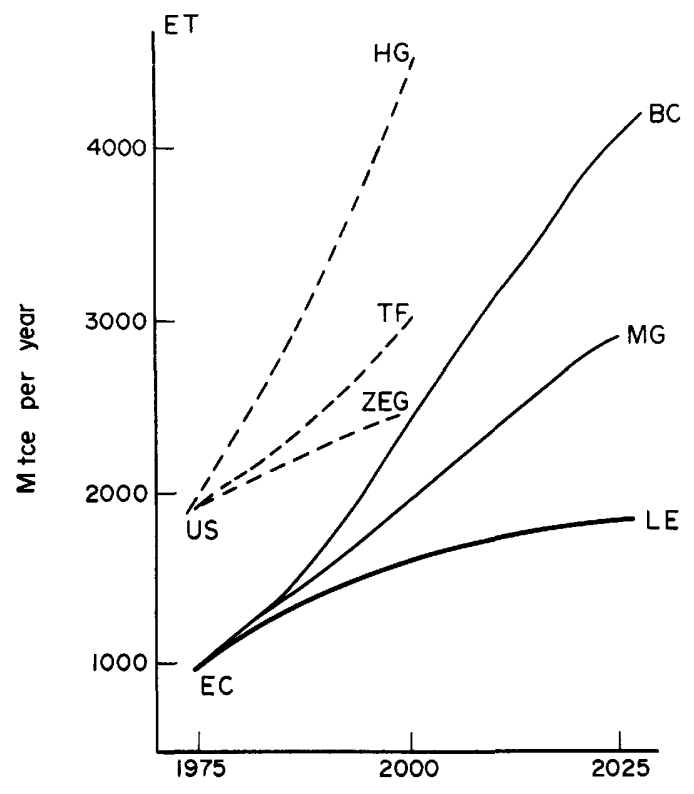

Fig. 32. Scenarios for the development of total energy demand in EC, 1973-2025, and in the US, 1973-2000. EC: BC, base case scenario.MG, moderate growth scenario. LE, low-energy scenario. US: HG, historical growth scenario. TF, technical fix scenario. ZEG, zero energy growth scenario.

To establish a genuine low-energy-consumption society it would probably be necessary to go through a stage of adjustment to new consumption models by means of a shift from quantity to quality, a step which is bound to be progressive and which implies the existence of a quality supply to replace a quantity supply. This problem is tackled elsewhere.

If priority is given to energy production, it is necessary to step up the effort devoted to all types of new sources, more particularly nuclear energy with special attention to safety. 1 The greatest danger would lie in postponing full-scale experiments in the nuclear programmes then finding after several years that economic activity was slowing down for lack of energy. This would be followed by rapidly trying to make up lost ground under the pressure of public opinion by suddenly speeding up the installation of nuclear power stations without adequate preparation. If it has an insufficient mastery of the problems connected with the production of nuclear electricity, Europe might well find itself crippled or completely dependent on experiments conducted by the United States. Unlike Europe or Japan, the United States has no driving need to master nuclear energy as it has a wealth of fossil fuels, in particular coal and bituminous schists, and is able to rely on political, and possibly military, power to control oil sources outside its frontiers. Nevertheless, it is clearly in President Carter's interest to take decisions aimed at energy conservation and the accelerated development of new sources.

${ }^{1}$ Although it appears contrary to common sense, the real safety problems are only finally solved once the operating stage is reached, as only then is the full extent of the difficulties revealed. This does not, of course, mean that all the preparatory precautions should not be studied and, in the case of nuclear energy in particular, prior consideration given to the risk of plutonium proliferation. 
The post-industrial civilization is a service civilization. We have already seen (pp 59 and 60) that jobs in the service and data-processing sectors will shortly account for more than half the working population in America. If the total productivity of the industrialized nations is to be improved, two lines of research must be carried out simultaneously:

(a) A study to gain an understanding of the origins of these phenomena and ascertain whether it is necessary for so many men to work without ever touching objects which will be produced or consumed. Is this a normal situation in a post-industrial civilization or is it an unrestrained eruption of complexity?

(b) Regardless of the results of this study, continuation of research and development and the organization of demonstrations on the simplification and automation of office working, ${ }^{1}$ local and remote data processing, etc.

There are very good prospects of a huge future market for these new techniques which come within the family of information technologies. Either Europe will design and produce them and become a major exporter, or it will have to import them and its balance of payments will suffer greatly, or it will reject this trend for fear of the social consequences, and overall it will then become less productive than its main rivals. How will it be able to live?

This introduction of new techniques to increase productivity in the services sector will have to be accompanied by appropriate studies to ensure that we are not caught at a loss by the social problems they will cause. Massive redundancies far exceeding previous estimates are to be expected in the next twenty years; it is therefore necessary to devise alternative activities or plan the organization of a life in which work will not play its usual part. This brings us back to the priority that must be given to the question of jobs and unemployment.

\section{(3) To increase the competitiveness of agriculture and industry}

No attempt will be made to describe all the efforts to be made sector by sector; we shall merely consider the criteria resulting from the identity of Western Europe.

It emerges from what has been said above that Community agriculture and industry should excel in all applications of scientific or technical knowledge where one or more of the following factors are relevant:

(a) limited space available; high population density;

(b) savings in energy and raw materials;

(c) protection of man and nature against pollution;

(d) high cost of labour.

A study should be carried out on the application of these criteria, which are more specific to Europe than to the United States and the Soviet Union; in this respect Europe has much in common with Japan, normally its main rival.

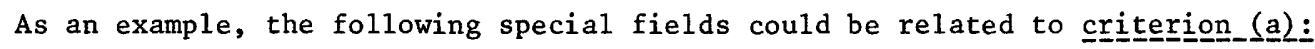

High-speed cheap transport, both urban and inter-city, over short and medium distances.

I Burotics: neologism meaning automation of office working. 
Intensive crops (agricultural production with a high yield per unit of area cultivated rather than per person employed.

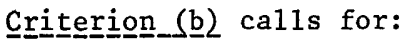

A high level of development in the recycling industries (water, non-ferrous metals, organic substances, etc.).

Possible specialization in durable and repairable industrial products.

Heavily insulated heat-treatment units controlled to be operated on minimum waste cycles:

Production from low-grade ores.

Substitution products.

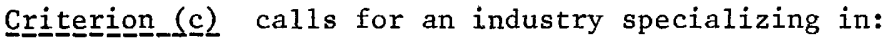

Pollution control (urban, motor vehicle, industrial).

Noise control.

Water regeneration.

Critererion_(d) necessitates considerable effort:

To automate industrial production with the gradual elimination of all human tasks that are arduous, dangerous, or without job satisfaction (automation, robotics, precision engineering, etc.).

To organize work so as to minimize arduous or dirty work (e.g., sorting and packaging of household waste, non-woven fabrics, etc.).

To establish highly productive industrial units of small dimensions (300400 people) where man-machine relations would allow account to be taken of initiative and interest.

To experiment with methods for the decentralization of power and participation in decision-making.

The launching of special projects of this type calls for a major research and development effort, a technical standardization policy, and in some cases the adoption of a policy to restrict imports. For example, it would be unacceptable to ban a European paper mill or cement works from discharging waste into the atmosphere or into water and at the same time to expect it to compete with an outside producer not subject to the same restrictions.

It is clear that the application of these criteria to research and development objectives should be preceded by an overall study of the systems analysis type, leading to proposals for scientific and technical action programmes and the preparation of ancillary measures, in particular as regards standardization. There would be nothing more dangerous than to act on emotional grounds without first predicting the direct and indirect consequences of the changes. 


\section{A Better Life}

For a better life it is first necessary to regain confidence in the future, to revive the hope of improvement, and to learn again that mankind can progress with all men jointly responsible. In practical terms, this aspiration to progress is reflected in development objectives which, as we have seen, can no longer be based on the growth of material goods for the peoples of the industrialized world.

In our study of the European identity and its interdependence with the identities of other regions, we believe we have detected three main poles of development:

(a) Development of trade with countries in the process of industrialization.

(b) Improvement of communications between men, dependent on the development of the information technologies.

(c) Development of the personality of the individual of small groups by the growth of "productive free-time activities".

How can scientific research help to promote these three poles of development?

\section{(1) The development of trade with countries in the process of industrialization}

Scientific and technical research can be no more than one of the many ancillary instruments in a major political venture of this kind. But however modest its relative position may be, its contribution is far from negligible.

In preparation for decisions, mathematical models could be used to help understand the problems arising and for co-ordination between the partners. In the early implementation stages, statistics and model construction would play an important information role for the partners. New socio-economic indicators would have to be devised.

A number of subjects for applied research, on which little is being done today, would emerge from the development of the tropical countries. They relate in particular to agriculture and nutrition, nature conservation, new town planning models, solar energy, etc. Other research topics include the transfer of technology, project studies, the testing of prototypes for small-scale manufacturing units to avoid spreading the disadvantages of mammoth industry, etc. New educational and vocational training methods should be proposed.

Socio-economic research would be necessary to avoid as far as possible falling into the trap of solutions that would be interpreted as, or felt to be, forms of neocolonialism. Long and difficult studies will be necessary in order to propose systems having free and reciprocal links between the partners, but surely the end is exciting enough to ensure that the obstacles that appear insurmountable today will gradually be removed.

\section{(2) The development of information technologies}

In this study there has been much talk of the productivity of industry and services. The new information technologies are at the root of these increases in productivity. Later in the text there will be frequent reference to "productive free-time activities". These can be developed only if a high level of culture and education can be made universal; this will be possible only by extensive use of the various new information technologies. The transfer of know-how to the 
developing countries will be largely based on communication techniques. Information may therefore be likened to the intersection at which all roads meet.

There are three particular areas in which research and development should be carried out. These are given below in increasing order of need:

(a) Activities concerning the support industries proper (telecommunications, electronics, computing, etc.) 1

(b) Activities relating to the applications of the new technologies in various disciplines (medicine, law, administration, linguistics, burotics, robotics, aids for architecture).

(c) Activities helping to predict the social and economic consequences of applying these new technologies (effects on life style, distribution of power, personal freedom, civil liberty, working hours, working conditions, education, etc.).

The European Community must take steps to harmonize legislation on this subject (to avoid, for example, the creation of computer havens ${ }^{2}$ in the same way as there are tax havens or to prevent excessive disparities in the provisions to protect private life, etc.) and to introduce standardization, especially as regards telecommunications, etc. It should also ensure that no excessive inequalities arise in the development of the applications of the information technologies, as this might result in the emergence of new underdeveloped areas.

The outlay by the various Member States and the resources available to the Commission of the European Communities to prepare for the future of the information technologies are totally insufficient; all the experts agree on this point. As regards highly integrated electronic components and microprocessors which it is unanimously agreed will be the nerve cells of tomorrow's society - it is by no means certain that a European company will figure in the five to seven companies in the world in which their production will be concentrated.

In many cases, governments have been deluded by the money they have lavished on manufacturers engaged in an almost hopeless struggle (with trade positions and the state of the art as they are present) against the stranglehold of the most powerful American multinational group. ${ }^{3}$ These sacrifices have concealed the inadequacy of the overall R\&D effort, especially with regard to small-scale equipment and applications holding out very much greater prospects of success.

In the context of the information technologies and their applications, Europe emerges as a curious mixture of competence, partial success, and underdevelopment.

\section{(3) The development of productive free-time activities}

It may seem a curious paradox to draw attention to the risk of impoverishment and at the same time to urge a study of free-time activities. Are we rich enough to plan to reduce working hours?

We have already given a list of free-time activities. (see p. 56). Each line on this list calls for careful study, if not actual research, to resolve such questions

\footnotetext{
I See page 61: Support industries.

2 Geographical areas where the excessive concentration of information would be uncontrolled.
}

3 IBM - see 1977 OECD study. 
as the transmission of knowledge, the necessary cultural level, and educational facilities.

A number of studies will be required to prepare for the increase in free time and ways of using it, as it could be very dangerous to declare this as an aim of civilization without a theoretical understanding of the consequences, a forward calculation of their economic implications, and a comparison of experiments carried out on a small scale. However, as we have already said, prudence counsels daring in this respect.

This list of priorities does not coincide with the priorities actually included today in national and Community research programmes.

There is not, however, an excessive gap between them if the armaments development effort is disregarded. For Europe, it seems right to recommend heading straight for the goal and acknowledging that the future will depend on economic confrontation and social hope. Consequently the major part of the resources available must be devoted to these objectives. However, it would probably be too easy, and somewhat demagogic, for scientists to express their views formally on the armaments policy.

At this point in our thinking, we must ask two further questions: Is it really possible to channel the innovation effort and to designate it aims? If science and technology cannot be planned, what good is a strategy of priorities?

\section{CATALYSIS OF RESEARCH AND INNOVATION}

At the back of all minds are the failures of, or the enormous cost to be paid for, some deliberate operations to channel scientific progress and define development aims. This experience counsels prudence. On the other hand, there are enough spectacular successes, such as the conquest of space, to give us encouragement. How can we understand this question today?

\section{Some General Points}

In the past twenty years many competent specialists and research groups have expressed their conclusions on the management of scientific and technical research. Everything possible seems to have been said. It is therefore rather discouraging to have to revert to this question, but for the non-specialist reader who will have to make up his own mind - either because of the pressure exerted by public opinion on decisions or because he is committed by a general or specific responsibility- it appears advisable to outline a few main ideas at this stage.

(1) An essential part of scientific research meets a deep-felt need of man, a need to know and to understand, and it is not necessary, or even desirable, to attribute any other purpose to it. This basic or fundamental research has no direct economic justification; it is not motivated by a social, still less commercial, objective. However, it is the vital source of knowledge for applied research; it provides a basis for evaluating education; it trains specialists who will then be capable of participating in the innovation process.

As has already been said, this basic research forms the seedbed without which intellectual and cultural development could not flourish; it is fertile only in an atmosphere of freedom. The financial resources required are small in 
comparison to the other phases of the innovation process. However impoverished Europe may be, everything possible should be done to preserve its basic research potential.

(2) In order to transform basic research results into concepts or products that will be useful in satisfying socio-economic requirements, it is necessary to create favourable conditions for the innovation process. This is an extremely complex process; in a cycle complicated by continuous feedbacks, it runs through the stages of applied and applications research, development, demonstration, and promotion. It is the process that is normally called R\&D but we would prefer to call it RDDP, so as to lay more emphasis on the final and essential stages of Demonstration and Promotion.

This innovation process is obviously costly. It is multidisciplinary and it is justified by the socio-economic aspect of the objectives. The decision to undertake an innovation operation must be taken at a high level in a company, administration, or state, as the gamble is always considerable and necessitates the investment of substantial financial, material, and human resources in relation to the size of the operative units.

In the final analysis the factor on which success most depends is the size of the potential market for the results and the prospect of disseminating them on a wide scale. This market may be found in the consumer public but it may also be artificially created, as in the case of the American and Soviet space or armament programmes. One of the great weaknesses of the nine member countries is the fact that the Community markets are not sufficiently receptive to innovation.

(3) Research, whether basic or applied, can be likened to the process of fertilization. How much pollen is wasted for every flower fertilized? How much trial and error before a goal is reached? How many attempts that are bound to be fruitless? However, there are various ways of catalysing reactions to increase the prospects of fertilization; we shall come back later to the question of the catalysis of communications in scientific and technical effort. Whatever the system, however, the main source of efficiency is, and will remain, the intellectual and human quality of the research workers. Research must be carried on by an elite that is highly competent, imaginative, and creative. This elitism may be shocking in what purports to be a mass civilization, but it is a fact that must be accepted. The European nations should do a11 they can to encourage their most gifted men to spend a few years of their careers in the laboratory.

(4) The ideas that underlie the proposal of a research programe or that help to solve the problems raised are like perishable foodstuffs. They are useful for only a short period of time. Put into cold storage, they lose their freshness or are taken up by rival teams. Originality will not wait; it calls for rapid decision-making processes. Originality is the reverse of the "scientific method", it is not popular with committees and research officials. And yet it is originality that must be preserved.

(5) The part played by the human element in innovating research, the importance of giving researchers some freedom of initiative and allowing them to move from one unit or specialized subject to another - all these significant psychological factors are just beginning to be understood. The traditional and rigid hierarchical structures of European research must be replaced by participative methods. The tendency to immure research workers on our old continent in protective and immovable structures must be counteracted by the mobility of young scientists. This problem is far from being solved. 


\section{The Innovating Effort can be Guided by Catalysis}

From all that has been said above it is clear that there can be no authoritarian planning of research objectives and that it is necessary to allow a degree of freedom and spontaneity. That is why moderate methods of intervention, described here as research catalysis, have been devised and gradually tried out.

What is research catalysis and by what means can catalytic action be applied and controlled?

(1) The first form is the establishment of communications. Since the beginning of history, scientists have been great travellers; they have a constant need to assess their results and the lines of their research for themselves by comparing them with those of other experts working at a distance from them or in a different environment. Reciprocal visits, symposia, congresses, seminars, publications, and documentation centres are the traditional instruments for communication. This self-assessment also leads to self-co-ordination. The scientific world has no frontiers; as soon as scientists or technologists experience a mutual esteem, a desire to work together is born - except in the reverse case where emulation becomes aggressive rivalry, but this is equally effective in providing strong motivation.

Within a single discipline, experts do not generally need outside agents to organize meetings. They know whom they have to see, when, where, and on what subjects. But often in Europe there is a shortage of funds for travel, entertainment, or publication, and in any case the slender resources tend to be used for visits to American rather than to European colleagues. An organization which could obtain some extra money to subsidize this travel, to award grants for stays abroad, or to organize meetings would have an appreciable catalytic influence.

This influence would become catalytic guidance if the meetings subsidized were of a different type from those that would otherwise be organized spontaneously. For example, meetings between European experts from different countries rather than bilateral meetings with the United States; or the organization of a multidisciplinary seminar bringing together participants who would normally be unknown to each other to discuss a topical subject; for example, scientists from basic and applied research, manufacturers, and potential consumers. Those who are accustomed to managing catalytic systems of this kind have learnt from experience that the contacts made between participants are not broken off when the meeting ends; they continue and lead spontaneously to bilateral or multilateral co-operation between partners who would never have known each other if the original event had not taken place.

(2) A more elaborate form of catalytic action specific to applied research and RDDP consists of carrying out studies on paper, possibly with the assistance of mathematical simulation, so as to predict the relevance of certain objectives, calculate their direct and indirect effects, and describe the resources and structures that would have to be provided to attain them.

These studies involve talks between possible partners coming from different specialized fields or having different interests. They attract interest and pave the way for the consensus that will be necessary for the establishment of task forces ${ }^{1}$ and "laboratories without walls" that are so important for

1 Task forces: these are, so to speak, research "commando units" bringing together carefully selected specialists, the team being dissolved once the aim is achieved. 
the cross-fertilization of multidisciplinary research.

It must be realized, however, that the studies are valuable only if they prepare the way for decisions on action. If they come to nothing because funds are not available, or because decision-making processes are too long or so complex that a negative response is all too likely, these studies generate a feeling of futility and frustration. It must be admitted here that the Commission of the European Communities, in most of its Directorates-General, provides an example of intense activity in the way of paperwork issuing from numerous committees and working parties. Although thy reach excellent conclusions, these are never followed up or are followed up too late, so that the results are out-of-date. This might be called anti-catalysis.

Although in some sectors, such as common financial or industrial policy, Europe is so divided that it is impossible to remedy this situation, it is unthinkable to allow scientific research to become bogged down in the same way. As will be seen later, arguments such as "a fair return" or "supranationality" should not seriously be allowed to prevent a European executive body for science and technology being given the power to make financial and other commitments, within the limits of a specific budget, when initial studies show that certain useful objectives can be successfully attained.

(3) A further step is taken in catalytic intervention when a body has funds to finance outside research. Generally speaking, a very little money is sufficient to influence research orientations; to what is this phenomenon due?

In the case of research centres belonging to private companies or non-profitmaking organizations, there is generally a shortage of funds for the operation of the laboratories; a customer placing research contracts is always welcome. If the customer requires an internal effort equal to his financial participation, and if the subject concerned is not outside the field in which the company specializes, the contract is readily concluded.

A research centre belonging to a public body is always slightly or even extremely short of money to purchase special equipment, for missions, for publication or documentation. Consequently the laboratories are ready to accept outside resources in the form of contracts and they acknowledge that in such cases they have to follow the wishes of the person putting up the money.

In this form of catalysis by research contracts it is possible to organize co-operation in the study of a single subject between several laboratories in different countries, specializing in different subjects and having different natures (public, semi-public, non-profit-making associations, research centres in private industry). This provides an excellent method of disseminating information, initiating co-operation, and promoting redeployment on a Community scale.

These contracts often have one shortcoming however: they are subject only to what might be called a judgement of peers based on the publications put out after the research by the team working on the contract. Consequently the person putting up the funds often finds it difficult to assess the results, as a11 he obtains for his money is paperwork or experimental results, and he is not easily able to promote exploitation by the economic and social sector.

(4) There is one method of intervention that is a more powerful spur and is judged on an all or nothing basis. A typical example of such programmes is the Apollo operation. The aim is to carry out, within a specific period and budget ceiling, an ambitious objective making wide use of new techniques and 
expected to yield extensive spin-off in many allied fields.

The armaments and space programmes have proved to the United States the validity of its role as a driving force in applied research. The U.S. examples cannot be carried over into Europe but they can serve as the pattern for a policy of catalytic activities organized around medium-sized pilot projects whose success or failure would be simple to check in the course of the project.

\section{Contracts for the Exploitation of Results}

When a European laboratory obtains a result that would appear to be of practical use in the economic sector, industry is often reluctant to finance its development. Company managements of ten lack the technical background to grasp the practical advantages to be derived from the results or to assess the prospects of success and calculate their risks, or they may quite simply have no confidence in the research workers with whom they are dealing. Sometimes the invention is taken up by the more receptive and aggressive U.S. market and European manufacturers then purchase a licence to work the patent and the necessary know-how without even realizing that the invention was conceived in laboratories close to their factories.

That is why it is often useful for an intermediate body that has followed the research work to propose to a manufacturer that it will finance part of the deve1opment effort. Once the first link-up is made, collaboration will follow smoothly and automatically. Naturally, the earlier co-operation has been organized between the laboratories and the "development department" or "test site", the more smoothly things will run; as far as possible contact should be made as soon as there is a prospect of obtaining results that have some practical utility.

This type of intervention should be distinguished from that known as development aid. This consists of support from an outside body for a project study or demonstration project that a manufacturer wishes to carry out to launch a new production method or a new product. Development aid may be regarded as coming under the heading of industrial policy.

Exploitation aid is something that extends the research project to make it of practical use: it comes under "scientific and technical policy".

\section{Means for a Policy}

The above considerations on the characteristics of scientific and technical research show that it is possible to influence research objectives and define ways and means of implementing a policy. This will be effective only if the following conditions are fulfilled:

(a) there is in existence strong, free basic research not excessively worried about its future; ${ }^{1}$

(b) there are extensive facilities for innovating research. These facilities must be such that they establish a continuous flow of exchanges, with numerous feedbacks, between applied research, applications research, development demonstration, and promotion;

1 This raises the whole question of the career of specialized research scientists working full time (not examined here but a particular problem in Western Europe). 
(c) there is a judicious amount of interpenetration between basic research and innovating research;

(d) there are bodies acting as catalysts to improve efficiency and provide guidance.

The complexity and subtlety now become clear. High-quality basic research can be obtained only from a "contract of confidence", as the indispensable freedom makes it impossible to intervene directly in the choice of subjects. The initiative of the commercial world is also the expression of a freedom: right to originality, right to take a chance and accept a risk, right to intervene outside the area of the planned objectives. The pursuing of objectives of general interest, on the other hand, reflects a deliberate policy of planning scientific and technical effort.

This counterbalance of planning and freedom must be respected. To ignore it would be to lose the benefit of originality which is essentially unpredictable in nature and in the order in which it enters the sequence of events. This brings us back to one of the main ideas expressed earlier. Research is a process of fertilization, its prospects of flourishing must be left to chance; chance is of a very special nature here since it is backed up by the inventive minds of research scientists.

This subtle complexity brings us to the question of the ownership of the resources connected with the planning objectives. Research resources consist above all of teams of research scientists and technicians working together in laboratories or scattered throughout administrations and industry. These research scientists have a specialized subject to which they are strongly attached, as they have put enormous effort into mastering it, obtaining contacts, and making themselves known. These research scientists are also strongly attached to their discipline as it is not difficult for them to let themselves speculate and to see the justification for their effort in the successful results that they expect to attain. These feelings of attachment to a profession, praiseworthy in themselves in many respects, have the effect of crystallizing the future on the pattern of the present. There is little, and in some cases no, mobility of objectives, still less mobility by changing specialization. Where these resources belong to a body that is powerful or not very mobile - such as a major industrial group, a government sector, an international organization - these stability factors are al1 the stronger and there is less possibility of moving towards new objectives or of encouraging originality to flourish. These comments account for the occasional difficulties experienced by industrial groups with their central laboratories and for the fact that, in research done in state 1aboratories, at least $95 \%$ of the budget appropriations go to the continuation of existing work, leaving a maximum of $5 \%$ - plus growth appropriations - to respond to changes required by the economic and social environment. This is one of the important paradoxes of research that must be borne in mind: the possession of expensive facilities does not give freedom but tends to confine research to its previous lines. Thus not only is research working for the long term but it is marked by considerable time constants.

The following advice can be derived from this analysis:

(a) The freedom so greatly needed by research must be guaranteed by ensuring a large number of financing sources. Unless a laboratory is closely integrated in an industry, it is better for it to be funded jointly by its owner and by outside financing agencies of a national and international nature.

(b) Research budgets must be multi-annual; they must predict lines of development sufficiently far in advance to allow researchers to prepare for them. They must be protected against economic and cyclical fluctuations. 
(c) When innovation objectives are defined in relation to the public interest they must as far as possible be entrusted to contractors independent of the persons carrying out the research, which implies that the contractors are not themselves the owners of the research facilities. They will merely be responsible - a considerable task - for finding the appropriate skills when the time comes, for putting them to work, and for co-ordinating them.

We shall come back to this advice when we study ways of implementing a policy at Community level. The reader will already have noted one of the main conclusions: it is necessary to promote flexible, active, and responsible catalysis that is only loosely interconnected with national policies.

\section{NATIONAL STRATEGIES AND COMMUNITY STRATEGY}

A11 that has just been said about the necessary freedom of scientific research and innovation argues in favour of a wide variety of financing sources, without very close co-ordinating links between them, and of a wide variety of participants.

Al1 too often large research concentrations are inefficient, difficult to control, overburdened by costs, and do not encourage originality. If there is one field in which power should be distributed and generously shared out, it is scientific research.

Hence there is no occasion to regret too keenly that national and Community policies within the Europe of the Nine are developing on somewhat divergent lines. If for a special reason such as a national bent or confidence in a particular specialization, a Community country wishes to make a major effort in a sector regarded as non-priority in the light of Community criteria, by what right should it be prevented?

This remark does not by any means imply that there should not be a Community policy; on the contrary, the efforts towards it should be greatly stepped up as the current level is totally inadequate, but the objectives must be specific to the interests of the Community. Going beyond national policies, the diversity of which must be maintained as a very precious asset, this policy will be an expression of Community solidarity; it would embody in its strategy the will to construct a Community.

Nor does this comment imply that it is not desirable to organize synergy between European researchers wherever they may be working. On the contrary, it is essential to stimulate co-ordination by research teams themselves, to disseminate knowledge and to avoid duplication. However, in developing synergic effects, reliance must not be placed on co-ordinating national programmes by tackling the problem from the top; it must be attacked from the base by catalysing communications between researchers and carrying out joint projects.

In addition, it is necessary to catalyse the transformation of industrial and economic circles to make them receptive to innovation. It must never be forgotten that in the United States the rich harvest from innovation is due much more to the fertility of the environment than to the relevance of scientific policies.

Needless to say, there will be many instances where the scale of the facilities required for research, and even more for development, will be beyond the capacity in terms of economics or manpower - of any one Member State. There should then be no hesitation in setting up a structure adequate for the scale of operations required (e.g. in space technology, nuclear fusion, high-energy physics, etc.). It would seem that, in the past, although these situations have been well enough understood, there has been too little resolution in the decision-making process and 
not enough delegation of authority in the execution.

\section{The Background to the Comminity Research Policy}

It is interesting to compare these general ideas with the facts observed when the past history of Community R\&D is examined.

Over the years, the Community scientific research policy has been built up layer by layer. The ECSC (European Coal and Steel Community) Treaty (1952) and Euratom or EAEC (European Atomic Energy Community Treaty (1958) made specific provision for common research and development facilities. It would appear that the guiding idea at that time was the concentration of facilities in order to profit more easily from the scale effect resulting from the size of the Community.

The Rome Treaty which established the European Economic Community, has no specific provisions except in the case of agricultural research (Article 41 of the EEC Treaty). In the mid-1960s the Euratom aims proved unattainable against the political background at the time. Coal and steel research are aided by financing sources provided by the ECSC; agricultural research is a special item and there are no action programmes for the other topics. The most that can be said is that Research Europe is not yet under way.

In 1967 a PREST (Scientific and Technical Research Policy) report proposed measures for the formulation of a Community scientific and technical policy. It would appear that at that time the predominant idea was to co-ordinate national policies.

The desire for action was re-stimulated by the Paris Sumit meeting in 1972. The Heads of State and Government came out in favour of the development of a common policy in the field of science and technology which would require "the co-ordination of national policies" and "joint implementation of projects of interest to the Community".

This decision was put to practical effect by a number of decisions taken by the Council of Ministers in January 1974, which laid the first foundations for the definition and implementation of a common policy in the field of science and technology.

In the years that followed, several steps were taken:

(a) the setting up of CREST (Scientific and Technical Research Committee), consisting of senior national officials and chaired by the Director General for Research, Science and Education; ${ }^{1}$

(b) the setting up of new ACPMs (Advi sory Comnittees on Programme Management);

(c) the setting up of an advisory committee consisting of twenty-one independent individuals; this was CERD (European Committee for Research and Development);

(d) the establishment of systematic links with the European Science Foundation ${ }^{2}$ founded in 1974;

1 Directorate-General XII of the Commission of the European Communities

2 The ESF consists of forty scientific organizations in sixteen European countries, including the nine Community countries. 
(e) the presentation of an initial communication of R\&D aims and priorities to the Council of the Community (November 1975);

(f) an organizational restructuring and the establishment of a new programme for the Community's Joint Research Centre (JRC), which brings together, under a single authority, the laboratories established under Euratom (Ispra, Geel, Kar1sruhe, Petten);

(g) the development of research on nuclear fusion and radiation protection and at the same time the preparation of the project for an experimental fusion reactor: the Joint European Torus (JET);

(h) the forwarding to the Council by the Commission, in June 1977, of the guidelines for common policy in the field of science and technology (1977-80). These guidelines form the framework within which Community projects will be defined. They lay down priority sectors and selection criteria used to decide on Community projects conducted in the form of either "direct action" in Community centres, "indirect action" by outside contract holders, or "concerted action" projects in which the Community merely ensures co-ordination and disseminates information without providing any funds for the laboratories (Table 11)

Table 11. Community R\&D programmes

Funds allocated up to the end of April 1978 (million u.a./EUA)

\begin{tabular}{|c|c|c|c|c|}
\hline Sectors & $\begin{array}{c}\text { Joint } \\
\text { Research } \\
\text { Centre } \\
\text { (dir.action) }\end{array}$ & $\begin{array}{l}\text { Contract } \\
\text { Research } \\
\text { (indir. } \\
\text { action) }\end{array}$ & $\begin{array}{l}\text { Co-ordination } \\
\text { (concerted } \\
\text { action) }\end{array}$ & Period \\
\hline 1. $\frac{\text { Energy }}{\text { Nuclear fission }}$ & 150.70 & 62.66 & None & $\begin{array}{l}77-80 \text { (with } \\
\text { some residue } \\
\text { from } 75-76 \text { ) }\end{array}$ \\
\hline Nuclear fusion & 12.75 & 124.00 & None & $76-80$ \\
\hline JET & - & 147.68 & None & $77-83$ \\
\hline New forms of energy & 41.29 & 47.62 & None & $\begin{array}{l}\operatorname{mid}-75 \text { to mid- } \\
79 \text { and } 77-80\end{array}$ \\
\hline Energy-saving & - & 11.38 & None & $\begin{array}{l}\operatorname{mid}-75 \text { to } \\
\operatorname{mid}-79\end{array}$ \\
\hline 2. Industrial policy & - & 4.59 & None & $1976-81$ \\
\hline 3. Environment & 29.95 & 16.00 & 0.14 & $\begin{array}{l}1977-80 \text { (with } \\
\text { residue 1976) }\end{array}$ \\
\hline 4. Raw materials & 7.49 & 23.90 & None & $1977-80$ \\
\hline 5. Agricultural policy & - & 10.30 & 0.25 & $1975-80$ \\
\hline 6. Medical and social & - & - & 1.29 & $1978-81$ \\
\hline 7. Long-term R\&D policy & token entry & token entry & token entry & $1977-80$ \\
\hline $\begin{array}{l}\text { 8. Miscellaneous } \\
\text { (training, measure- } \\
\text { ments, etc...) }\end{array}$ & 154.96 & - & None & $1977-80$ \\
\hline
\end{tabular}


Table 11 is a synopsis of an internal document of the Commission of the European Communities entitled "Community R\&D programmes - situation at the end of April 1978".

Since the outcome is still unknown, these figures do not include the proposals which will be presented to the decision-making bodies of the Community at the end of 1978 (reactor safety, decommissioning of reactors, data-processing, FAST programme, etc.).

It should be remembered that the research managed by the Community is distinct from that carried out within the ECSC framework. Moreover, most of the Directorates-General have study appropriations to which no reference has been made here.

The extent of the resources may be assessed by reference to 1976. Budget appropriations for Community research amounted to 162.8 million units of account or $\$ 180.7$ million. This corresponds approximately to $1.2 \%$ of the total publicly funded research and development effort in the nine Community countries, or $0.6 \%$ of the total funds devoted to R\&D in the Community, allowing for expenditure by private undertakings, which was of the same order as that of public bodies. Of these funds, approximately 100 million u.a. are taken up by the priority programmes and by the Joint Research Centre. In the latter the mobility required to adapt to new aims is hampered by the obstacles normally found in large structures, although it has been agreed that this will be given special attention in the drafting of each four-year plan. Consequently, $80 \mathrm{million}$ u.a. remains for synergic projects, approximately $0.2 \%$ of the total European expenditure on research and innovation. This is barely a homeopathic dose, let alone a therapeutic one.

It cannot be denied, however, that encouraging progress has been made even if the scale of the resources is still extraordinarily modest. The decision-making circuits are in keeping with the Community pattern, being pointlessly cumbersome, and consequently the methods used are still excessively technocratic.l

\section{Desirable Innovations}

If Europe's progress towards a new development model is to be promoted gradually and by means of mild therapy, all that has been said above indicates that a number of changes must be made.

Amongst the negative changes, it would be necessary to give up the idea of any organic concentration of research facilities within centres belonging to the Community. The exception, such as the JRC, is excepted only to confirm the rule. Illusory ideas on the co-ordination of national policies would also have to go. These policies are either virtually non-existent or linked to dominant industrial systems, or governed by national objectives unlikely to be influenced by outside forces.

The positive changes would be based on the general idea that science and innovation are steps towards action in which the protagonists are research scientists and engineers, in contrast to administrative set-ups. The method proposed for Community intervention would essentially be catalytic in action. The main types of catalytic action examined in an earlier chapter are summarized in Table 12 .

I This comment does not reflect on the value of the remarkably able, tenacious and open-minded senior Community officials; it is aimed directly at the shackles to restrain their freedom of action imposed by a system of controls and committees. 
Table 12. Types of catalytic action on research and innovation

1. Meetings, symposia, seminars, publications, extension work

2. Studies, models, futurology

3. Research contracts

4. Pilot projects

5. Exploitation contracts

To conduct a policy of catalytic intervention, encouragement and incentive, it would be necessary to have: a suitable structure and facilities; a set of reference criteria to show how to select specific fields for action; and a policy for selecting participants.

\section{Structure and Facilities}

The launching of a programme of catalytic projects, supervision of performance and correction of false moves or errors by the partners resembles in all respects the work of a prime contractor. It will therefore be necessary to have an executive body with the following characteristics:

(a) capable of taking rapid decisions (research ideas are perishable foodstuffs that must be consumed fresh);

(b) responsible to the relevant political authority in advance as regards the content of the programmes and after the event as regards their execution;

(c) capable of encouraging originality by taking the advice of independent experts;

(d) having numerous degrees of freedom, in particular with regard to national policies, so as to adhere to the rule of a wide variety of financing sources;

(e) having a substantial multi-annual budget enabling it to go well beyond the homeopathic doses administered up to now.

This is not the place to define this executive structure. Once its principle is decided, a serious study would have to be carried out so as to set it up without unduly burdening the Community with new bureaucratic procedures but rather trying to alleviate it and if possible to integrate the Joint Research Centre in a vast system of extra-mural exchanges. The level of the budgetary appropriations would be a political matter of the first importance. Now that the way is being prepared for elections to the European Parliament by direct universal suffrage, and in view of the tendencies expressed by public opinion, it would be desirable to devote substantial funds to European science and technology. The need for a decision to try to catch up on the efforts of our main commercial rivals outside the Community would indicate that these additional appropriations should be granted without a proportionate reduction in research and innovation budgets at national level, which are already inadequate.

\section{Characteristic Criteria of a Comminity Policy}

The general idea underlying the new proposals for a Community science and technology 
policy is the recognition that for European R\&D there are certain factors specific to the existence of the Community. These specific factors cannot be taken into account at national levels, as in the national context their expression would not be encouraged and they would not be given the priority they merit.

At the Milan symposium (May 1976) certain "Community criteria" were established. After making the alterations that we deemed necessary, we can describe these factors specific to the Community under four categories of ideas: dimension, homogeneity, political consequence, communication.

There is no need to go into the dimension factor at length. It means that projects requiring facilities for execution beyond the scale of national facilities should be transferred to Community level. This applies to certain aspects of energy, space, information technology, the exploitation of marine resources, etc. It does not in any way mean that states can no longer continue to work in these fields at national level.

The homogeneity factor is a fundamental element from the political viewpoint. If we wish to develop towards a genuine community, it is unacceptable that the concentration of scientific and technical assets to the benefit of a limited number of countries or regions should lead to excessive disparities in wealth, working conditions, industrial competiveness, or welfare. This applies, therefore, to everything connected with health, life at work, spare-time activities, environmental protection, the automation of production and services.

Political consequence may justify special projects in areas where Europe must present a single image in order to carry weight with her international partners in negotiations where the technical factor is important. The standardization of computer equipment and networks is a good example. Some aspects of research for the benefit of the developing countries could gain from being presented under the Community label. International law on the exploitation of the oceans is another example of a political-technical problem.

Communications between scientists can lead to useful savings by stimulating emulation between research workers in different countries, helping to reduce duplication, speeding up the dissemination of knowledge and innovation, and catalysing self-coordination amongst research workers. 1

\section{Partners}

A policy of catalytic action is valid only if it applies to numerous free, responsible, mobile, imaginative, and daring partners. The futility of the environment in respect of innovation has seriously deteriorated in Europe. Governments are sometimes embarrassed by the huge structures they have themselves set up; these structures have to some extent crystallized as a result of the proliferation of certain considerations of corporate interests expressed by research scientists without taking sufficient account of the general interest, and in particular the needs of the economic sector.

Al1 too often, inertia prevails over mobility, specialized work prevails over multidisciplinary research, a research scientist's career is based on the intrinsic

1 Care must be taken not to use the wrong methods; these objectives of communication and self-co-ordination will not be attained by comparing programmes, i.e. not by bureaucracy but by action, by associating various teams of research workers in a joint study, and carrying out a joint project (partly financed by the Community). 
merit of what he publishes rather than on a concern to find practical applications. The "interstitial" life, that of the non-profit-making societies, foundations, and undertakings set up by researchers, is not well developed and is tending to become more and more stifled.

The situation is the reverse of that in the United States, and we must realize this. Whereas in the United States there are numerous relay points between research and its practical utilization (non-profit-making foundations, institutes specializing in certain functions of the transfer of knowledge, independent universities, private research companies, design companies, industrial research centres, small and large bodies subsidized by the Federal Government, the States, the large towns, Federation of Scientific Associations, technical interest groups), Europe is marked by the rigidity and monotony of its structures. There is an arterial research network but almost no capillary network. And yet initiative, originality, the beginnings of innovation come from the most part from cells supplied by capillary action.

If national governments are enmeshed in the complicated structures they have themselves set up, the Community has the huge advantage of being unencumbered by any heritage of this kind. Consequently it can by catalytic action help to promote the creation of this interstitial life, these bodies capable of forming bridges between basic research and industry. In this way it would contribute towards the development of the fertility that is to a great extent lacking.

\section{Fields Suitable for Intervention}

Apart from the judicious choice of partners for catalytic activities, the main aim should be to eliminate the vulnerable lines of the European research and innovation system. The sensitive areas are situated more particularly at the following meeting points considered individually or in their relations to each other:

(a) the interface between basic research and applied research;

(b) the interface between applied research and industrial development;

(c) the interface between social sciences and exact sciences;

(d) the interface between human requirements and scientific and technical programmes;

(e) and, of course, the exchange of knowledge and exploitation of results within Europe.

Naturally, depending on the case in point, the sensitivity of these vulnerable areas varies and the examples given above are not restrictive.

$$
* * *
$$

Thus a Community strategy and procedures distinct from national strategies and procedures emerges more and more clearly. This Community policy is not a supplementary or complementary accessory, which would be of minor importance in comparison to that of the national states, but is one of the most important expressions of the will of the states to benefit from their solidarity as members of a Community. While preserving their own identities and differences, the Member States could thus overcome the major obstacles which, if they acted in isolation, would hamper their harmonious technological development and as a result their economic and social development. 


\section{CONCLUSIONS TO PART II}

In view of the state of the world and the rivalries being acted out in it, and in view of the potential for progress generated by recent scientific discoveries, there is every sign that the phenomenon of technological evolution has not dried up. On the contrary, its pace will increase in the next thirty years provided it manages to solve the financial problems. The radical changes that have occurred in the space of a hundred years in the way of electrification, public health, agricultural and industrial productivity, road transport, and urbanization are probably less important than those foreshadowed with the economic and social conquest of new territories such as nuclear energy, space, the ocean, bio-techniques, information technologies, and new instruments to improve productivity in industry (robotics) and the services sector (burotics).

To survive, Europe must improve its innovation effort in both quantitative and qualitative terms. From the former angle, if we wish to raise ourselves to the American or Japanese leve1s, improvements of 50 to $100 \%$ must be made. From the qualitative aspect it is necessary both to increase the fertility of the research environment and to supplement the Member States' efforts by Community action, the only way of overcoming a number of vast and heterogeneous obstacles. The theory upheld here is that competition must also be shifted to the area of man's social needs and desires so as to get away from the prestige and power aims where Europe is handicapped and the post-industrial society is taking the wrong turning.

The Community scientific and technical policy should have an important part to play in this effort towards consolidation and redeployment. It must be separate from national policies. It would be specific to European solidarity if it adopted as its priorities the criteria of size, homogeneity, political weight, and communication. In the proposed project, the financial appropriations would be greatly increased but would not be used to develop the bodies under the direct control of the Commission of the European Communities. The co-ordination of national policies would have only limited ambitions, so as to allow Member states to give rein to the diversity and leave them great freedom in the choice of national priorities. On the other hand, a responsible executive body would be set up to organize energetically, by means of flexible and rapid decision making, the implementation of a policy to catalyse scientific research and innovation. The main aim would be to increase the synergism between European research scientists and engineers. This policy of catalytic action would aim at promoting the creation of an interstitial life encouraging innovation, in particular by swelling the funds devoted to the 
sensitive areas forming the interfaces between basic research, applied research, and industrial development, and by devoting particular attention to the meeting point between the exact and human sciences. This would be done by organizing meetings between European research scientists, setting them joint objectives under contracts for research or pilot projects carried out by multidisciplinary and multinational teams. The "laboratories without walls" and "temporary contract supervision" would enable efficiency and mobility to be combined.

To arouse controversy and fire imaginations, a list of priority subjects is proposed that takes account both of certain ascending trends particularly evident in contemporary science and of the objectives of survival and a better life. This is mild therapy, but it would be wrong to believe that its effects will be negligible, as can be shown by two examples concerning public research systems and industry.

The machinery of research carried out in universities and public bodies has become excessively cumbersome over the past fifty years. This situation is reminiscent of the excessive training required for 0lympic sports at the level of international competition: instead of games played by gifted amateurs, these physical sports have become techniques compelling athletes to accept a way of life and medical care quite out of the ordinary. The "brain sports", as one might in the past have called the intellectual activities of research workers, a small and elite group, have become forces recruited to fight international competition.

Forced to find an effective reply to the competitive pressure exerted by other countries, Europeans appear to have lost the feeling for the fair balance between the degrees of freedom that have to be granted to these different stages in the acquisition and practical utilization of scientific and technical knowledge. Innovation is a long climb from basic research to applied research and applications research, then on to development and demonstration. The higher one moves up the scale towards practical exploitation, the greater must be the pressure for a practical and immediate result, the greater and more precise the facilities, the more administration and management prevail over inspiration, initiative, and imagination. The closer one is to basic research, the more necessary it is to leave some scope for chance, the unexpected, the originality of the researcher's mind, and the more the constraints on freedom must be reduced.

In Europe, all too often, management methods that are of use only in the final stages of innovation have been transferred to the fields of basic and applied research. As a result, much of the effort to acquire knowledge and much inventive work is today over-administered, over-co-ordinated, and over-controlled.

The university has been the chief victim in this gradual transformation of its vocation and its administration. It is expected simultaneously to change over from elitist education to mass education, to adapt to the explosion in scientific knowledge, to take on basic research and to establish efficient links with industry for applied research - too much to hope for in one go. It is necessary to rethink the whole apparatus, probably to set up intermediate bodies having different statutes, to solve the problems involved in the links between research and applications.

This is being done in most of the European countries, but the process encounters numerous psychological inertias. Those enjoying advantages already acquired are reluctant to relinquish them without an assurance that they will be participating in real progress. Progress is blocked when an attempt is made to tackle this problem at national leve1. Probably a change to a Community basis would, by 1llowing dissimilar experiments to be compared, reopen the dialogue in a constructive Eashion. This would be one way in which Europeans could take advantage of their liversity in order to help each other to make progress. 
Turning to industry, we can imagine for a moment what European company structures would be like if manufacturers, forced to seek alliances in order to attain the necessary scale of operation, had been able to learn by experience to know their European colleagues through research contracts jointly concluded at the initiative of the Community. How many of the industrial mergers that were concluded at national level, of ten creating national monopolies not really in the general intere would then have taken place between European manufacturers, thus establishing the foundations for future multinational groups capable of counterbalancing the nonEuropean groups?

\section{$* * *$}

It is clear that the ideas expressed in Part II of this work are far from guaranteeing a solution. They should be taken as rough proposals needed to stimulate constructive discussion. They do not claim to be exhaustive, and many fundamental issues have not been covered. The work may therefore be considered as the beginnin of a study rather than a conclusion.

Some members of CERD, influenced in particular by their industrial experience, have expressed the opinion that the solutions proposed in this Part II would not be sufficient to give Europe the innovating capacity it needs. They would like to see four complementary measures added:

(1) Promotion of the mobility of personnel between research centres everywhere and the economic sector. This mobility should reflect the scientists' awareness of their role in the construction of society.

(2) The establishment of funds to finance innovation so as to make up for the unwillingness shown by European commercial banks to invest in small - and medium-sized ventures with a high technical risk. This could be the aim of a European Innovation Bank.

(3) Encouragement for the formation or development of multinational Europeanbased undertakings having as their object investment in North America, the Far East, and the countries in the process of industrialization so as to counterbalance the influence of the major American and Japanese companies.

.(4) The adoption of a standardization policy taking account of the factors specific to Europe, in particular protection of the environment and possibly certain social factors.

This study of these questions has not been pursued, as the subject tends to fall under industrial policy rather than scientific and technical policy. 


\title{
Conclusion \\ TOWARDS THE SECOND RENAISSANCE?
}

\author{
How strange is Europe's situation today! \\ Europe invented the modern form of scientific and technical research and in the re- \\ cent past still regarded it as the source of progress. Today, it is allowing \\ its most direct rivals to take the offensive with more powerful and better-employed \\ resources.
}

Europe invented the university but no longer knows how to make the best use of it. It overburdens it instead of leaving applied research, for economic and social purposes, to others, and yet it cannot manage to break the isolation of the academic research staff who educate its youth.

Europe invented industry which, replacing craft, established the domination of the economy of scale. It still has one of the most concentrated and best-educated bodies of consumers but it lacks the cohesion to provide a unified market for the sensitive products of innovation and the advanced technologies that are paving the way for tomorrow's world.

Europe was the cradle of the artificial world around us which moulds the sensibilities of our children, remote from contact with nature: industrial noise, chemical odours, landscapes of skyscrapers and factories, contact with artificial fabrics and plastics, synthetic food and drink, preventive medical care, mechanical transport, continuous availability of audiovisual entertainment. But Europe is reluctant to step up its efforts on these lines; it is lagging behind in the progress accompanying the advent of the machine kingdom. As a result, the position of superiority that Europe has won for itself in the international division of labour are now being challenged one after the other.

And yet never has the need been expressed in such inarguable terms. Dependent on imports for its survival,. Europe can pay for its purchases only by selling manufactured products or capital goods. Intrinsically poor except in manpower, it must now negotiate the raw material and energy resources that it had for centuries been accustomed to control politically in more than half the developed world. Poorly equipped to counter the diffuse violence of the poor peoples, Europe is also on the verge of being confronted with the most serious population imbalance that the history of the world has ever known.

Is Europe on the way to impoverishment? 
The feeling of danger is, however, poorly understood because many factors tend to reassure us for the immediate future:

(1) Economic patterns are not broken as easily as political treaties. Despite decolonization, therefore, Western Europe remains one of the major trading and financial centres of the world; its political stability encourages the investment of capital; some world commodity markets are still centred there.

(2) If world economic and political balances are examined, it is clear that Western Europe's role is still a major one; its eclipse would have unforeseeable consequences. Neither the Soviet Union nor, above all, the United States show any intention of destroying that balance; on the contrary, they appear anxious to consolidate it. This attitude is in keeping with history; the hegemonies have always tried to preserve the balance of forces on which they were estab1ished. A11 the European options are implicitly based on the postulate of the American guarantee not only in defence but also in economic matters.

(3) Europe's force today is based partly on the weakness of others: the low competitive capacity of the manufacturing and capital goods industries in the planned-economy countries; the long way to go for the countries in the process of industrialization, however rich they may be in primary resources before they gain any real power in international trade in the products in which the Europeans excel. Even Japan is itself threatened by the excesses stemming from its success: saturation of building land; pollution; extreme dependence on commodity imports; risk of a revival of protectionism by its customers.

(4) Europe has built-in assets resulting from its temperate climate, its domesticated nature, the strength of its investments, and still more from the quality of its peoples accustomed to industry and international trade and the wealth of its cultural background. It is also an ideal partner for countries eager tc continue their development or to work towards their economic take-off because it now combines competence with an absence of imperialist ambition.

This combination of favourable factors guarantees Europe's survival, and perhaps even relatively comfortable existence, for a period that is difficult to predict but is probably no more than a few decades. These balances are precarious; some are no more than the relics of a past that will be eclipsed, others depend on external forces. What would happen if American public opinion grew tired of bearing the weight of the world or if North American technological superiority were no longer able to contain the consequences of the population growth in the south? Can we take the risk of entrusting the fate of a continent to outsiders?

But let us keep calm there is still some time in which to act.

The gravity of the European situation is reflected in the abnormally deep-rooted conflict between short-term and long-term interests. If the Europeans make no sacrifice for the future, things will go better in the immediate term. Household consumption or the fight against inflation will be improved. Impoverishment will be driven underground, progressing in a way almost imperceptible to public opinion. But in ten or twenty years the crisis whose first tremors we are now experiencing will erupt and we will no longer have the resources to recover from it.

The struggle has already started and will be played out in the next few years, but the full implications of the gains and losses will emerge only towards the end of the century. The drama in Europe is that, however widely it may be shared, this feeling of an unacceptable risk is not of a nature to rally forces. Men will make sacrifices only if they are actually suffering a crisis or are carried away by enthi siasm for an ambition or a project. The artificial content deriving from the 
existing balances minimizes the painful effects of the crisis in its initial stages; the crisis can therefore pursue its hidden course without arousing reactions. Few proposals based on hope or feeling have been made. This study is an attempt to sketch the broad outlines of a project and to describe ways of making Europe the laboratory of a new way of life, the centre of a new Renaissance. In international competition, Europe would select its own ground on which to fight. It would no longer seek only to compete at economic level, but would lead its main rivals towards the concept of a better life that would be remarkably well suited to its main specific features.

A Renaissance can take place only on two conditions: if the forces attaching us to the past have become negligible or are challenged, and if there is a desire for the future to be newly constructed to comply with the new ideas that are shaping our destiny.

The break with the past was not complete as long as the philosophies and ideologies derived from the previous socio-economic context remained the reference point for our thinking. This heritage from the last century, which for long has served as a freezing and blocking force, is now rapidly vanishing. It is curious to note that this reduction in the influence of these ideologies follows very closely on the heels of the weakening of the system of moral values of "middle class" society.

The manifestations of this deep desire for change are a rather incongruous and contradictory collection: Vatican II, Club of Rome, May 1968, Solzhenitsyn, Sakharov, Eurocommunism, the "new philosophers", the ecological movement, the Helsinki agreements, the evolution in the status of women, the Carter Plan for energy, etc. Some may view these events as portending the decadence of the white man, chiefly at the expense of Europe.

This assumption of decadence cannot be ruled out. However, other signs are more optimistic as new constructive concepts are emerging. Ilya Prigogine ${ }^{1}$ demonstrated remarkably well this metamorphosis of the interaction between science and society, which we are just starting to witness. His explanation for the behaviour of the dissipative structures extends to the social phenomena built up on an order that is tending to change constantly. We are remote indeed from the glorious scientists whose laws were going to provide explanations for everything and guarantee happiness in the world. But the part played by the unexpected, the humility experienced in the face of the irreversibility of the phenomena of the living world and the unpredictable nature of influential fluctuations are suddenly giving a new meaning to the concept of freedom. Freedom is no longer merely an advantage for individuals or groups that enjoy it, but is above $a 11$ the condition for adaptation, the necessary slack in the social machinery, to ensure that certain ends can be attained. Freedom can no longer merely be reduced to a philosophy of human rights; it is now seen to be the instrument for the uprooting of outdated structures and the establishment of relevant new ones that will also be temporary.

According privilege to the concept of freedom in this way does not mean that man is powerless, forced to submit to the unpredictable laws of evolution. As these concepts were gaining ground, biology and information theory were at the same time making an essential contribution towards the understanding of complex systems and their regulation. As a result, we can now see how to plan without compulsion and

11977 Nobel prize for Chemistry - member of CERD. "Metamorphose de la Science; Culture et Science d'aujourd'hui", paper at the ESIST conference held in Brussels at the end of May 1977 under the auspices of the Commission of the European Communities. 
how to organize without imposing autocratic hierarchical systems.

An image of these new balances of forces in social organizations is obtained if we observe the hormonal balances in the higher orders of living beings. The cells are immersed in an inland sea consisting of a variety of chemical substances, the interplay of their conflicts and balances governing metabolism. These hormonal messages, loaded with specific information, are remarkably powerful. They act on our growth, our waking or sleeping activity, and our aggressiveness. The exercise of political power must be understood today in the light of these hormonal systems.

At Community leve1, power will be reflected in the issuing of specific messages of interest to the Community, which will most frequently act by catalytic means, influencing the sensitive points at which systems of value are developed and links of communication and interdependence are established. This is how the confederal ambitions of the Community political system should be understood.

Although it is far too early to declare that a system of this type must be adopted by the Member States in their difficult quest for a balance of forces within the Community authority, it is not too late to try it out in the field of scientific and technical research. And if this attempt were to be made in an effort to foster a Second Renaissance, we should have an opportunity of combining the testing of a new model of political action with the formulation of a project based entirely on the desires of man.

We can give no more than a vague outline of the content of this new Renaissance, as it will be brought about by children who are still at school or not yet born. The minds of these future leaders, unlike our own, will not be shaped by the written tradition and by a universe of mechanical machines, but by the environment of the information civilization into which we have broken almost without realizing it. Their minds will not be the same as ours. During childhood and adolescence, when their sensitivities are being formed, they will be exposed to audiovisual means of dissemination and to the use of programmable computers for games and creative activities in the graphic and plastic arts and in music. However, if we venture to make a prediction, we can base it on what we know of the direction of evolution, the drive towards complexity and psychism. This Second Renaissance will meet man's heartfelt desire if it enriches his spirituality, individually, and collectively. The twenty-first century will tend towards a civilization of the mind, or else it will come up against formidable material and human obstacles.

These few words are sufficient to show the enormity of the effort that must be made to achieve this transition and the great danger of the transitional phase. There are probably many possible solutions and many different approaches to improving the consumption of cultural goods in order to compensate for a restriction in the consumption of material goods. However, all these ways involve progress in the mastery of complexity, in the practical forging of bonds of solidarity ....... and in the acceptance of the constraints of interdependence, in the challenging of the values concerning the use of the time allotted to different pursuits throughout one's life, and, finally, in the more equal distribution of intellectual, artistic, and social culture which is increasingly proving to be the most precious asset of the human race. 


\section{THE SECOND RENAISSANCE}

Stimulus

Revival of economic hope

Aid to countries embarking on the process of industrialization

Increased dissemination of information and knowledge

Promotion of productive spare-time activities

Ways and means

Increase in service productivity

New sources of energy and energy-saving

Education with a cultural bias

Promoting mechanism

Scientific and technical research acting according to a procedure of a biological nature controlled by a programme of priorities

Financing of innovation of a social nature

\section{Objectives}

Priority for individual or small group activities

Emphasis on cultural pluralism 


\section{Science and the Second Renaissance of Europe}

"This book is the offspring of anguish and hope. Europe may well slip towards underdevelopment. This study shows that the risk is a real one and that very little seems to be being done to counteract it.

Europe, eroded by scepticism, lacking ambition, wanting in projects relating to man and society, is not even aware that its divisions make it illsuited to the dimensions of the modern world.

... It is gambling its very existence as the cradle of independent civilization. I hope that this book will bring home the importance of the stakes, that it will bring the realization that the game is already lost if the peoples neglect their community of interest as they play."

André Danzin 